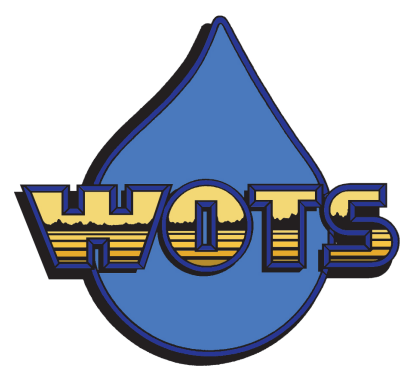

ERDC WQTN-MS-08

August 2014

\title{
Analysis of the Challenges and Opportunities of Hydrokinetic Turbine Development Affecting the US Army Corps of Engineers
}

by David L. Smith, John M. Nestler, Richard Styles, and Brian Tetreault

BACKGROUND: National energy policy supports increased development of green (renewable) energy to lessen dependence on petroleum-based fuels and reduce their attendant environmental impacts. One family of renewable energy technologies experiencing increased national interest is hydrokinetic turbines. Hydrokinetic turbines include systems that convert waves, tides, and river flow (without impoundment) into electric energy. River hydrokinetic turbines (hereafter referred to as kinetic energy turbines (KETs)) were the focal point of a recent workshop, although hydrokinetic turbines in estuarine or coastal settings may also impact US Army Corps of Engineers (USACE) missions.

This document summarizes a two-day interagency workshop that was convened at the US Army Engineer Research and Development Center (ERDC) on 29 February 2012. The workshop was attended by representatives of the US Geological Survey; Fish and Wildlife Service; National Park Service; Department of Energy (DoE: Oak Ridge, Pacific Northwest, and Sandia National Laboratories); US Coast Guard; USACE Headquarters; USACE New Orleans District; Mississippi State University; and ERDC's Environmental Laboratory (EL) and Coastal and Hydraulics Laboratory (CHL). A complete list of attendees can be found in Appendix A. Recorders at the workshop summarized information from both the presentations and ensuing discussions. This Technical Note succinctly synthesizes information developed during the workshop, capturing major discussion points and conclusions. This information was analyzed to identify challenges such as internal communication shortcomings, external coordination requirements, and critical technology gaps. By addressing these challenges, USACE is poised to effectively execute its Federal responsibilities in support of the national green energy policy. Additionally, a consistent roadmap of USACE expectations and requirements that can be used by developers when they enter the "one door to the Corps" will expedite the national goal of green energy.

Purpose and objectives. The purpose of the workshop was to describe institutional and technology issues facing USACE as the Nation proceeds with development of KETs. The workshop was structured to meet the following specific objectives:

1) Summarize ongoing research and development at Federal laboratories and elsewhere that would be of interest to the attendees. Specifically, describe hydrokinetic energy development status and assess the likelihood of implementation in the short term (1-2 years) and long term (more than 2 years).

2) Identify potential mission actions (Regulatory, permitting, and coordination) with which USACE should engage. A critical question that the workshop attempted to address was, "Is 
adequate information being developed now to address anticipated permitting data requirements?"

3) List and briefly describe critical research and development needs to address unresolved navigation, flood risk management, and environmental issues.

Workshop organization. The KET workshop was organized into two sessions to meet the objectives listed above. Day 1 was an open session in which speakers from different agencies presented information on issues or emerging technologies specifically to address Objective 1 (Technology Status and Needs Assessment). Day 2 was restricted to USACE attendees and featured perspectives of different mission areas addressing Objective 2 (Mission Status and Needs Assessment). Discussion of present, emerging, and anticipated issues and needs of specific interest to USACE was encouraged. Findings from the Day 1 presentations and the Day 2 discussions were integrated to address Objective 3.

\section{WORKSHOP SUMMARY}

\section{Day 1-Technology Status and Needs Assessment}

Presentation summary. After a brief introduction by the conveners, Day 1 of the workshop began with 10-minute presentations by USACE business line managers for navigation (James Walker), hydropower (Kamau Sadiki), and Regulatory (Amy Klein). These presentations were critical because the corporate perspectives of each speaker structured the second day of deliberations.

For clarity and brevity, the rest of the presentations are not described in the sequence in which they were given, but rather in the order of how they contributed to the overall narrative. The actual sequence of presenters and their titles can be seen in Appendix B (Workshop Agenda). The following summary is included to describe the general flavor of the presentations. Detailed notes taken during the presentations can be reviewed in Appendix $\mathrm{C}$ and copies of the slides can be found in Appendix D. Mr. Stephen Bowler of the Federal Energy Regulatory Commission (FERC) summarized the mission responsibilities of his agency, the FERC license process, and the agency interfaces (with emphasis on USACE interfaces) typically required for the hydropower licensing process. Department of Energy (DoE) representatives (Drs. Neary, Jepsen, and Grippo, and Mr. Weiland) from four national laboratories (Oak Ridge, Sandia, Argon, and Northwest Pacific, respectively) gave coordinated presentations providing a comprehensive overview of how the DoE hydrokinetic program was distributed and implemented within their agencies. They also summarized the status of hydrokinetic turbine development of many types (not just KETs), the different types of applications, the status of tools that could be used to describe or assess the operation and performance of KETs, and the types of environmental impacts that could be anticipated. Dr. Alex Haro of the USGS gave a presentation on studies, both ongoing and anticipated, describing likely physical effects of KETs on different species and life stages of fishes. Dr. William (Bill) McAnally of Mississippi State University summarized fundamental effects of kinetic energy extraction on the hydraulic regime of an open river. He then connected a suite of issues of importance to USACE to these fundamental effects. Mr. Randy Thoreson of the NPS presented his agency's perspective on KETs progressing from identification of impacts to their likely direct and indirect effects on recreation and other social dimensions. George Detweiler of the US Coast Guard summarized his agency's roles and responsibilities in KET development. Paul 
Hartfield summarized studies conducted by his agency and colleagues at Mississippi State University describing how microhabitat associations of the endangered pallid sturgeon could be affected by KETs. Will Veatch and Brenda Archer of the New Orleans District jointly presented a summary of their agency's experience dealing with the complex array of technical, coordination, and permitting issues associated with KETs. Their presentation was particularly valuable because the New Orleans District is one of the first USACE districts dealing with what may become a major increase in KET inquiries.

Day 1 summary. A number of important conclusions about KET environmental impacts and the tools to assess them were developed during the workshop.

Conclusions about environmental impacts associated with KETs can be separated into two categories: geophysical and biochemical effects versus the effects on higher trophic levels. Most geophysical effects and some biochemical effects can be inferred from Figure 1 (from the presentation by Dr. Bill McAnally). This figure compares average cross-section hydraulic conditions (depth and velocity) at cross sections both with and without a 10\% kinetic energy extraction base-lined to the hydraulic control structure located at $0 \mathrm{~m}$. A change in hydraulic characteristics of the magnitude shown in Figure 1 produces a cascade of effects. First, the reduction in energy slope will increase water surface elevations as well as alter the erosion and deposition regime in the wake of each KET. In the longer term, shifts in the erosion and deposition regime (and debris loading) to a new equilibrium in an array has the potential to affect channel geomorphology and flow pattern. These alterations in the geophysical environment affect water quality patterns in the short term by altering residence times of constituents. In the long term, the alterations affect those parts of water quality patterns that are coupled to sediment dynamics. The effects of KETs on geophysical variables and water quality dynamics generally described above (plus other effects that are more direct and therefore easier to understand) can be connected to higher trophic levels in a marine environment using conceptual models, either for a single KET (Figure 2) or an array of KETs (Figure 3).

The precise magnitude and extent of potential impacts will be determined by flow, season, number of units and their distribution, local hydrology and geomorphology, degree of existing river infrastructure (e.g., levees, dams, and harbors) and other site-specific factors. More precise forecasts and assessments of impacts are difficult to quantify without additional detailed information. However, the potential impact of an extraction of $10 \%$ of the kinetic energy of river flow can be analytically shown to have a substantial impact on a number of important flow variables (Figure 2) that, in turn, affect other resource categories. Figures 2 and 3 depict effects of KETs in a marine environment; however, conceptually similar effects can be expected in estuarine and river environments.

Evaluations of the accuracy of tools to forecast and assess the environmental effects of KETs varied by discipline. Physics-based models (both numerical and physical modeling tools) are relatively mature in their development, so that relatively robust statements can be made about impacts on the geophysical environment, although a few unresolved issues remain. For example, it is difficult to include the small-scale hydraulic effects of individual turbine blades within larger-scale modeling efforts that must simulate conditions within a spatial domain many kilometers in length. 


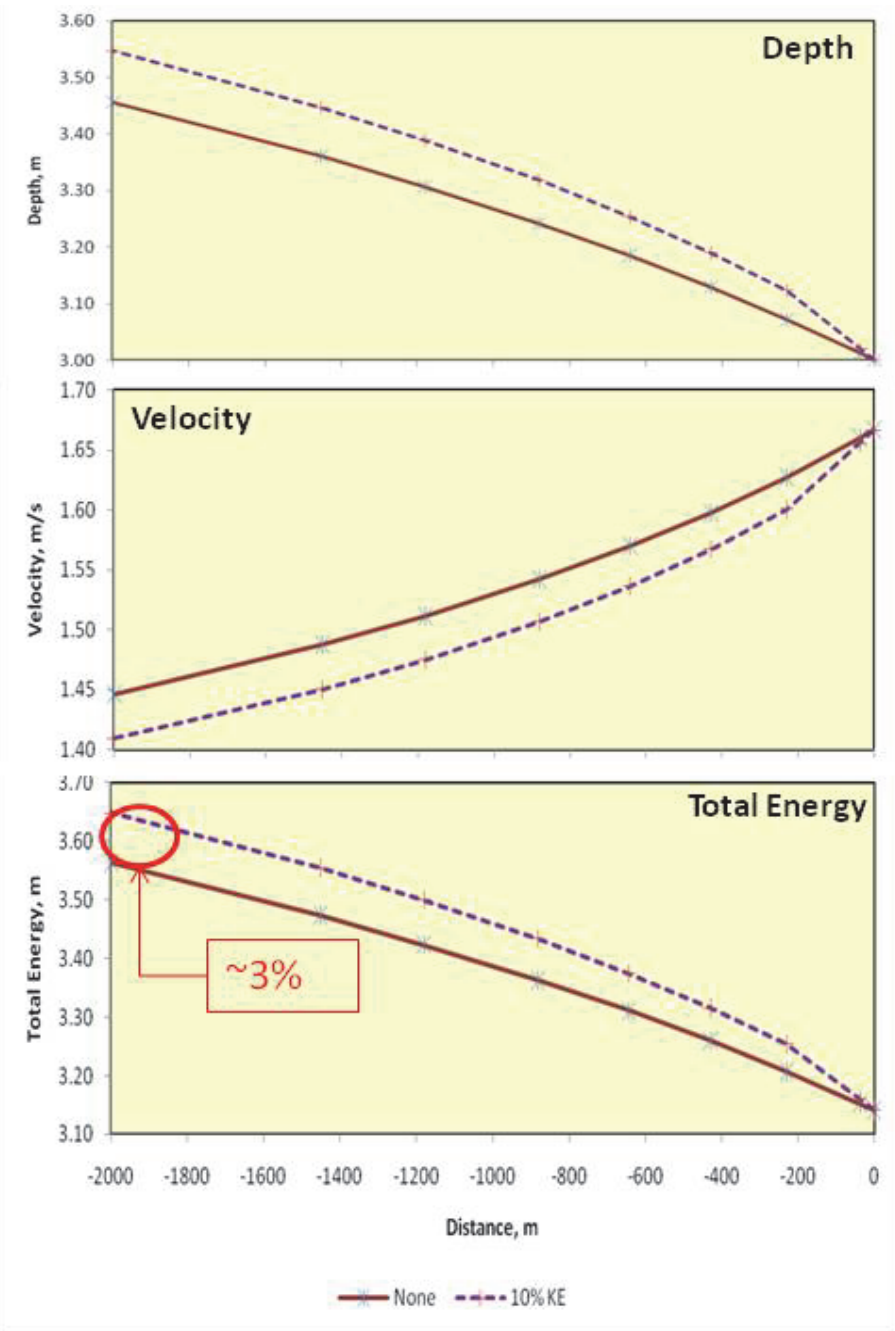

Figure 1. Upstream effects from a hypothetical hydraulic control structure at $0 \mathrm{~m}$ comparing with and without KETs. Note substantial effects on energy slope, average velocity, and flow depth for a uniform channel where $Q=10,000 \mathrm{~m}-3$ sec -1 , roughness $(n)=0.025$, bottom slope $=$ $0.0001, \mathrm{KE}$ coefficient $=1$, tailwater depth $=$ $3 \mathrm{~m}$, and kinetic energy extraction $=10 \%$. Note the substantial upstream effects of kinetic energy extraction on river depth and velocity, which affects stage-discharge relationships and conveyance of sediments and nutrients. 


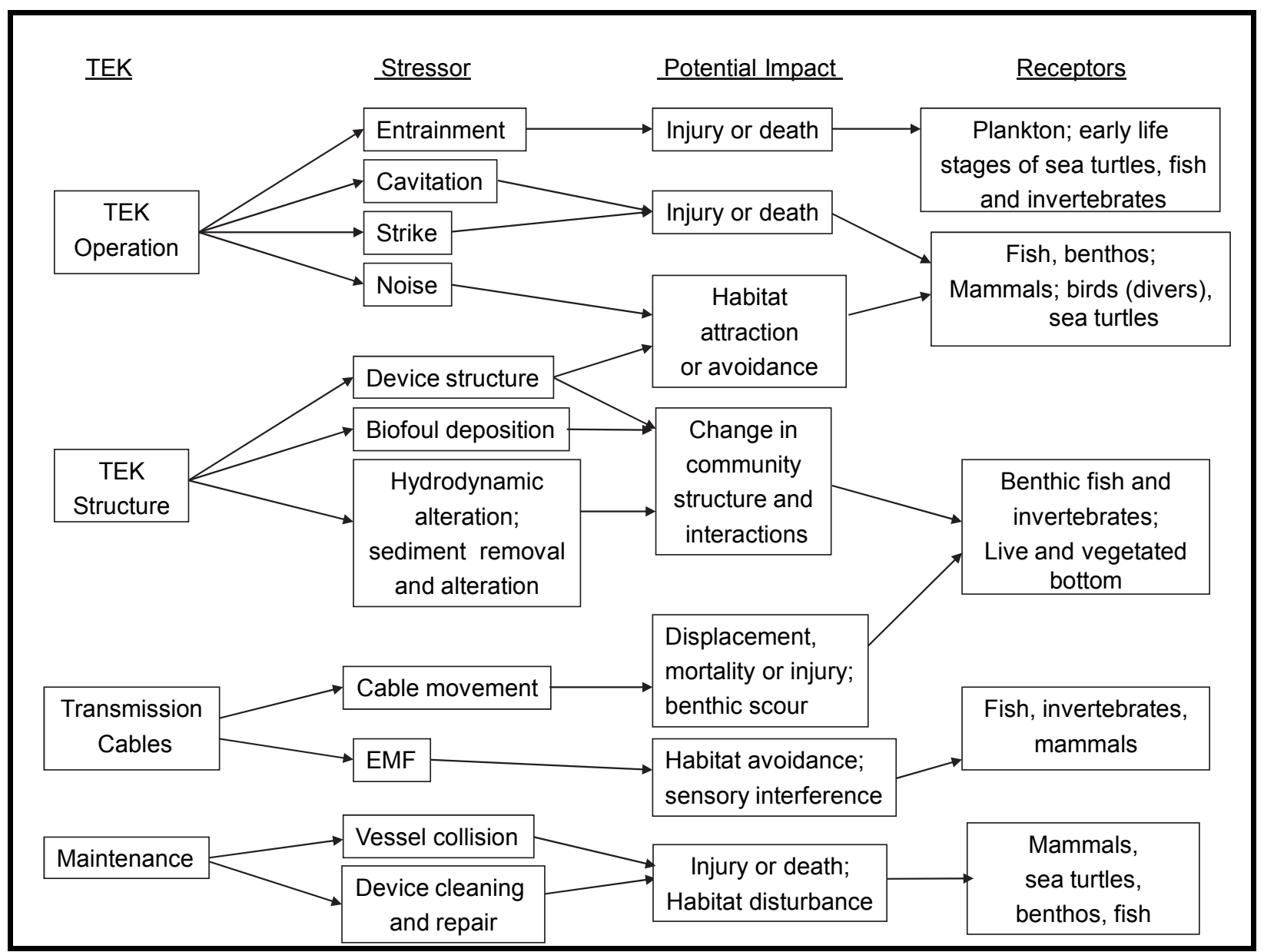

Figure 2. Conceptual model of expected impacts of a single KET deployment in a marine environment. Conceptually similar effects can be anticipated in estuarine or riverine environments. The conceptual model does not include construction impacts (taken from a presentation by Dr. Mark Grippo).

The relative maturity of physics-based forecasting tools mean that a number of alternative approaches may be available for each application. Unfortunately, experience has shown that applicants are typically supported by their own cadre of modeling professionals, each using different, often proprietary, models. To avoid confusion and expedite the licensing process, there is value in establishing "reference models" to address specific aspects of the geophysical effects of KETs. Each reference model will include documentation of state variables, appropriate boundary conditions, and relevant time and space scales to adequately address specific geophysical effects. These public-domain models can be used to develop baseline costs of energy and to identify cost reduction pathways. They will be based on generic KET designs commonly used in high kinetic energy environments and based on real data. With this approach, both applicant and regulator can be assured that best science is used when an applicant chooses a model with attributes similar to the reference model. Geophysical uncertainties still exist that limit the forecast accuracy of physics-based models. For example, the degree to which the structures (posts, reinforcements, and cabling systems) used to deploy KETs are subject to debris loading is unknown. These unknown factors create uncertainties about the effects of debris loads on hydraulic characteristics and fluvial 
geomorphology response. FERC encourages relatively small-scale pilot studies to address local physical impacts of individual KETs. At the larger scale, monitoring of effects based on the tenets of adaptive management is required to address population, community, and ecosystem-level impacts.

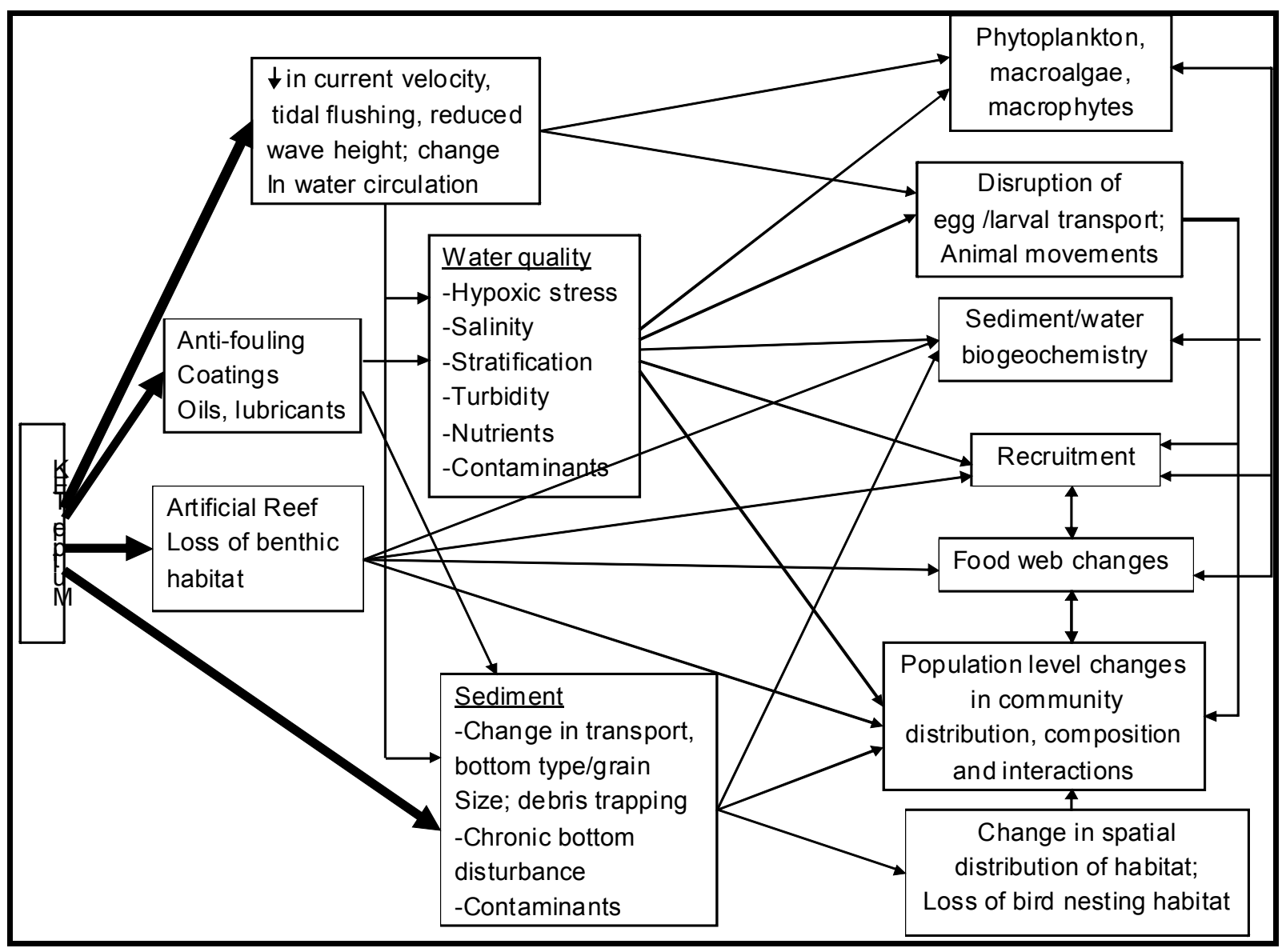

Figure 3. Conceptual model of expected impacts of an array of KETs deployed in a marine environment. Conceptually similar effects can be anticipated in estuarine or riverine environments. The conceptual model does not include construction impacts (taken from a presentation by Dr. Mark Grippo).

Ecological response models are less mature than physics-based models, particularly for effects that are longer-term or far-field in nature. A number of concerns were identified by Dr. Paul Hartman of the US Fish and Wildlife Service (USFWS) on impacts of living resources that should be addressed by field studies. There are also a large number of water quality, population, and community models that could be used to forecast and assess impacts of KETs at various time and space scales. It is beyond the purview of this technical note to discuss them in detail. However, several presenters at the workshop expressed interest and/or presented coordination plans for the use of the Numerical Fish Surrogate (NFS) family of models. These models were developed at ERDC to address direct impacts (e.g., blade strike) and indirect effects (e.g., alteration in movement behavior) on various fish species. There appeared to be a consensus that the NFS type of models should be developed to more efficiently evaluate some aspects of the environmental impacts of KETs. This family of high-fidelity models can be used in conjunction with monitoring 
data of different scales and high fidelity Computational Fluid Dynamics (CFD) modeling. This combination provides the fine-scale resolution necessary to address many of the more difficult ecological questions associated with KET development.

USACE institutional involvement in KET development is clearest from a Regulatory standpoint (see summary in Text Box A). KET developers require both Section 10 (Rivers and Harbors Act 33 U.S.C. 403) and Section 404 (Clean Water Act) permits and both USACE permitting actions are typically coordinated with FERC as the lead agency. In addition, USACE internal coordinating activities are conducted from the perspective of the KET EIS to ensure that issues associated with major USACE mission responsibilities are addressed.

One of the most important findings from the workshop was the sheer number of proposed KETs for the Lower Mississippi River. Fields of KETs numbering in the tens of thousands have been proposed. Each KET will likely have a relatively minor effect because of its small size (1- to 3-m turbine blade-tip diameter). However, fields of KETs that extract up to $10 \%$ of the kinetic energy of the river will likely have a substantial impact on a number of physical processes (Figure 1) and the biogeochemical cycles, living resources, and human uses coupled to these physical processes. A generalized cascade of biological to ecosystem-level impacts and agency mission considerations is shown in Figure 4.

Figure 4 also demonstrates that KETs have the potential to affect USACE mission areas beyond the Regulatory mission. KET development has the potential to directly affect major USACE mission areas such as navigation, flood control, and ecosystem restoration. The reduction in average channel velocity may increase sedimentation within a navigation channel, which will require an increase in channel maintenance activities. Increased water depth will affect the stage discharge relationship that is used to calculate flood risk and could affect levee heights needed to protect against floods of a specific recurrence interval. Alteration of the physical environment by arrays of KETs will also likely affect both upstream and downstream stage-discharge relationships, which are often the basis of USACE project EISs. Therefore, KETs can affect existing USACE projects in ways not addressed in the original USACE project NEPA documentation and, therefore, affect USACE project benefits in unexpected ways. The general conclusion from the presentations by Will Veatch and Brenda Archer (both of MVN) was that many concerns remain to be addressed about the effects of KETs. 


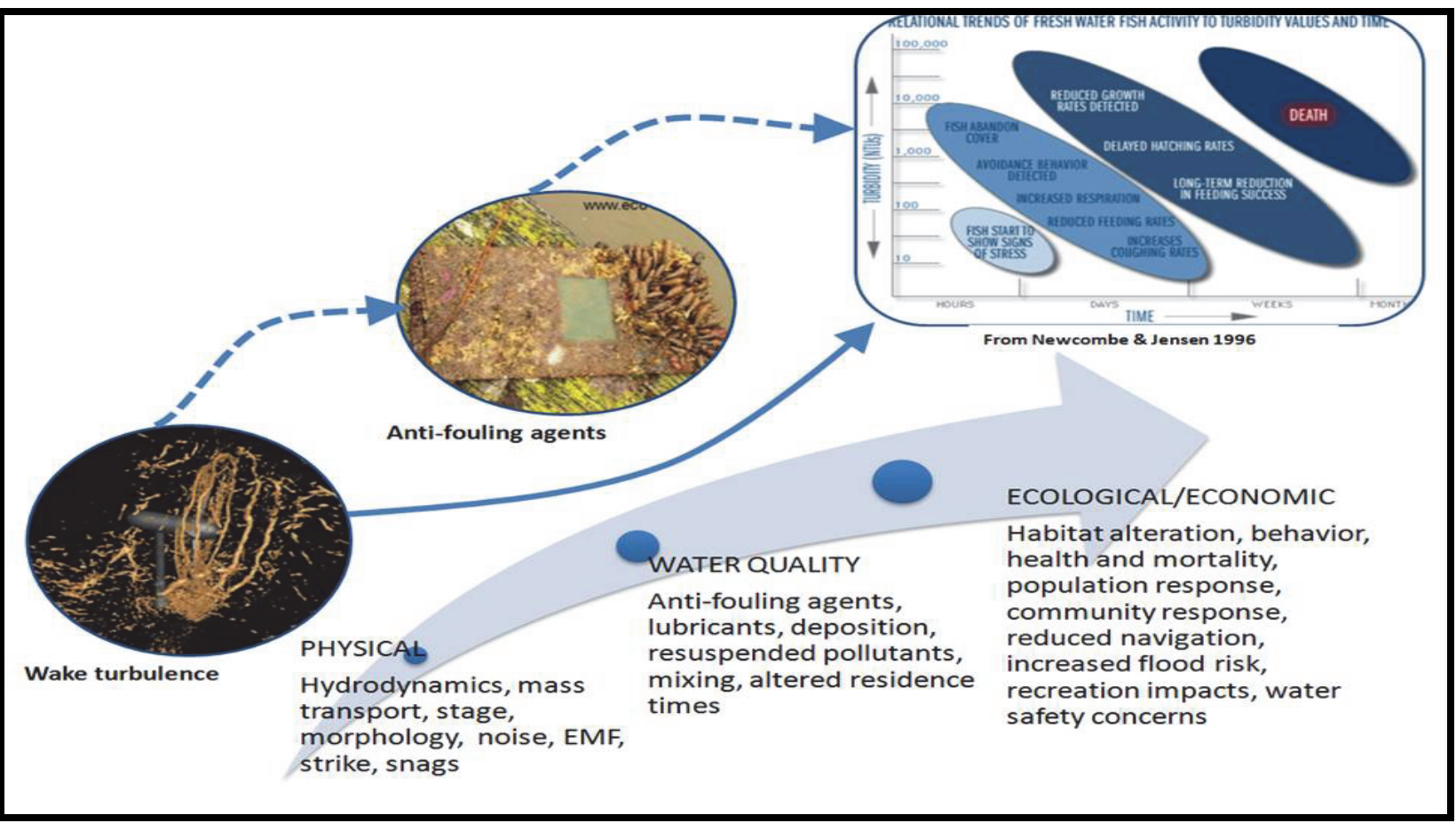

Figure 4. Generalized cascade of coupled physical and chemical processes, living resources, and human uses affected by large fields of KETs (modified from Vincent Neary workshop presentation).

The first day presentations confirmed the large amount of uncertainty surrounding direct effects of KETs (e.g., fish entrainment and mortality, installation and maintenance, construction of shoreline facilities on maintained river levees, modification of levees for power lines and utilities access) and indirect effects (e.g., wake sedimentation and debris loading of turbine support structures (posts, struts, and cables) induced by reduced water velocity). The major finding from the Day 1 summary is that the number of USACE mission areas affected by KET and their interactions deserve further evaluation, discussion, and synthesis.

\section{Day 2- Mission Status and Needs Assessment}

Day 2 of the workshop began with a summary of the previous day's most significant events followed by a short session to identify technology needs to adequately forecast impacts of KET development. An open discussion ensued in which a variety of topics were introduced and explored. The discussion was far-ranging, reinforcing the perception that issues associated with KET development are complex and affect many agencies and a number of critical USACE mission areas. The following three related topics were discussed and are briefly described later in this techical note:

- Department of the Army permit program (Regulatory)

- Process by which the Corps addresses its responsibilities under Section 408 (Civil Works)

- Protection of navigation, flood control, and other Federal investments (for which USACE is responsible) from the negative impacts of hydrokinetic projects. 
Relationships among the three topics are symbolically represented in Figure 5. Note that FERC is the lead Federal agency for Hydropower License application and that USACE supports FERC. The relationship between FERC and USACE (based primarily on procedures developed and used within MVD) is summarized briefly below to give context to the recommendations at the end of this technical note. For brevity, the descriptions below do not include the considerable internal and external coordination that characterizes the USACE response to each license application. More specific responsibilities of USACE in support of FERC KET license decisions are described in detail in "Memorandum of Understanding between United States Army Corps of Engineers and the Federal Energy Regulatory Commission on Non-Federal Hydropower Projects" dated 30 March 2011 (http://www.usace.army.mil/Portals/2/docs/civilworks/mous/ferc corps 30mar2011.pdf).

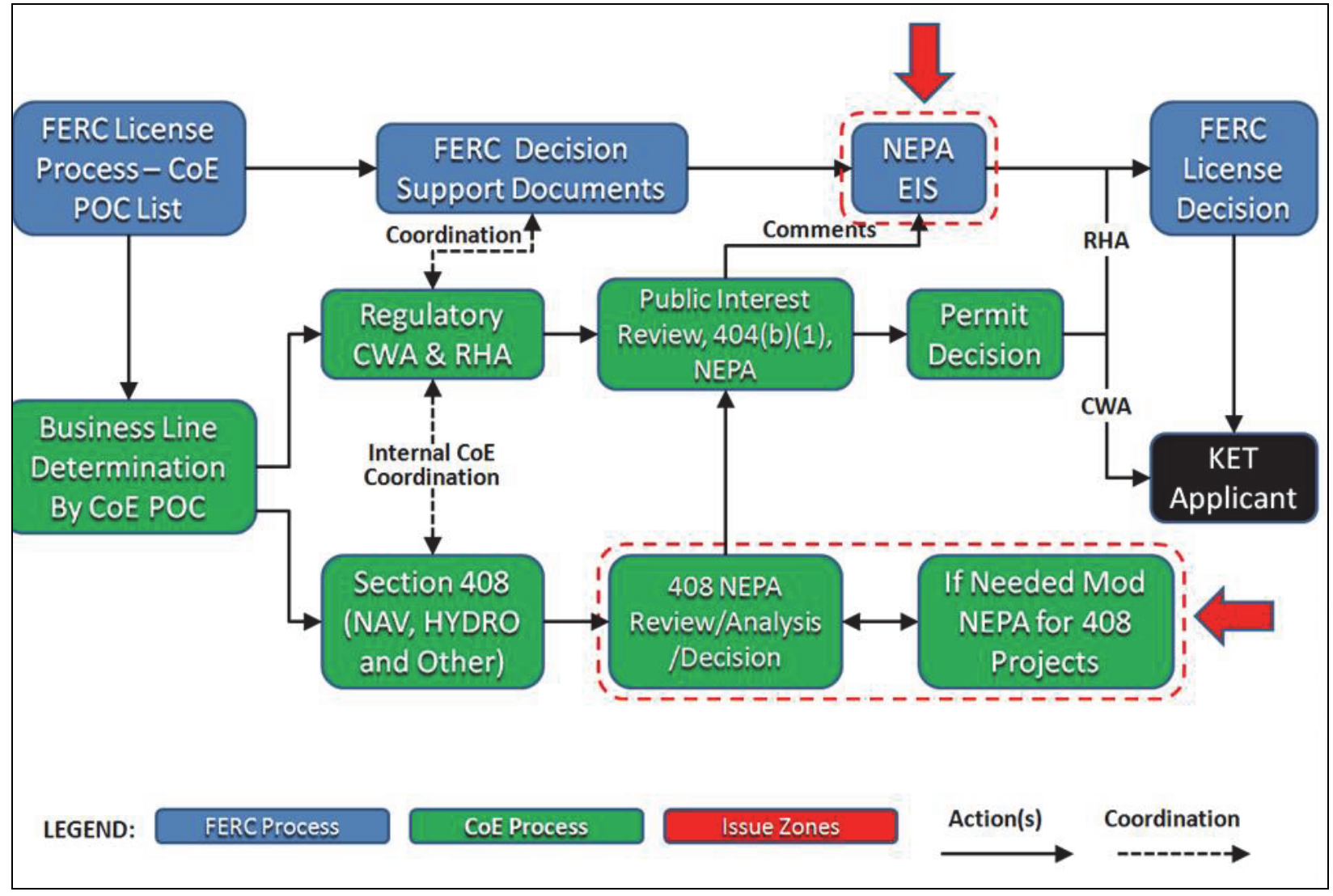

Figure 5. Simple box-and-arrow diagram summarizing joint FERC and USACE license and permitting process for KET development. Red arrows denote challenge areas for each agency. State of the science is presently inadequate to determine impacts of large-scale KET development with sufficient accuracy and precision to fully support NEPA analysis and decision-making. The same uncertainties over impacts also affect the ability of USACE to fully assess the effects of KET development on existing USACE Civil Works projects. The mission responsibilities of other agencies such as the Coast Guard, Fish and Wildlife Service, Park Service, etc. are not shown but must also be considered.

In its simplest form, the USACE response to a FERC request is as follows. FERC initiates contact through a designated USACE office for each district or division. From the perspective of USACE, support to FERC falls into either Regulatory or Civil Works business lines. From the Regulatory business line, a KET applicant may require either or both a Section 404 Clean Water 
Act (CWA) Permit or a Section 10 Rivers and Harbors Act (RHA) Permit. For the successful applicant, the Section 10 RHA permit will be issued as part of the FERC Hydropower License and the 404 Permit will be issued directly to the applicant. In contrast, initial Section 408 activities are primarily internal to USACE as the agency assesses the effects of the applicants' proposed activities on existing Federal projects as part of a thorough public interest review. The completed assessment is communicated to FERC as formal comments to be included within the license documentation. Internally within USACE, the assessments are used to determine if impacts of the proposed KET are sufficient to invalidate existing EISs of affected USACE project(s). For example, extraction of a significant amount of kinetic energy from a river may decrease water velocity and increase the water elevation associated with flood flows. These changes to the geophysical environment may result in increased maintenance dredging and reduced flood protection in addition to numerous additional substantial impacts.

Day 2 conclusions differed in accordance with the business lines affected by KET development. USACE representatives in attendance felt that the Regulatory business line could generally discharge its responsibilities to FERC as required in the MOU. Regulatory is an existing USACE business line with a dedicated institutional infrastructure, established legal foundation, and a reasonably well-known set of information needs, tools, and procedures to support permit decision-making. The MVN and MVD representatives felt comfortable that their internal processes were generally adequate to discharge their responsibilities to support FERC and to conduct necessary internal coordination with regard to FERC support. MVD requires each of its districts to have a dedicated FERC POC and established lines of communication within the district to fully execute the "one door to the Corps" policy. This is very similar to MVN's typical review process, with the exception of the up-front addition of MVN's legal and public affairs staff. The consensus opinion was that the MVD process could serve as a template for a national process, although there is likely value in coordinating the MVN process with other USACE districts that have substantially different mission portfolios to more fully develop a national template for non-Federal KET development.

In contrast, Civil Works business lines may have less experience with how KET arrays potentially impact existing USACE investments. For example, a district like MVN, with no Federal hydropower projects within its boundaries, may not have experience with the suite of impacts associated with conventional hydropower projects or large-scale KET arrays. To adequately assess the potential impacts of KET on Civil Works investments, a team approach or access to outside support may be required (as required within MVD) to ensure that necessary expertise is available to support decision-making. To further complicate the Civil Works assessment, district boundaries for the Regulatory and Civil Works business lines may not be the same. Consequently, a large KET array located within the Regulatory boundary of one district may affect Civil Works investments in one or more additional districts.

In addition, the time and space scale of impact associated with KET arrays can be large. For example, as described in the presentations of the first day, large-scale KET arrays as proposed by Free Flow Power for the lower Mississippi River may have substantial impacts on geophysical and chemical patterns and biotic response for substantial distances in both the upstream and downstream directions that could affect large-scale USACE navigation, flood control, hydropower, and ecosystem restoration projects. This awareness led some participants to a 
corollary question regarding the definition of a Corps Civil Works "project" on the Mississippi River. According to the Headquarters representatives, for navigable rivers such as the Mississippi River, the navigation project is considered the length of the mainstem river channel and port facilities that are maintained to meet authorized navigation specifications. Similarly, for flood control structures such as river levees, the flood control project is considered to be the entire mainstem river channel on which authorized levees are constructed, inspected, and maintained. Similar spatial definitions necessarily apply to ecosystem restoration projects, which inherently have large geospatial scales. For example, addition of KETs into an ecosystem restoration project such as LCA may profoundly affect the delivery of sediments upon which the success of the program depends. The group came to the realization that addition of a KET array and its likely large-scale effects into a system that already contains large-scale Civil Works projects will likely affect the Civil Works projects. Therefore, KETs have the potential to either reduce or enhance the performance of USACE Civil Works projects relative to the projections in the NEPA documentation.

The challenge for USACE to support national green energy policies can best be summarized from a NEPA perspective. FERC has primary responsibility for only a single EIS focused on KET development as proposed by a hydropower license applicant. This requires specific and well-defined inputs (i.e., comments and permits) from USACE. The completed EIS will form part of the support material for FERC license decision-making. From the USACE perspective, there are at least two NEPA documents that it must consider. The first supports the NEPA process necessary for FERC license deliberations. The second (or possibly more than two) is associated with existing Federal investments within the proposed KET impact boundary, which may be substantially larger than the project footprint and may extend outside district boundaries to affect one or more additional districts. Civil Works business line portfolios (the basis for the expertise of each district) vary across USACE districts and divisions, which further complicates development of consistent corporate support to KET development. For example, the districts responsible for providing input to the FERC hydropower license process may have little or no corporate experience with hydropower issues and impacts if Federal hydropower projects do not occur within the affected district boundaries.

Attendees generally found value in the workshop and expressed interest in future workshops to allow them to keep abreast of developing technologies and emerging issues. Although not discussed in detail because of time limitations, the attendees also supported the need for the kind of tools described during day 1 of the workshop and applauded technology coordination efforts with DoE scientists and engineers. Technology recommendations that follow in the next section will be based largely on Day 1 discussions combined with comments made during the first session of Day 2.

\section{WORKSHOP RECOMMENDATIONS}

The workshop generated a number of recommendations. For clarity, the recommendations parallel the structure of the workshop summary. Technology recommendations immediately follow this paragraph. Institutional process recommendations then follow and are separated into either Regulatory or Civil Works business lines. 
ERDC WQTN-MS-08

August 2014

\section{Day 1- Technology Recommendations}

Recommendation Day 1-A - Uncertainties in the fluid geophysical environment

Status Summary: Computational tools to address impacts of KETs on the fluid environment are relatively mature in their development, although there is uncertainty regarding the importance and magnitude of key physical processes (e.g., sediment transport and debris loading) in large rivers.

Recommendation: Corps engineers and scientists should coordinate (information exchange to active participation) with DoE staff, FERC, relevant agencies, and TEK developers in studies conducted to better understand and forecast impacts of KET development. Coordination should include international opportunities to access new technologies and databases. This coordination will allow USACE engineers and scientists to gain experience in tool selection and impact forecasting.

\section{Recommendation Day 1-B - Targeted studies}

Status Summary: Several uncertainties in the physics-based models prevent their routine application to address KET issues including scaling effects and small-scale hydraulic processes.

Scotlandville Bend would be an excellent site for a case-history study to address many of the impacts, technology needs, and institutional issues associated with KET development listed in this recommendation and others that follow.

\section{Recommendation Day 1-C-Uncertainties in effects of KET support infrastructure}

Status Summary: Many of the geophysical effects of KET construction, operation, and maintenance that could directly affect USACE projects are incompletely known (e.g., land structures such as transmission lines, buses, transformer fields, modifications to levees; KET construction and operation; and scheduled and emergency KET maintenance).

Recommendation: Participate in monitoring phase of DoE's adaptive management plan to describe and manage effects of KETs described on Day 1 to improve descriptions of effects of KETs on the fluid environment.

\section{Recommendation Day 1-D-Need for Reference Models of the Fluid Environment}

Status Summary: KET developers typically each have their own cadre of hydraulic modelers using individual, often proprietary, codes. Therefore, permitting agencies face a wide array of different, sometimes unfamiliar, codes whose output must be assessed as part of permit decisionmaking.

Recommendation: USACE engineers and scientists should collaborate with DoE to develop required attributes (e.g., dimensionality, spatial and temporal resolution, boundary conditions, and output requirements) of hydraulic models used to support KET license applications to improve permitting decisions and assessment of impacts on existing USACE projects. 
Recommendation Day1-E - Application of Numerical Fish Surrogate Family of Models

Status Summary: Direct and indirect impacts on higher trophic levels are the greatest uncertainties in KET deployment and the most expensive to address. Several presenters mentioned ongoing or anticipated use of the NFS family of models developed by ERDC coupled to computational fluid dynamics models or detailed monitoring to help reduce uncertainty on KET impacts on higher trophic levels.

Recommendation: NFS models should be developed to improve the forecast accuracy of the effects of various KET designs or deployments.

Recommendation Day 1-F-Co-development of tools to improve forecast accuracy

Status Summary: FERC requires that some KET development be conducted in phases of increasing investment using basic concepts of adaptive management to systematically reduce uncertainties in license decision-making. DoE scientists and engineers use the opportunities provided by adaptive management to better understand impacts, build more accurate forecasting tools, and conduct focused studies to answer critical questions. Many of the uncertainties that plague KET from the DoE and FERC perspectives are also important to USACE, particularly for the Civil Works business lines.

Recommendation: USACE scientists and engineers should be hands-on participants or observers in the phased DoE Adaptive Management Program to help them understand and better anticipate the effects of KET development on existing USACE Civil Works projects.

\section{Day 2 -Mission Status and Needs Assessment}

\section{Recommendations Day 2-A}

The Regulatory business line is relatively experienced in dealing with KET institutional and technical issues. Consequently, recommendations to improve the ability of the Regulatory business line to support KET development are relatively modest in nature. In contrast, Civil Works business lines are less experienced in dealing with KET issues and, consequently, the recommendations are more comprehensive in nature. The red dashed lines of Figure 5 show the parts of the joint FERC and USACE FERC license process having the greatest engineering and ecological uncertainty (note that many other agencies are also involved but are not shown in the figure because this document focuses on the USACE perspective). Note that uncertainties about the impacts of KET development that limit the accuracy of the EIS for a license applicant will be similar to the uncertainties of KET development that plague existing USACE Civil Works investments. That is, similar uncertainties about possible impacts affect the missions of multiple agencies. Therefore, future efforts to reduce these uncertainties must be coordinated among the participants in the FERC license process.

\section{Permitting Recommendation Day 2-A - Building a national USACE template for KET development}

Status Summary: MVD and MVN have more experience than any other USACE division/district in dealing with KETs and FERC. This is because of their experience with the license application 
of Free Flow Power for the lower Mississippi River. Other districts may have little or no experience in KET development.

Recommendation: Take advantage of the experience and processes established by MVD and MVN to build a national guidance document that will allow USACE to address Permitting and Civil Works business lines affected by KET development. This document may include a "tool" that describes the process from a USACE perspective including types of information required from the applicant as well as "triggers" to meet 408 requirements. The FERC Study Plan Determination for Free Flow Power could be a good starting point to develop a national template (http://elibrary.ferc.gov/idmws/File list.asp?document id=13788453).

\section{Permitting Recommendation Day 2-B - Availability of advanced support to districts}

Status Summary: Experience within MVD and MVN has shown that study requirements in support of a license or permit application may be unclear. In addition, studies prepared by the applicant to document the impacts of KETs can be complex and difficult to interpret.

Recommendation: Expertise should be available to districts from programs like the Dredging Operations and Technical Support (DOTS) Program or the Water Operations Technical Support (WOTS) Program to allow the districts to judge the adequacy of applicant studies. For example, MVN has an agreement with the Coastal and Hydraulics Laboratory at ERDC to review applicant documents.

\section{Civil Works Recommendation Day 2-A - Improve district ability to respond to 408}

Status Summary: While Regulatory requirements are clear within each district to respond to FERC requests, responsibility to meet 408 requirements is less clear. Oftentimes the USACE 408 POC is simply an office symbol (i.e., not an individual) and the appropriate response is unclear.

Recommendations: 1) Build a POC list within each district responsible for addressing 408 requirements. 2) Prepare a list of large-scale USACE Civil Works projects that includes a definitive description of project boundaries and the scale of critical geophysical, water quality, and ecological effects that can be matched to similar information from an applicant for a proposed KET project.

\section{Recommendation Day 2-B}

Status: Along with a few other districts, MVN has the most USACE experience in dealing with the institutional and technical issues associated with KET development. In comparison to other districts, MVN also has a reasonably clear vision in dealing with potential environmental impacts.

Recommendation: Take advantage of the technology and science uncertainties identified by MVN (and others that may be identified in the future) to build an R\&D program that will identify many of the physics-based tools that already exist or develop new tools that provide critical information to decision-makers. 
SUMMARY AND CONCLUSIONS: The national policy supporting development of renewable green energy affects several important USACE business lines, broadly separated into Regulatory and Civil Works. Although it can be improved, the Regulatory business line as it relates to KET is relatively mature and appears adequate to discharge its mission requirements. In contrast, the Civil Works business line has less experience with KETs, and both institutional adjustments and technology advancements are necessary to support the national policy. It is recommended that USACE consider developing a program to address these shortcomings. The program should be separated into technology advancement and institutional adjustment. Scientists, engineers, and regulators in affected agencies should coordinate their efforts to advance technology; this will avoid duplication of effort. Efforts should be supplemented with targeted $\mathrm{R} \& \mathrm{D}$, as described above. Moreover, this phase of the program should include participation by multiple agencies in the adaptive management paradigm used by FERC to reduce uncertainties when making decisions regarding licensing. These same uncertainties affect USACE assessments, particularly with regards to Civil Works projects. The institutional adjustment portion of the program should include substantial participation by districts and divisions that have experience in KET to ensure that the USACE can corporately support renewable green energy development. These same districts should also participate in technology development efforts to ensure that selected technologies address issues from both the Regulatory and Civil Works business lines.

POINTS OF CONTACT: For additional information, contact David Smith (601) 634-4267, David.L.Smith@usace.army.mil or the manager of the Water Operations and Technical Support Program, Dr. Patrick Deliman,(601)634-3623,Patrick.N.Deliman@usace.army.mil.This technical note should be cited as follows:

Smith, D. L., J. M. Nestler, R. Styles, and B. Tetreault. 2014. Analysis of the challenges and opportunities of hydrokinetic turbine development affecting the US Army Corps of Engineers. ERDC WQTN-MS-08. Vicksburg, MS: U.S. Army Engineer Research and Development Center.

http://el.erdc.usace.army.mil/ansrp/ansrp.html.

NOTE: The contents of this technical note are not to be used for advertising, publication, or promotional purposes. Citation of trade names does not constitute an official endorsement or approval of the use of such products. 
ERDC WQTN-MS-08

August 2014

\section{Appendix A: Workshop Attendees}

\begin{tabular}{|c|c|c|}
\hline Name & Agency & Contact Information \\
\hline Brenda Archer & USACE-MVN (New Orleans District) & $504-862-2046$ \\
\hline Jeff Artman & USACE-MVK (Vicksburg District) & $601-631-5577$ \\
\hline Wayne Babcock & US Fish \& Wildlife Service & \\
\hline Stephen Bowler & Federal Energy Regulatory Comm. & $202-502-6861$ \\
\hline George Detweiler & US Coast Guard & 202-372-1566 \\
\hline Mark Grippo & Argonne National Lab & $630-252-3091$ \\
\hline Beth Guynes & USACE-MVD (Mississippi Valley Division) & Now retired \\
\hline Alex Haro & US Geological Survey & 413-863-3806 \\
\hline Paul Hartfield & US Fish \& Wildlife Service & 601-321-1125 \\
\hline Ronnie Heath & ERDC-CHL & 601-634-3592 \\
\hline Richard Jepsen & Sandia National Lab & 505-284-2767 \\
\hline Jack Killgore & ERDC-EL & 601-634-3397 \\
\hline Amy Klein & USACE-HQ & 202-761-4559 \\
\hline Jeff Lillycrop & USACE-CHL/HQ & 202-761-4229 \\
\hline Steve Maynord & USACE-CHL & 601-634-3284 \\
\hline Bill McAnally & Northern Gulf Institute & $662-325-9848$ \\
\hline Vince Neary & $\begin{array}{l}\text { Oak Ridge National Lab (now at Sandia } \\
\text { National Labs) }\end{array}$ & 505-284-2199 \\
\hline John Nestler & ERDC/BTS & $601-634-2720$ \\
\hline Howard Park & ERDC-CHL & 601-634-4011 \\
\hline Rick Robertson & USACE-MVD & \\
\hline Kamau Sadiki & USACE-HQ & 202-761-4889 \\
\hline COL George Shepard & Deputy Commander MVD & \\
\hline David Smith & ERDC-EL & 601-634-4267 \\
\hline Richard Styles & ERDC-CHL & 601-634-4065 \\
\hline Brian Tetreault & ERDC-CL & $410-456-0417$ \\
\hline Randy Thoreson & NPS & $651-293-8450$ \\
\hline Jeff Trulick & USACE-HQ & 202-761-1380 \\
\hline Will Veatch & USACE-MVN & $504-862-2858$ \\
\hline Jim Walker & USACE-HQ & Retired \\
\hline Mark Weiland & Pacific Northwest National Lab & $509-427-5923$ \\
\hline Timothy Wendt & US Coast Guard & Timothy.J.Wendt@uscg.mil \\
\hline Rusty Wright & US Coast Guard & Rusty.H.Wright@uscg.mil \\
\hline Pat Wycko & US Coast Guard & Patrick.D.Wycko@uscg.mil \\
\hline
\end{tabular}


Appendix B: Workshop Agenda 

Evaluating Data Gaps Relevant to United States Army Corps of Engineers

Sponsor: $\mathrm{CHL}$

Escort: Dr. Richard Styles

\section{Wednesday, 29 February 2012}

8:00 - 08:30 AM Arrive Coastal and Hydraulics Laboratory

8:30 AM Welcome and ERDC Overview

Richard Styles

8:45 AM

USACE-HQ

Jim Walker Kamau Sadiki

"10-minute comments from business line managers"

Amy Klein

9:15 AM Sandia National Laboratories

"National Lab Activities in Marine Hydrokinetics:

Model Development"

9:45 AM

ORNL

"National Lab Activities in Marine Hydrokinetics:

Vincent Neary

Testing \& Environmental Studies"

10:15 AM

BREAK

10:30 AM

MSU

"Hydrokinetic Energy Effects on Navigation"

William McAnally

11:00 AM

USFWS

"Habitat Association of Pallid Sturgeon in the Lower Mississippi River"

11:30 AM

ARGONNE

"Risk analysis of the Potential Ecological Impacts of MHK Arrays"

Richard Jepsen

Paul Hartfield

Mark Grippo

12:00 PM LUNCH

1:00 PM

Tour Physical Models/Ship Simulator

Richard Styles

2:00 PM

FERC

"The FERC Hydropower Licensing Process, Hydrokinetic

Stephen Bowler 
Turbines, and Agency Coordination"

2:30 PM

USACE-MVN

"USACE New Orleans District Approach to Evaluating

Will Veatch

Hydrokinetic Projects"

3:00 PM

USCG

"Coast Guard's Roles and Responsibilities Concerning

George Detweiler Alternative Energy Projects"

3:30 PM

BREAK

3:45 PM

NPS

"Hydrokinetic Energy Projects \& Recreation: A Guide to

Randy Thoreson Assessing Impacts"

4:15 PM

PNNL

"Assessment of Fish Behavior and Vulnerability to Hydrokinetic Devices"

4:45 PM

USGS

"Present and future USGS research on effects of

Hydrokinetic Turbines on Fish Behavior, Injury, and Mortality"

5:15 PM

ADJOURN

\section{Thursday, 1 March 2012}

8:30 AM Corps-only meeting

Recap Day 1, Planning our way forward

What are the research and regulatory requirements needed for the USACE to adequately assess the impacts of KET?

How should USACE proceed to incorporate these requirements?

10 - 11:00 AMAdjourn 
ERDC WQTN-MS-08

August 2014

Appendix C: Workshop Notes 
US Army Corps of Engineers.
U.S. Army Engineer Research and Development Center Vicksburg, MS

Coastal and Hydraulics Laboratory

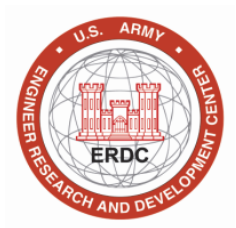

\section{Ongoing Research and Development of Hydrokinetic Turbines: Evaluating Data Gaps Relevant to United States Army Corps of Engineers}

Sponsor: $\mathrm{CHL}$

Escort: Dr. Richard Styles

Wednesday, 29 February 2012

8:00 - 08:30 AM Arrive Coastal and Hydraulics Laboratory

8:30 AM Welcome and ERDC Overview Richard Styles

Dr. Martin welcome - there has been long time interest/work on alternative energy - at least from 1970's energy crisis.

Challenges - Concern with impeding navigation - taking into account water level changes; anchoring - different bottoms, changeable bottom, debris, sand waves; marking for navigation; connection to land - and how to get power where it's needed; optimal location for best velocity but where scour is a problem.

Richard Styles - Corps overview; why are we interested in KET? - Proposals (e.g., Free Flow Power) may have an impact on waterways - $3-5 \%$ of river cross section.

Purpose:

- $\quad$ Present ongoing research by USACE and others

- Identify potential regulatory and permitting requirements for USACE and other's action

- Develop list of R\&D needs to address unresolved navigation, flood risk management and environmental issues.

Introductions -

8:45 AM USACE-HQ - Business line managers

Jim Walker - Navigation BLM - lots of Inland and coastal navigation infrastructure - interested to see how KET can coexist with navigation. Taking into account need for dredging.

Kamau Sadiki - Hydropower BLM: not a new technology, but lots of developments. Corps the largest hydropower producer in the US - 350 plants, lots of revenue - \$1.5B back to treasury. Army policy - encourage non-Federal hydropower development. Challenges $-1^{\text {st }}$ non-federal unit at Lock \& Dam 2 in Minnesota. Want to make technologies modular - ability to easily modify, move as conditions warrant. Risks - Navigation, others as well - need to make sure developers do things responsibly an address risks. Need to make sure "all boxes are checked" regulatory, permitting, research, engineering. Want to take lessons learned from others international as well.

Amy Klein - Regulatory program manager: USACE regulatory authorities:

- $\quad$ Rivers and Harbors Act - structures/work affecting Nvigable waters

- $\quad$ Clean Water Act - discharge of dredged/fill material into US waters (not just navigable)

- District Commanders permit decision making

FERC has lead on KET - USACE cooperating agency - MOU, comment on documents 
Permit type - Individual vs. general

Coordination with USACE Navigation and Hydropower

Challenges - Competing interests - public interest - many aspects and impacts to be assessed, understood and mitigated.

\section{"National Lab Activities in Marine Hydrokinetics:}

Model Development"

- Main focus on model development

- Program mission - Research, test and develop innovative water resource energy generation

- Wave energy, tidal currents, free flowing rivers - potential for generation

- Focus - determine potential, address environmental challenges, demonstrate performance; identify cost drivers - make commercially viable.

- Main areas of SNL work: Model development, research tools, environmental impacts

- CACTUS Code - single device turbine analysis - provides power vs. current speed curves

- High performance turbine blade design

- Modeling acoustics - predictions for environmental impacts

- Environmental fluid dynamics code (EFDC) - large scale hydrodynamics:

- evaluate if can be used for evaluating MHK affects

- modify to provide more realistic output - momentum sink.

- Can be used for single device and also for arrays of multiple devices.

- Help determine optimum spacing of devices.

- Various configurations can be compared.

- Often end up "chasing the flow" as devices are deployed - affect flow

- Wave device modeling - Modeling to determine effect of devices on wave patterns

$\circ$ Different from flow modeling - different amplitudes and frequencies of waves

- Monterey Bay model

- Similar evaluations of spacing, configurations.

- Scale model tests with Oregon State Univ. -

- Miss River environmental studies - Scotlandville bend - look at current changes, changes in bottom and bank sedimentation, etc.

- Quantifying effects of altered flow around array - both across river and above and below turbine. Affects navigation, bank and bottom stress, erosion rates - model can inform environmental sampling plans.

- Environmental study - Cobscook Bay - affect on migration of baby scallops

- SF Bay - tidal case- evaluate effect of array on flushing of water in the Bay - even at relatively long distances from array.

- Hawaii wave testing - just beginning

- Reference models - develop a set of models to develop baseline cost of energy and identify cost reduction pathways. Generic designs and resources (sound, river, waves) base on real data. Will be in public domain - allow others to develop tools, designs

- Cost drivers - maintenance, installation, permitting, infrastructure, device - ID pathways for improvements - lower costs, more power

- Questions:

- power capacity - how relate to other sources? $20 \%$ development of potential may $=6 \%$ of US energy needs. But estimates are uncertain

- Details on array modeled in river - not real river - generic model. Observation that ship effects "happen every day" - possibly more than KET impacts. 
- Technology performance testing - supporting model validation

- Not just machine performance - also environmental impacts - recognize multiple stakeholders

- Assess resource potential - theoretical, technical and practical.

- Many technologies - need to be advanced to test and assess

- Assess environmental impacts: physical, water quality, environmental

- Need to be able to assess survivability of devices

- Cost of Energy = Cost (of manufacturing, installation, O\&M, etc.)/Annual Energy Production (AEP)

- Need to develop a standardized calculation to allow for comparisons among technologies an other energy sources.

- Lab testing - using large flume at St. Anthony's Falls to be able to test arrays

- Objectives:

- Validation data sets

- Tech Readiness level (TRL) and ERL assessment

- COE assessment

- Best practices for lab and field testing - e.g., ship-mounted ADCPs issues with moving sensors

- Experiment set up - device, multiple sensors - ADVs, PC-ADPs - upstream and downstream from device

- Outputs:

- Performance curve - operating efficiency vs. tip speed ratio

- Inflow and wake flow measurements - includes "wake recovery" after flow through device

- Inflow and wake turbulence measurements - effects on environment and on other turbines

- Validation - of SNL-EFDC code using flume test data

- Some differences based on flume constraints - width

- Future work - additional device types.

- Full-scale field testing - Scotlandville bend - Miss. River

- Free Flow energy device

- Identifying a lot of knowledge gaps:

- MHK resource: machine specs, siting constraints

- Technology readiness: Survivability, wake effects on spacing

- Environmental readiness: Fish-machine interaction, physical impacts of wakes, EMF, noise

- COE drivers: Spacing, Maintenance costs, permitting and monitoring

10:30 AM MSU

"Hydrokinetic Energy Effects on Navigation"

William McAnally

- Number of preliminary permits issued - inland and coastal

- "Can navigation and HKE coexist?"

- Potential effects: 
- Visual navigation, electronic navigation, response (SAR, pollution, etc.), cirrents, navigation safety - allision and collision

- Many benefits of HKE but also need to be clear-eyed of downsides

- Simulated passes through turn- vessels stray out of channel

- Probability of vessel excursion from channel - intentional and inadvertent

- Also vertically - vessels load as much as possible, squat, heel and trip effects

- Cannot be ignored - historical info on probability of excursions

- Physical effects - hypothetical waterway

- Compare baseline with energy extraction due to HKE devices

○ $10 \% \mathrm{KE}=\sim 2 \%$ total energy; however increases with increased number of devices.

- Even more for stress and transport - square, cube and $4^{\text {th }}$ powers

- Cumulative, upriver to next control point.

- Expected physical effects - will vary site-to-site:

- Decreased flow

- Altered water levels

- Increased sediment deposition

- Altered salinity (in estuaries)

- Conclusions:

- Scour at structures with downstream deposition

- Contribution, but potential drawbacks

- Multidimensional modeling of sites is required

- Cumulative impacts of multiple installations (e.g., 1000s in river) need to be considered.

11:00 AM

USFWS

"Habitat Association of Pallid Sturgeon in the Lower

Paul Hartfield

Mississippi River"

- 3 endangered species in Miss. River - sturgeon, tern, mussel.

- USFWS concerns with HKE:

- Lack of knowledge of composition and abundance of aquatic specis affected by projects

- Turbine entrainment of species

- EMF effects - sturgeon and other species detect EMF

- Noise

- Geomorphic effects - may affect O\&M of navigation system

- Range of Pallid Sturgeon - Lower Miss and Missouri River

- Annual "take" was as low as 1 fish/year - could be a showstopper - many turbines could easily reach jeopardy level

- Better data on fish abundancy has allowed higher takes - 1,500/year

- Track fish with acoustic tags

- Have quantified various habitats - different parts of rivers (e.g., point bars, crossovers, etc.) and breakdown where fish are based on location; also other factors (water temp)

- Potential effects of HKE on sturgeon - study plan, not fully funded:

- Collect, measure and tag

- Collect additional data

- Monitor fish for 2-3 years

- Sites - FFP sites: Tunica, Vicksburg, Baton Rouge; several control sites

- Analysis - compare data by species, reach, season, river stage and other variables

- Pre-HKE development baseline 


\section{MHK Arrays"}

- Argonne's role - take data from other studies and funnel into risk assessment

- ID highest risk impacts

- Data gaps to be investigated

- Suggest new research areas

- Using EPA risk assessment protocol

- Problem formulation

- Analysis

- Risk characterization

- Conceptual model development

- Review existing literature

- Review by managers

- Very little data; much speculative

- $\quad$ Need to consider:

- Incremental impact increase from single to array

- Impact of other stress factors

- Problem formulation:

- Have captured complex array of factors to consider - diagrams in presentation

- Existing anthropogenic stressors in addition to MHK - need to determine what role MHK will play, and comparison to existing. - Cumulative impact

- Barriers - little info exists, inconclusive results, need to understand incremental increase to do cumulative analysis.

- Analysis:

- Characterization of exposure

- Characterization of ecological effects

- Modeling interactions with MHK devices

- Determine exposure (blade strike, noise)

- Determine behavioral effects (avoidance, etc.)

- Empirical and mechanistic models

- Final product visual simulation, forecast fish trajectories - aid in design of arrays/devices to minimize impact.

12:00 PM LUNCH

1:00 PM Tour Physical Models/Ship Simulator $\quad$ Richard Styles

2:00 PM FERC

"The FERC Hydropower Licensing Process, Hydrokinetic

Stephen Bowler

Turbines, and Agency Coordination"

- Hydropower program - licensing, dam safety, license administration and compliance

- Issuances:

- Preliminary permits - don't permit anything - allow developer to keep site while preparing for authorization; feasibility studies, etc.

- Licenses - authorize construction and operation

- Exemptions - $5 \mathrm{MW}$, Conduit

- Licensing processes - Integrated, Traditional and Alternative

- ILP is default

- Pre-filing: initial proposal, scoping meetings, study plan development - conduct studies. 
- Post-filing: Application: proposal and mitigation measures, FERC and public review, FERC env. document, FERC authorization (License order)

- Process - about 3 years

- Licensing standard:

- Equal consideration to power and environmental users within waters of US.

- Authorize projects that best serve public interest.

- Other agencies - USFWS, NOAA, State gov'ts, USCG

- To allow for real world testing, have some limited issuances for non-grid and limited grid connected testing

○ May still require authorizations from other agencies

- Pilot project license

- Small, short term, removable

- Test technology, evaluate sites

- Protect environment - short term, monitoring, shutdown if harm

- Processed in as little as 6 months

- Abbreviated pre and post filing tasks

- 97 preliminary permits issued (tidal, wave and inland)

- 61 pending projects

- 2 pilot licenses issued

- Work with other agencies

- Agreement with USCG - working on nationwide MOU

- MOU with USACE

- Coordinate review

- Rivers and Harbors Act - Corps requirements met through licensing process

- FERC is lead agency

- "Orange book" (formerly "Salmon") - outlines all three licensing processes and exemption process

- No fee for license process; but once license issued there is a fee for regulation

2:30 PM

USACE-MVN

"USACE New Orleans District Approach to Evaluating

Will Veatch Hydrokinetic Projects"

- $\quad$ MVN regulatory process

- DA permits - Rivers \& Harbors Act; Clean Water Act

- Hydrokinetic project permit process

- Pre-app consultation

- FERC lead agency

- Establish MVD formal review team, members from multiple disciplines

- Application submission

- USCG and FERC process workshop

- FERC and USACE permit coordinated submittal

- Permit review

- Same as regular permit process

- Permit decision

- FERC license includes

- Areas of concern:

- Water quality - mainly leakage of lubricants, etc.

- Wetlands - impact to riparian wetlands - mainly with getting power from turbines and maintenance/support activities. 
- Fish and wildlife - impacts in entire project area - all, not just threatened and endangered, also not just aquatic.

- Navigation

- Low water hazards

- Altered river currents

- Traffic during installation/maintenance

- Altered sedimentation patterns

- May lead to hazards and currents

- Have set up team at ERDC-CHL to evaluate submissions by applicants

- Effects on shipping channels

- Dredge access

- Local and cumulative effects

- Flowline - water surface will rise if velocity goes down

- Need to determine what this will be - effect on levees, etc.

- Construction between levee and river (batture) - impedes flow at high water

- Channel stability

- Revetment integrity, access to failure areas, altered currents, levee loading during construction, power line impacts on levees

- Conclusions:

- Support HKE, provided concerns are addressed

- Work closely with FERC

- Many concerns remain to be addressed

- MVN's Hydrokinetic Project Team and Independent Technical Review Team address concerns and technical validity.

3:00 PM USCG

“Coast Guard's Roles and Responsibilities Concerning

George Detweiler

Alternative Energy Projects"

- USCG main purpose - safety of navigation

- Not just commercial - recreational as well

- USCG involved if in Navigable waters of US

- Work with whoever is lead agency - FERC, BOEM, USACE, NOAA - depending on project, location, etc.

- USCG authorities come from the Ports and Waterways Safety Act

○ Navigation, vessel safety

- Cooperating agency

- May develop recommendations to provide for safety of navigation

- Safety measures - routing measures

- Minimize impacts on other CG missions - SAR, environmental protection, security

- Private Aids to Navigation (PATON) may be involved

- USCG will not approve or disapprove a project or issue a permit

- Criteria USCG considers

- Site location

- Traffic - types, uses

- Navigation Safety risk assessment - but still don't know what the "acceptable number" is

- Structure - risk of collision, clearances, impact on SAR and MEP, Security

$\circ \quad$ Navigation and collision avoidance 
- Currents/tides

- Weather

- Visual navigation

- Communications

- Radar

- Markings

- Mitigation measures

- Charting, routing, exclusion zones, monitoring, shutdown procedures

- Acceptable navigational risk?

- Increased vessel density

- Mix of vessel types

- Allision risk

- Traffic patterns, routing measures

- Economic impact

- $3^{\text {rd }}$ dimension

- Underkeel clearance

- Towing catenary

- Anchoring

- Fishing

- Recreation

- Some question about USCG role in working directly with proposals - probably limited to PATON, evaluation of safety zones, routing measures, operations associated with construction.

- " $3{ }^{\text {rd }}$ dimension" - air as well - make sure that's considered - FAA's role?

- Electric transmission towers

- Commonality of technology and studies different agencies are using - is it available to other agencies for their use in the regulatory process?

- Richard Jepson comment - concern with interpretation of what he had presented earlier - large alterations of flow are possible but not likely as for performance of device you will want the result to be as close to the same as possible. Optimizing for performance and for environment impact often converge

\section{3:45 PM NPS}

"Hydrokinetic Energy Projects \& Recreation: A Guide to

Randy Thoreson

\section{Assessing Impacts"}

- NPS perspective on HKE

- Authorities:

- Federal Power Act

- Wild and Scenic Rivers Act of 1968

- Outdoor Recreation Act of 1963

- DoE report to Congress in 2009 on MHK did not cover social and recreation impacts (land use, aesthetics)

- Hydropower Reform Coalition - website with good information

- Publication- "HKE Projects and Recreation" - 2011

○ Types of projects

- Types of recreation

- Concepts for assessing impacts

- Potential impacts on recreation 
- Types of studies for recreation impacts

- Held workshops in Memphis and Portland - 2011

- Agencies, Free Flow Power, others

- Facilities, activities, use levels - but also experiences

- Recreational opportunities spectrum - "primitive to paved"

- Can be quantified by recreational use

- Direct and indirect effects, short term/long term

- Scale and cumulative impacts

- Other development and uses

- Other potential restrictions

- Progression of study effort

○ Desktop \& secondary sources

- Limited studies

- Intensive studies

- Protection \& Mitigation strategies

- More vs. less sensitive areas

- Reduce impacts (project modifications)

- Mitigation - trade offs

- Variety of river recreation activities

- Considerations

- Aesthetics - viewscapes and soundscapes

- Similar to what others have mentioned, but slightly different from perspective of recreation.

- Integrate early and often - start as soon as you can

- Reach out to stakeholders:

- Non-gov't groups - e.g., Mississippi Wild Miles, clubs

- Property owners

- Local govt's

- Business community

- Recreation (including aesthetics and land use), as it related to hydrokinetic projects, can be recognized and evaluated in a systematic way.

- NPS main focus: recreational access and safety

\section{4:15 PM PNNL}

\section{"Assessment of Fish Behavior and Vulnerability to}

Mark Weiland Hydrokinetic Devices"

- Hydrokinetic "stress:"

- Trauma, altered behavior, change in migration patterns, dispersion

- Survival - immediate and delayed mortality

- Long-term effects - reproduction, population structure, community interactions

- Acoustic monitoring

- Variety of uses (sound, monitor behavior, characterize environment), variety of capabilities - no "one size fits all"

- JSATS - use for fish monitoring

- Use to track where fish go, and their survival rate

- Receiver arrays ashore (mounted to structures) or tethered underwater - collect data on board then download when retrieved.

- $300 \mathrm{~m}$ detection range - greater in quiet waters

- Variety of systems that can be used for a wide variety of purposes - different capabilities, appropriate for different animal monitoring, locations, etc. 
- Recommend baseline monitoring prior to installation of devices - reference level for subsequent changes

- Compromises with technology - need to identify what works best for specific application.

4:45 PM

USGS

"Present and future USGS research on effects of

Alex Haro

Hydrokinetic Turbines on Fish Behavior, Injury, and

Mortality"

- S.O Conte Anadramous Fish Research Lab (CAFRL)

- HKT testing:

- Hydraulic and mechanical

- Biological - impacts on fish,

- (others)

- Various types tested in flume

- Specific Encurrent EN-005 test

- Different fish effects:

- Strike, avoidance, delay, disruption of schooling

- Observations:

○ - underwater video - some constraints

- PIT telemetry

- 3D acoustic telemetry

- Did control condition as well - turbine out of water

- Evaluated survival rates - short term and long term

- 2D tracks of fish

- Free Flow Power turbine tests:

- Grapefruit and fish

- Some strike indications

- Plans for tests in 2012

- More turbine tests as before

- Larval strike/shear testing

- Challenges:

- Many designs - results for one may not apply to another

- Fast vs. slow blade speed

- Lab vs. field evaluations - differences?

- Identification and quantification of effects

- May be able to do a lot through modeling

- Need to decide on limits, metrics, thresholds

- Questions:

- Consideration for FFP to use screen to prevent fish entry? - no, too much loss of efficiency

- Difference between shrouded and non-shrouded turbines on fish mortality? Too early to tell

\section{Main points}

- Multiple agencies have roles and responsibilities

- There is some coordination between agencies (FERC, USCG and USACE)

- Common areas of concern were outlined

- All support hydrokinetic energy development, but need to be aware of and address concerns 
- Different agencies have different roles in the approval process - agencies should coordinate efforts and share information, technology, studies.

- There are many considerations when evaluation HKE projects - some obvious (safety) some not (recreation, aesthetics)

5:15 PM

ADJOURN

Thursday, 1 March 2012

8:30 AM Corps-only meeting

Recap Day 1, Planning our way forward

Corps Participants

What are the research and regulatory requirements needed for the

USACE to adequately assess the impacts of KET?

How should USACE proceed to incorporate these requirements?

- Approach by developer - what's our response?

- "One way street" - i.e. they provide us information? Or dialog - they provide, we ask for more, etc.?

- USACE involvement with FFP came through FERC process

- Made concerns known through response to documents provided

- Pilot projects -

- Each district has a FERC coordinator - main conduit for information - not directly from applicant. However each District different

- If KET installation will be a modification to a Corps asset (levee, channel, structure, etc.) requires 408 permit (?)

- 208 permit process - smaller scale, approval by Dist. Engineer - need to clarify line between 208 and 408

- Need for standardization/coordination between Corps Hydropower, Navigation, Civil works, regulatory, etc. offices?

- Need to be able to identify and act on "triggers" for Corps permitting ativity - 408

- "who defines what is the project" - example of FFP - various sites, across Districts, changes year-to-year - how handle this?

- Good starting point - FERC's study plan for FFP

- Captures a lot of USACE concerns

- Applicable to Miss. River - may be other issues for other locations - PNW, New England

- Is there a way to scope the basic information required for any project? Rather than "rock management"

- Difficult - need to know impacts before can tell what is needed - applicant provides this

- Research issues -

- Possible to have a "checklist?" -

- Jeff - is there an "EC" (?) on this that can provide guidance?

- [John's suggestion for a "tool" to use when contacted by potential applicants]

- Lay out coordination required, process/steps, information needed, etc.

- Triggers - e.g., for 408 approval

- Jeff - didn't hear a lot about impact on river on KET devices - and if they are impacted what is subsequent impact on Corps structures/waterways/etc.?

- "Damaged turbine recovery study" -

- From Will Veatch: 
- FYI, here is FERC's Study Plan Determination for Free Flow Power. This might provide a starting point for a skeleton list of common issues to investigate for KET projects, at least for riverine projects in big rivers.

○ http://elibrary.ferc.gov/idmws/File_list.asp?document_id=13788453

- "Really need to answer the 408 question - determination of whether it applies or not."

- As early as possible

- May need to ask lawyers

Ronnie Heath - R\&D needs

- Scotlandville bend proposal - lots of turbines

- How will we address questions private developers don't have capability to determine?

- Cannot easily scale up single turbine model to array

- Need for physical model to validate numerical models

- Need to break into smaller steps - can't go from 1 unit to many - either for evaluation or for deployment

- Is there a requirement for monitoring once units are deployed? What are Corps requirements for monitoring?

- In Corps permits there are monitoring requirements - District responsible for this and determination of action if monitoring shows need (e.g., removal of units)

- Based on risk - on our interest to move slowly - incremental - e.g., percentage of total desired deployment

10 - 11:00 AMAdjourn 
Appendix D: Workshop Slides 


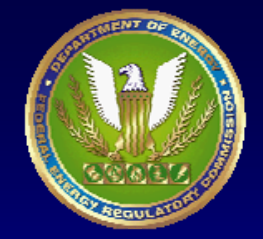

Marine and Hydrokinetic Energy, FERC and the U.S. Army Corps of Engineers

Vicksburg, MS

29 February 2012

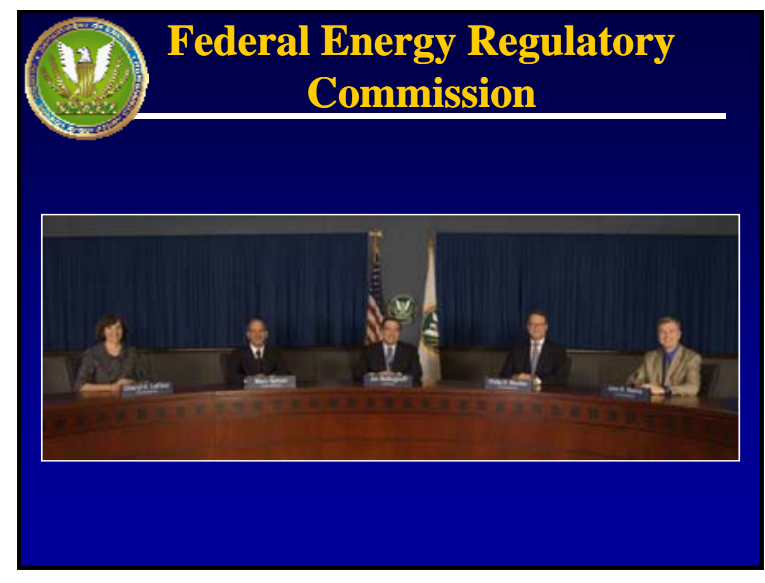

\section{Hydropower Program}

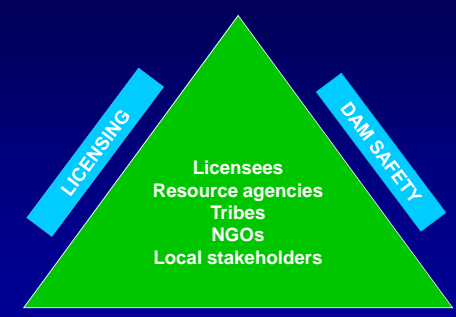

LICENSE ADMINISTRATION \& COMPLIANCE

\section{Types of Issuances}

- Preliminary permits

- Maintains priority of application for three years

- Conduct feasibility studies and prefiling activities

- Does not authorize construction

- Licenses

- Authorizes construction and operation

- Exemptions

$-5 \mathrm{MW}$

- Conduit
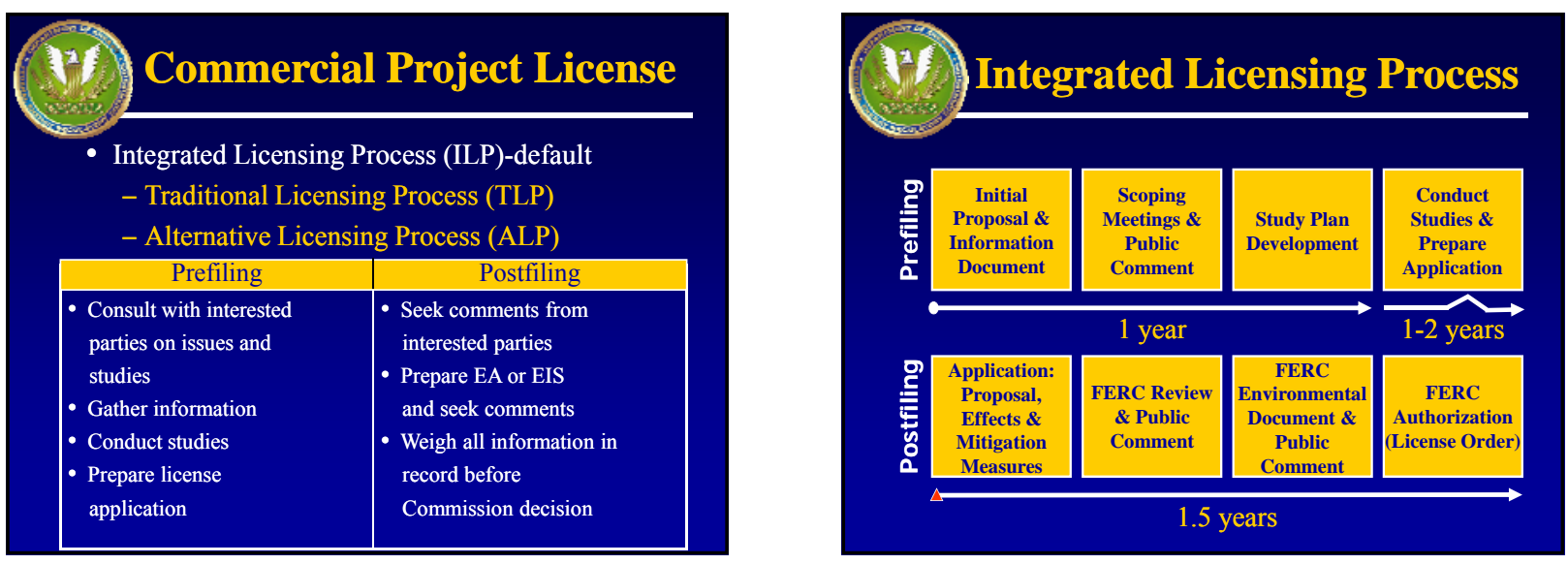

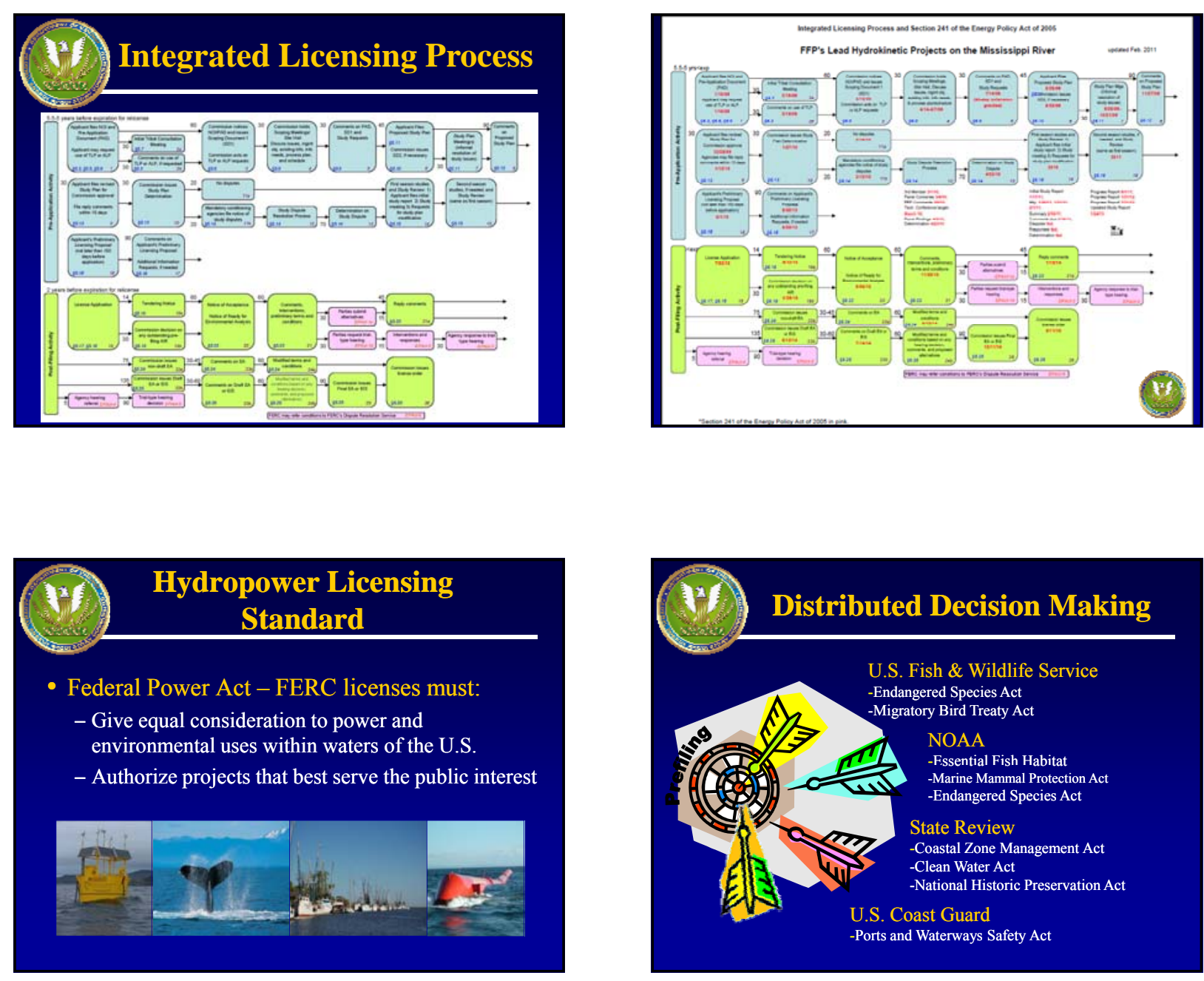

\section{Regulatory Approach}

- Recognizing the conundrum of need for real-world testing, yet limited information to prepare applications the Commission has tailored its existing program to meet the needs of new technologies:

- Preliminary permits

- Device testing (no grid connection)

- Pilot project license (grid connection)

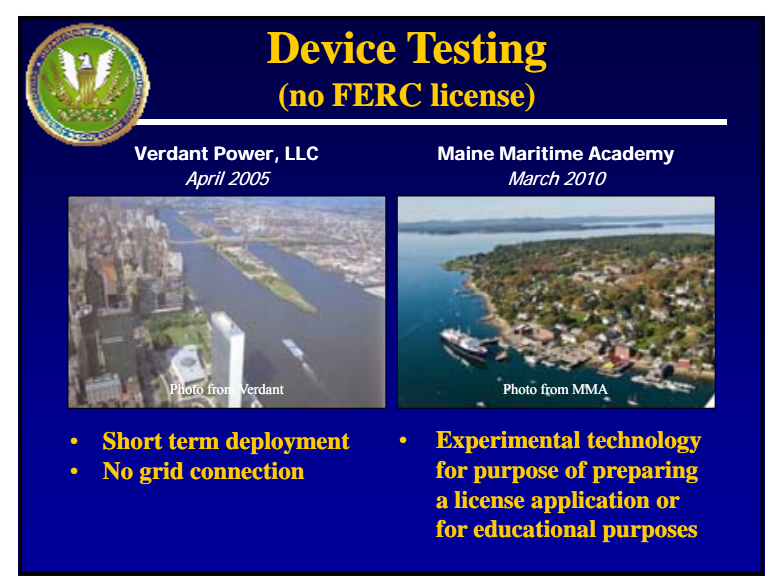




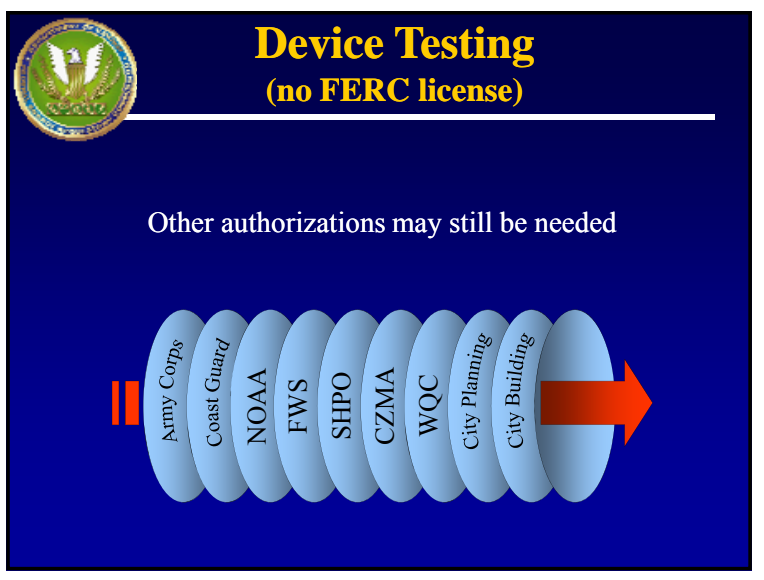

\section{Pilot Project License}

- Small, short term, removable projects

- Test technology and/or evaluate sites

- Protect the environment

- Short license term and small footprint

- Post-license monitoring

- Project shutdown or removal if harm

- Process license applications in as few as 6 months

\section{Pilot Project License}

From the Integrated Licensing Process (ILP)

\begin{tabular}{|c|c|c|c|}
\hline $\begin{array}{c}\text { Draft License } \\
\text { Application } \\
\text { and Waiver } \\
\text { Request }\end{array}$ & $\begin{array}{c}\text { Comments on } \\
\text { Process/DLA/ } \\
\text { Monitoring } \\
\text { Plans }\end{array}$ & $\begin{array}{c}\text { Public } \\
\text { Meeting } \\
\text { (if needed) }\end{array}$ & $\begin{array}{c}\text { FERC } \\
\text { Determination } \\
\text { on Waiver } \\
\text { Request }\end{array}$ \\
\hline
\end{tabular}
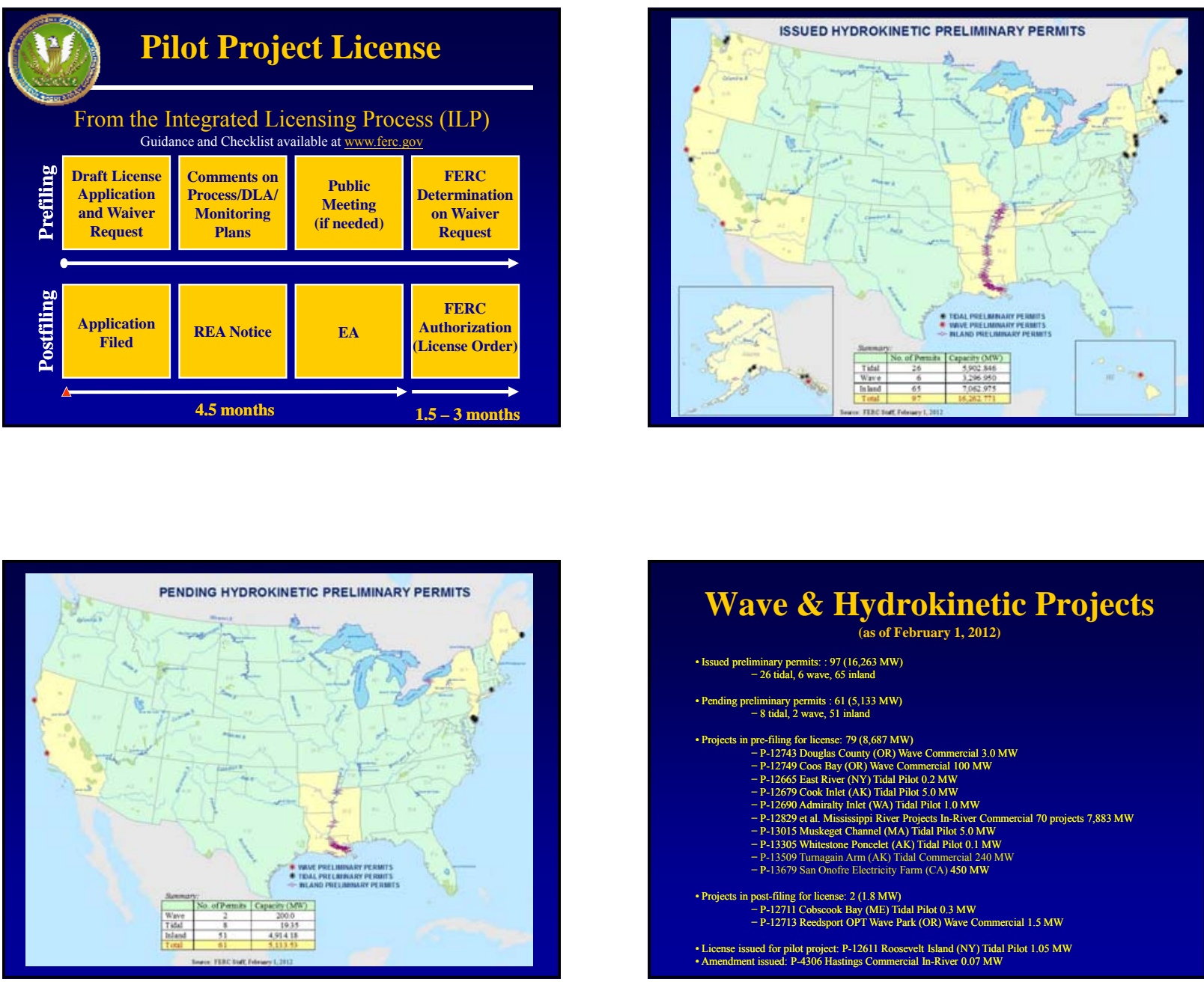

\section{Wave \& Hydrokinetic Projects} (as of February 1, 2012)

- Issued preliminary permits: $97(16,263 \mathrm{MV})$

-Pending preliminary permits: $61(5,133 \mathrm{MW}$

-8 tidal, 2 wave, 51 inland

- Projects in pre-filing for licenses: $79(8,6877 \mathrm{MW})$ P. 12665 Sos Bay (OR) Wave Commercial $100 \mathrm{MW}$

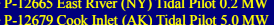
P-12679 Cook Inlet (AK) Tidal Pilot $5.0 \mathrm{MW}$
-P.12600 Adminalty Inlet (WA) TTidal Pilot 10 M -P.12829 et al Mississippi River Projects In-River Commercial 70 projects 7.883 MW -P-13015 Muskeget Channel (MA) Tidal Pilot 5.0 MW -P-13305 Whitestone Poncelet (AK) Tidal Pilot 0.1 MW

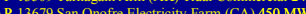

- Projects in post-filing for license: 2 (1.8 MW) D.27r Cobscook Bay (ME) Tidal Pilot $0.3 \mathrm{MW}$

-P-12713 Reddsport OYT Wave Park (OR) Wave Commercial 1.5 MW - License issued for pilot project: P-12611 Roosevelt Island (NY) Tidal Pilot $1.05 \mathrm{MW}$
-Amendment issued: P-4306 Hastings Commercial In-River $0.07 \mathrm{MW}$ 

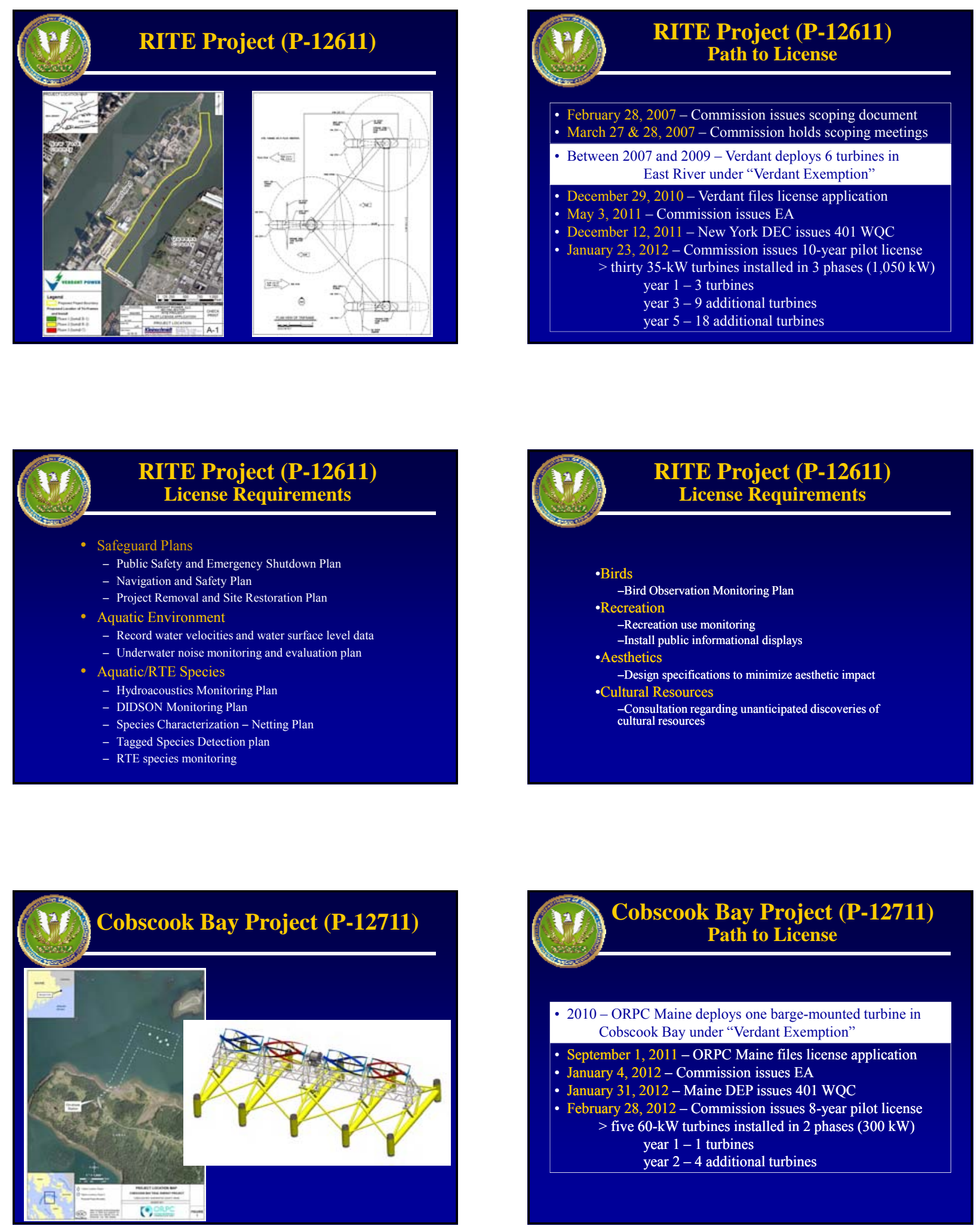
Cobscook Bay Project (P-12711) License Requirements

- Safeguard Plans

- Project Operations and Monitoring Plan

- Project Inspection and Maintenance Plan

- Project and Public Safety Plan

- Navigation Safety Plan

- Emergency Shutdown Plan

- Project Removal and Site Restoration Plan

- Aquatic Environment

- Hydraulic Monitoring Plan

No pile driving activities between April 10 and

November 7 of any year

- Acoustic Monitoring Plan

- Benthic and Biofouling Monitoring Plan
Cobscook Bay Project (P-12711) License Requirements

-Aquatic/RTE Species

-Fisheries and Marine Life Interaction Plan

-Marine Mammal Monitoring Plan

-Birds

-Bird Monitoring Plan

-FWS' Bald Eagle Management Guidelines

-Recreation

-Install public informational displays

-Aesthetics

-Design specifications to minimize aesthetic impact

-Cultural Resources

-Consultation regarding unanticipated discoveries of cultural resources

-Adaptive Management

- Adaptive Management Plan

\section{Free Flow Power Mississippi}

- 11 studies approved in Commission's study plan determination (issued 1/27/10)

- Studies designed to gather data to meet agency information needs (e.g. NVIC)

- Study progress reports \& comments

- Commission's last set of comments issued 11/10/11

- FFP's Fifth study report filed 1/31/12

- Two more progress reports before Preliminary Licensing Proposal is due (target 3/1/13)

- Anticipating FFP request for schedule adjustment

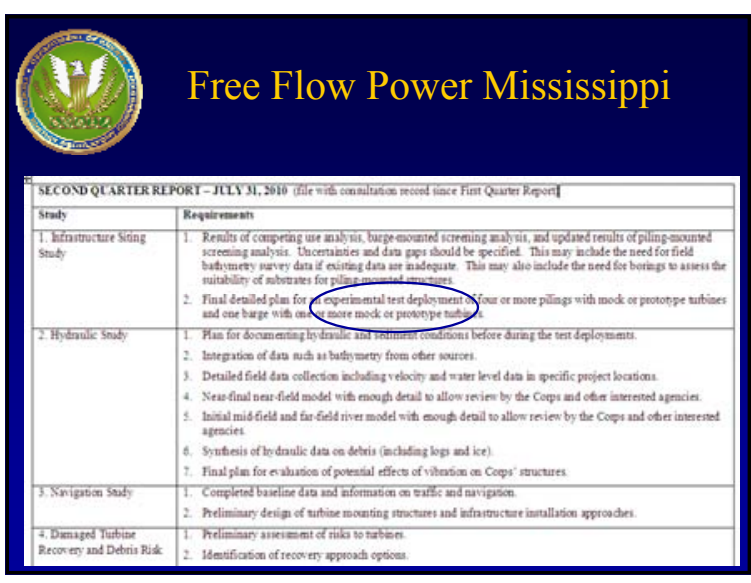

Letter of Understanding (LOU) USCG \& FERC

Free Flow Power Mississippi ILP Sites

- Commission is lead agency for NEPA

- Coast Guard is navigation safety \& security subject matter expert

- Coordinate comments on study reports \& analysis in NEPA documents

- USCG sector comments consolidated

- Communications with Free Flow Power \& other stakeholders

- USCG technical advice for Free Flow Power

- FERC/ USCG deliberations \& merits of the projects

\section{Corps - FERC MOU} Purpose
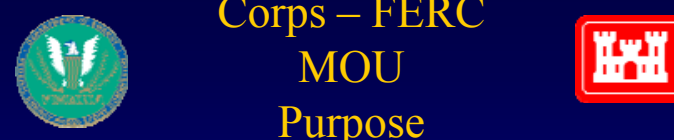

- Coordinate regulatory review processes

- Establish framework for early Corps participation in Commission licensing processes

- Ensure timely review and action on non-federal hydropower development 

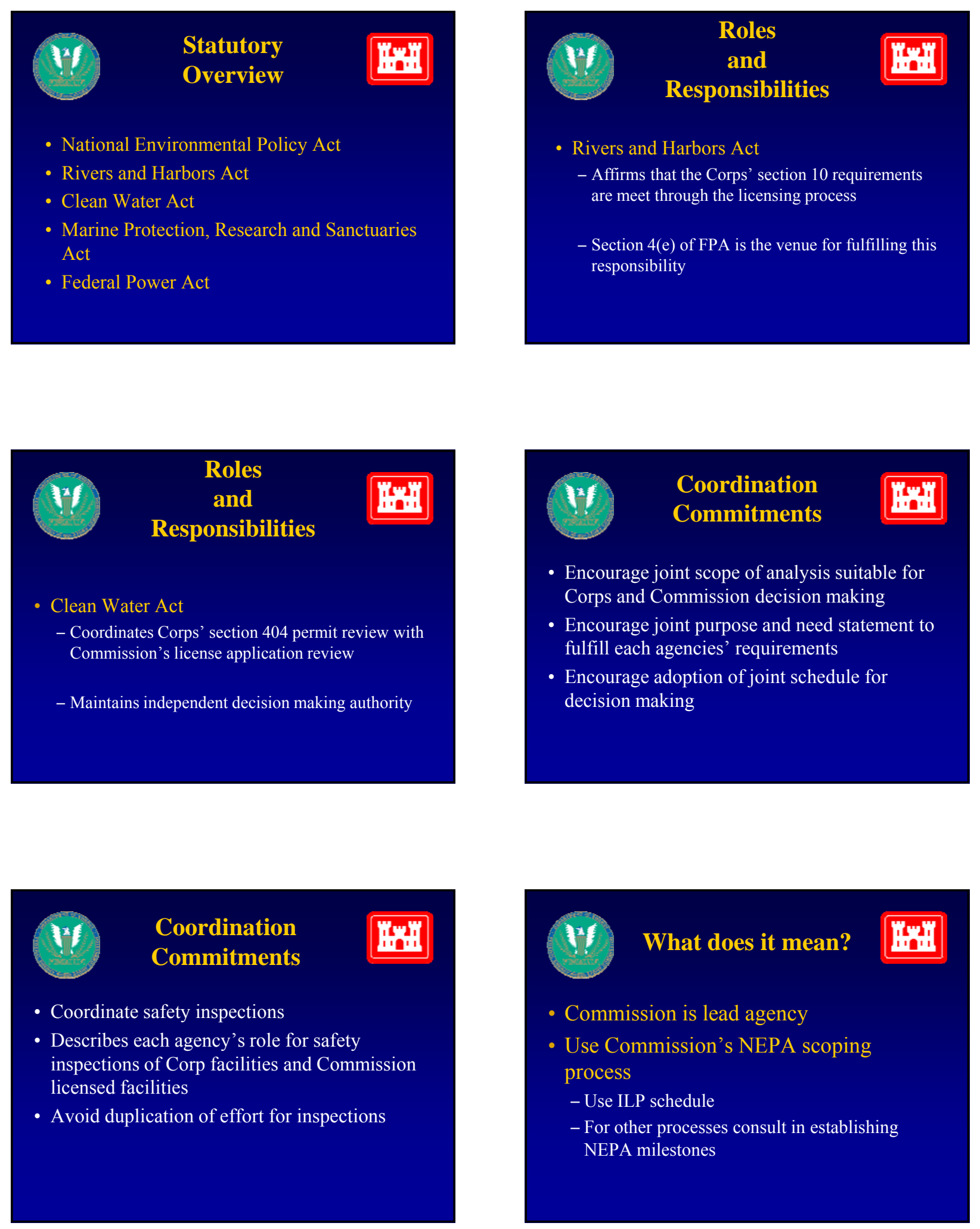


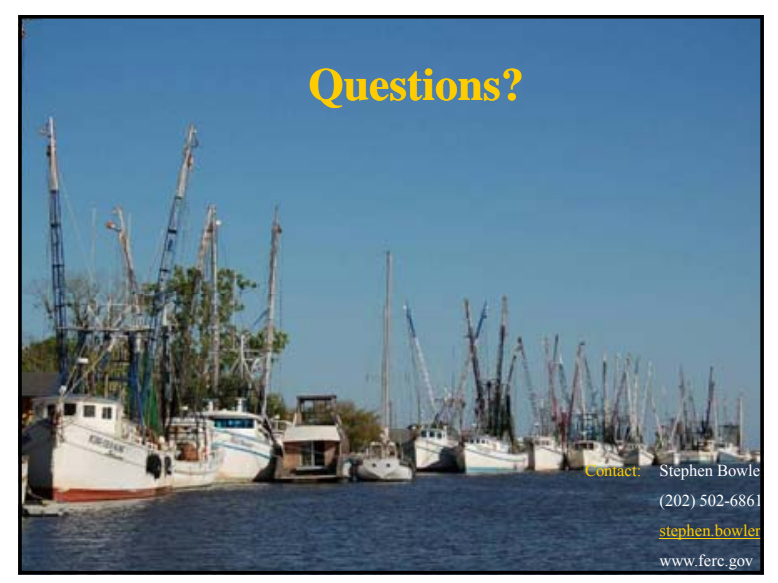



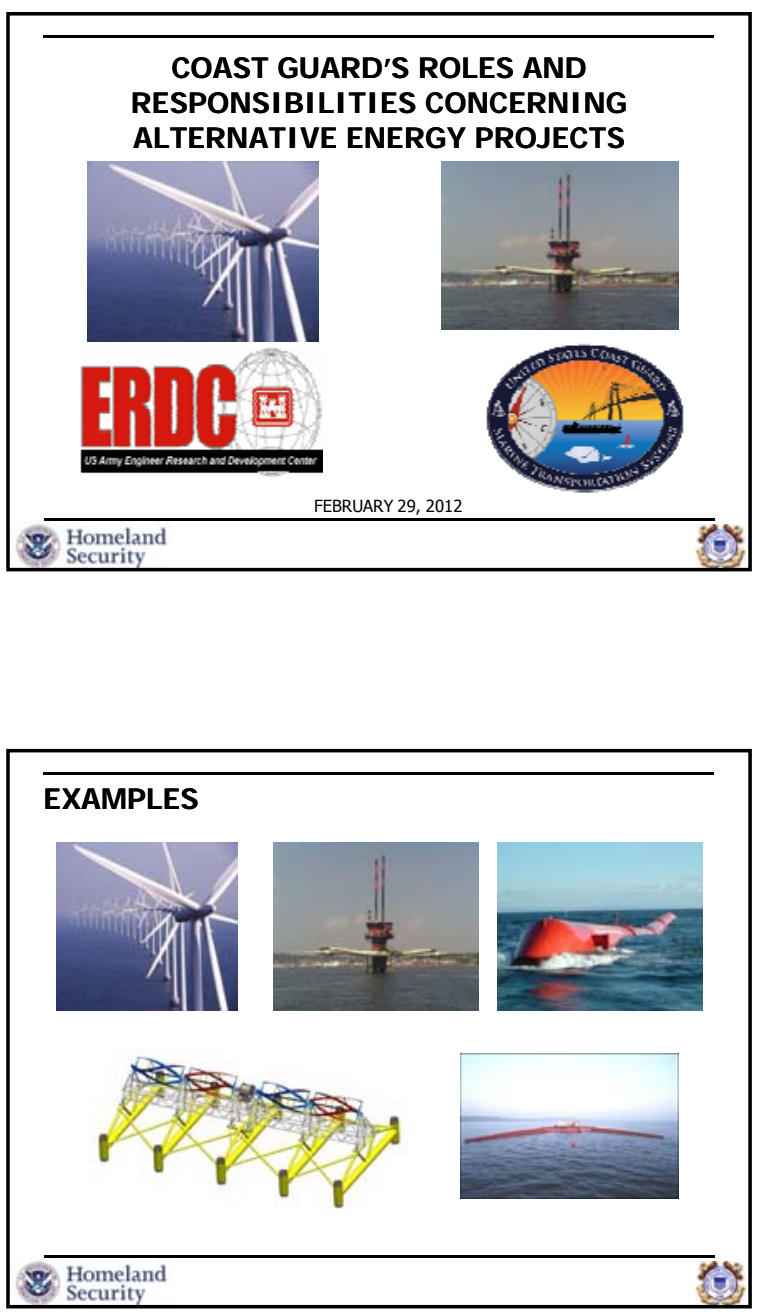

\section{COAST GUARD'S ROLE}

- Cooperating agency for NEPA purposes with the Lead Permitting Agency (LPA) such BOEM, FERC, USACE

$\checkmark$ Develop recommendations (project specific) to provide for safety of navigation

$\checkmark$ Develop routing measures, Limited Access Areas (safety zones, security zones) and/or Regulated Navigation Areas (RNAs) as appropriate

$\checkmark$ Minimize potential impacts on other CG missions (SAR, MEP, Security)

$\checkmark$ PATON if necessary

-WILL NOT APPROVE/DISAPPROVE PROJECT OR ISSUE PERMIT

\section{TYPES / LOCATIONS}

- HYDROKINETICS

-WHERE THE WAVES / CURRENTS / TIDES ARE

-NEAR SHORE / RIVERS

-WEST COAST / MISSISSIPPI RIVER / ME / FL

-WIND

-WHERE THE WIND IS

-OFFSHORE

-EAST COAST AND GREAT LAKES

\section{AUTHORITY-RESPONSI BI LITY}

- PORTS AND WATERWAYS SAFETY ACT (PWSA)*

- Navigation, vessel safety, protection of the marine environment are matters of national importance

- Navigable waters of the United States

\section{CRITERIA}

$$
\begin{aligned}
& \text { - Site Location } \\
& \text { - Traffic Survey } \\
& \text { - Types } \\
& \text { - Uses } \\
& \text { - Navigation Safety } \\
& \text { - Within the site } \\
& \text { - Proximity } \\
& \text { - Structure } \\
& \text { - Risk of collision } \\
& \text { - Clearances } \\
& \text {-Impact on SAR } \\
& \text { - Impact on MEP } \\
& \text {-Security }
\end{aligned}
$$

-Navigation Safety Risk Assessment 


\begin{tabular}{|l|}
\hline CRITERI A \\
- Navigation and Collision Avoidance \\
- Tides and Currents \\
-Weather \\
- Depths \\
-Visual Navigation \\
- Communications \\
- Radar \\
- Marking \\
- Mitigation Measures \\
-Charting / Marine Information \\
- Routing Measures \\
- Exclusion Zones \\
-Monitoring \\
-Shutdown Procedures \\
\$omeland \\
\hline Security
\end{tabular}

\section{$3^{\text {rd }}$ DI MENSION}

- Under keel clearance

- Towing catenary

-Anchoring

- Fishing

- Recreational boaters

\section{SI TI NG SUI TABI LITY CRITERIA}

Is Navigational Risk Acceptable

- $\Delta$ Vessel Density $\rightarrow$ increase in encounters

- $\Delta$ Risk Due to Mixing Vessel Types

- $\Delta$ Risk Due to Allisions (fixed objects)

- Traffic Pattern Changes

- Routing Measures- Size, type, etc

- Is Economic Impact justifiable

-Rerouting of traffic- (time and distance $=\$$ )

-Impacts to navigation stds \& watchstanding

\section{QUESTIONS}

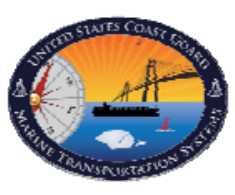

“We Help Mariners Get There"

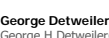

$\frac{\text { George.H.Detweiler(@usca.m. }}{202-372-1566 \text { (office) }}$

$202-372-1566$ (office)
$202-372-1991$ (fax)

COMMANDANT (CG-5533) ATTN: NAVIGATION STANDARDS DIVISION 2100 2ND ST SW STOP 7580
WASHINGTON, DC 20593-7580

. Homeland 

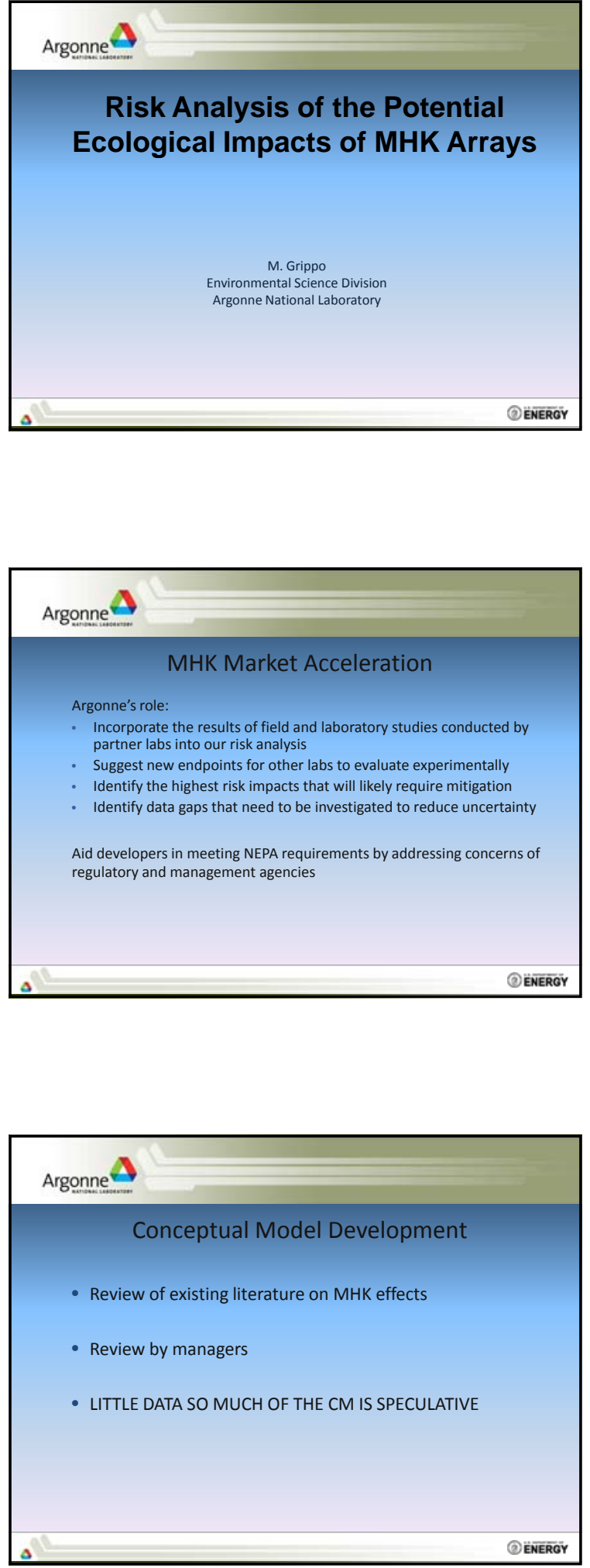
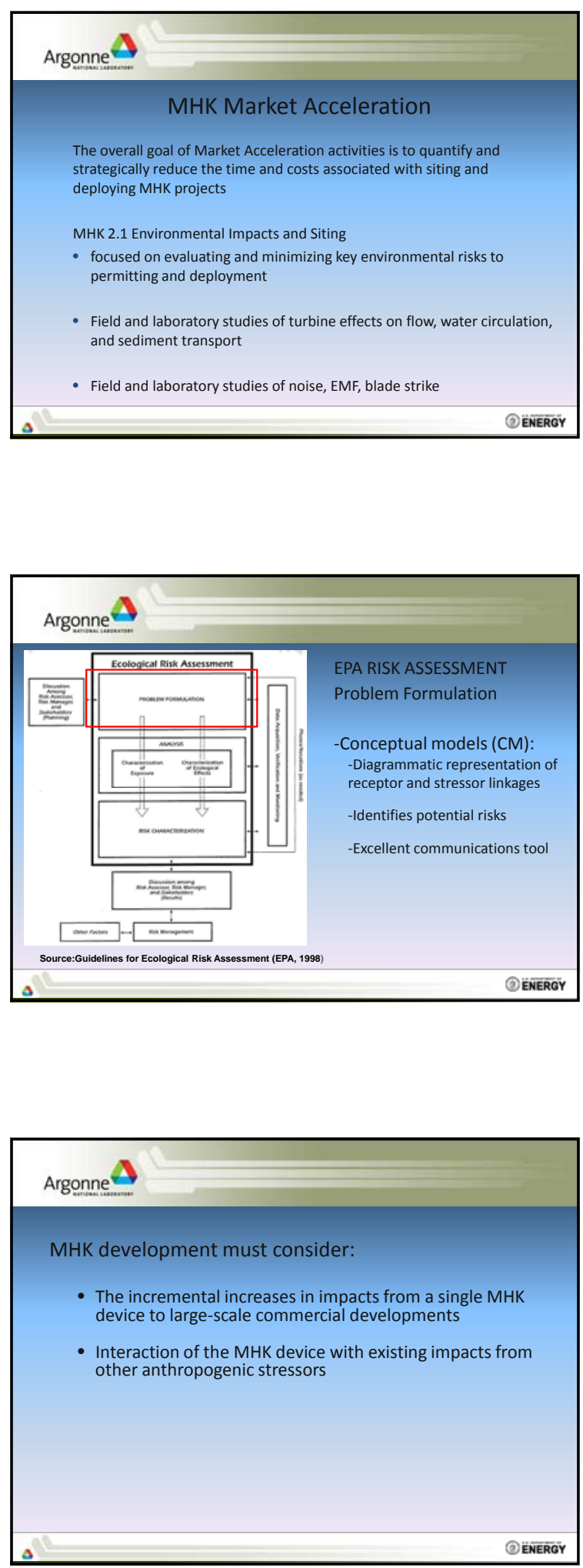

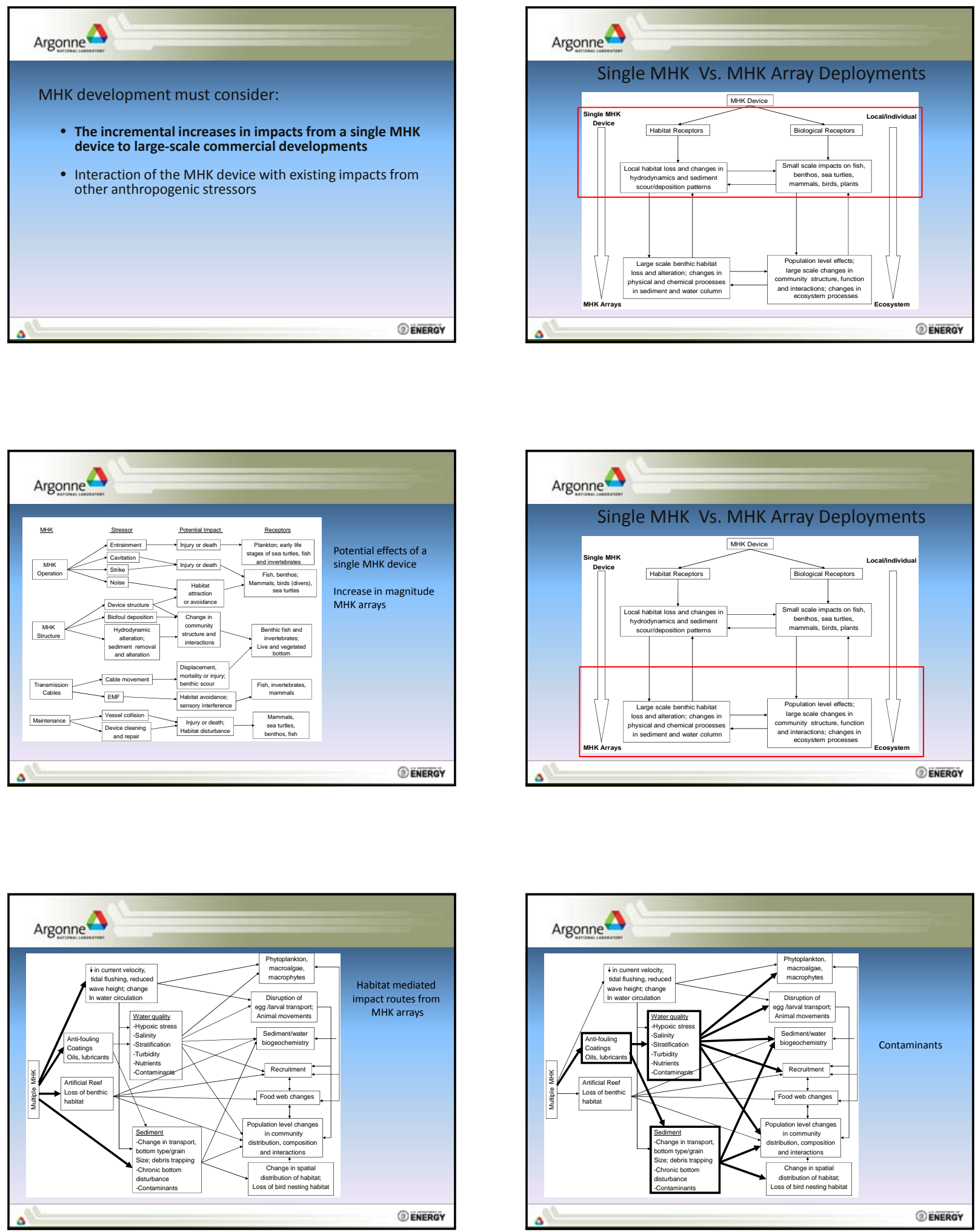

Go to "Insert (View) | Header and Footer" to add your organization, sponsor, meeting name here; then, click "Apply to All" 

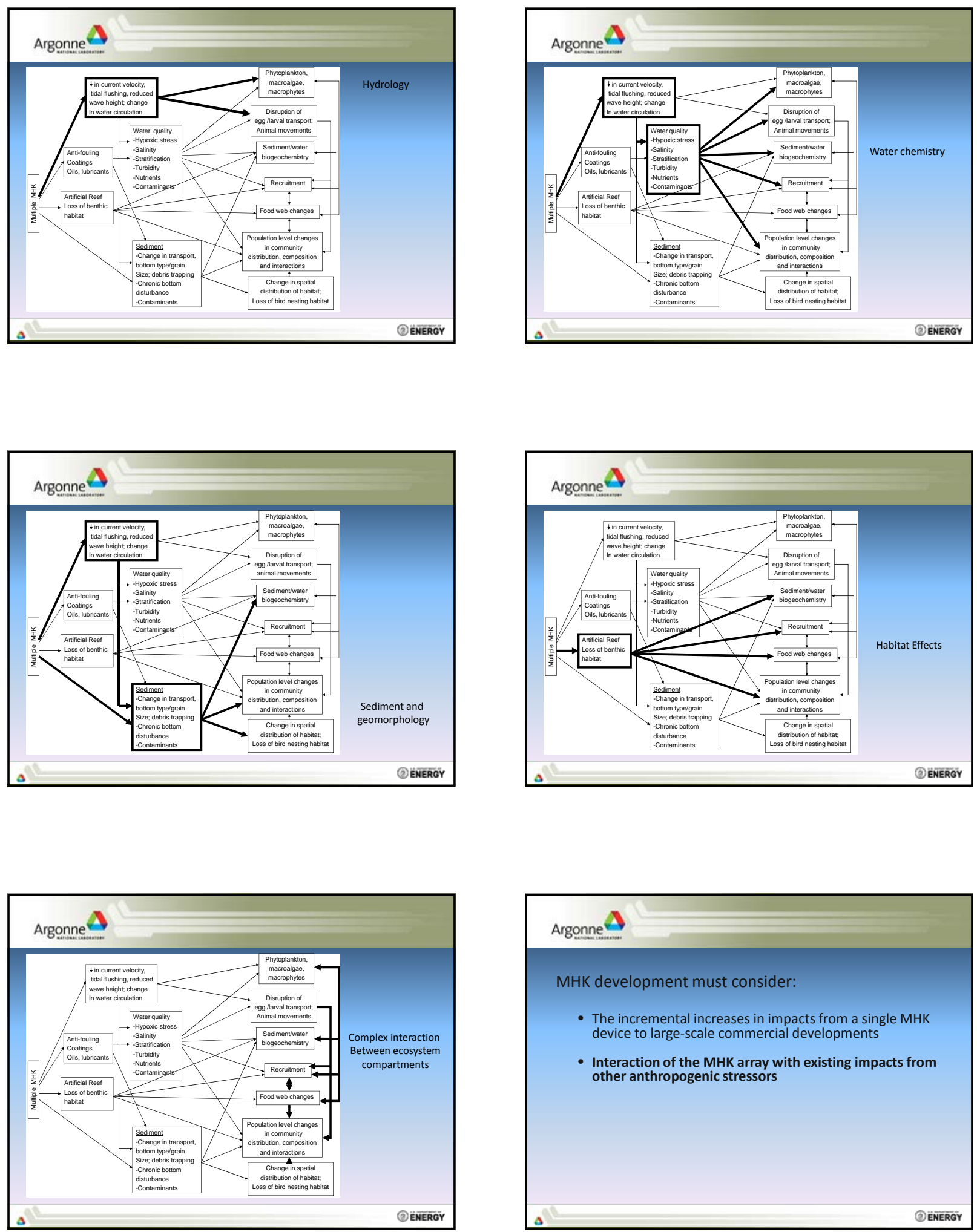

Go to "Insert (View) | Header and Footer" to add your organization, sponsor, meeting name here; then, click "Apply to All" 

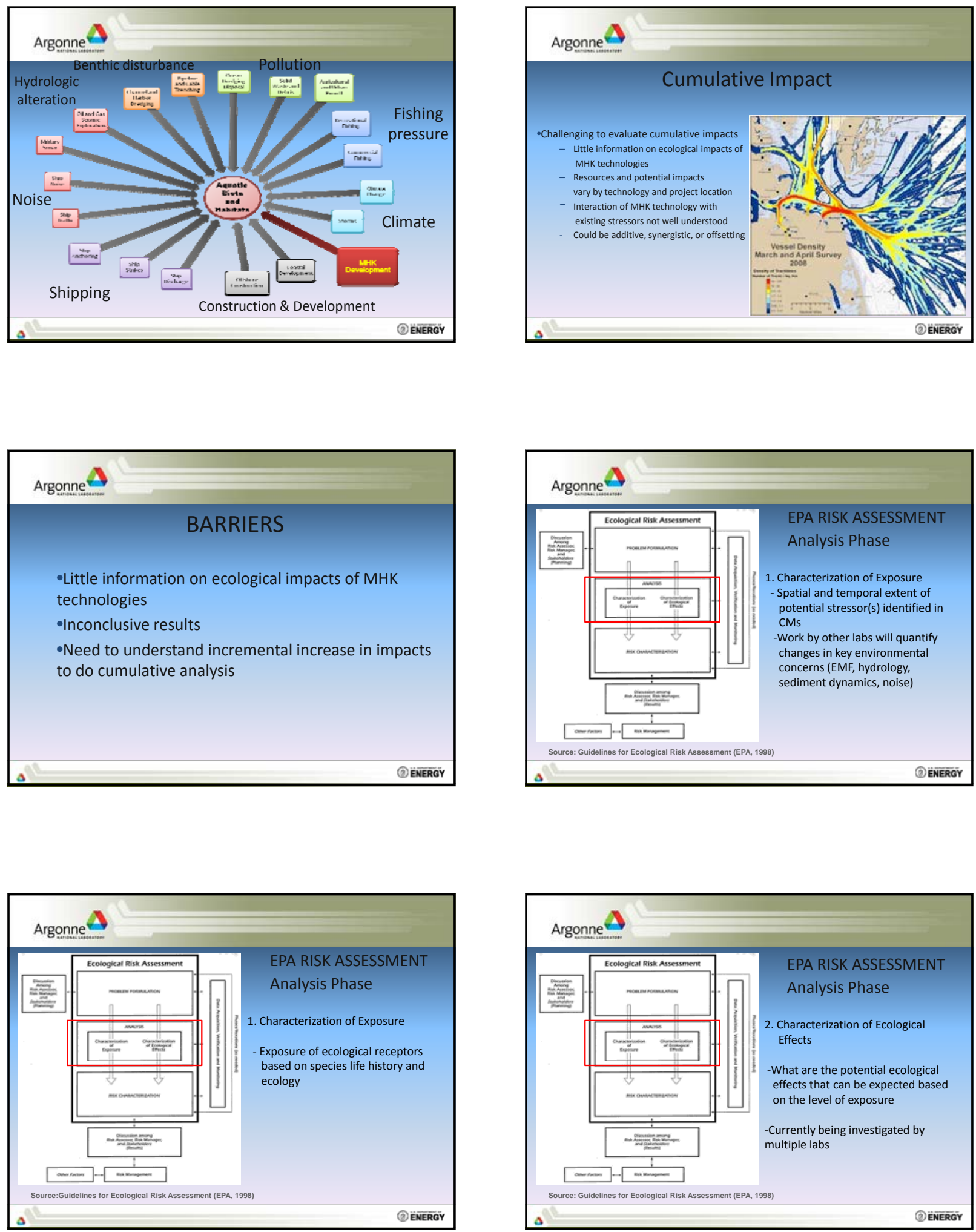

Go to "Insert (View) | Header and Footer" to add your organization, sponsor, meeting name here; then, click "Apply to All" 

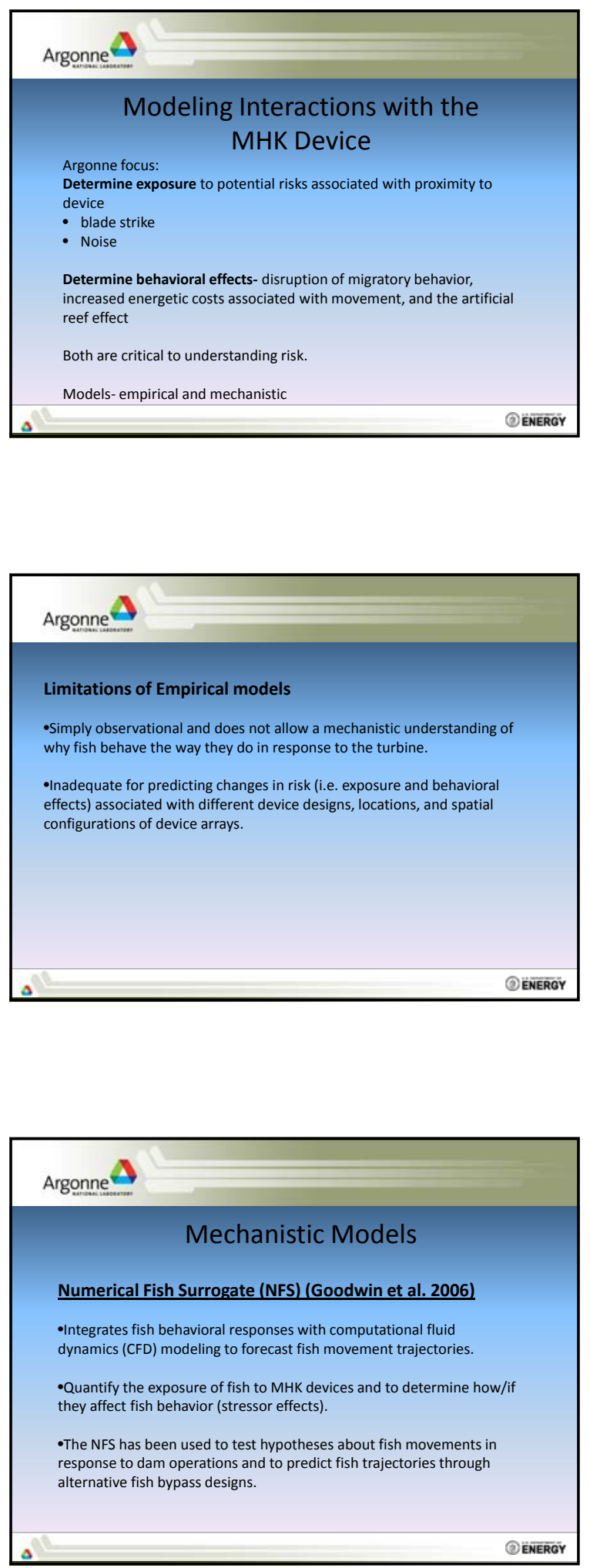
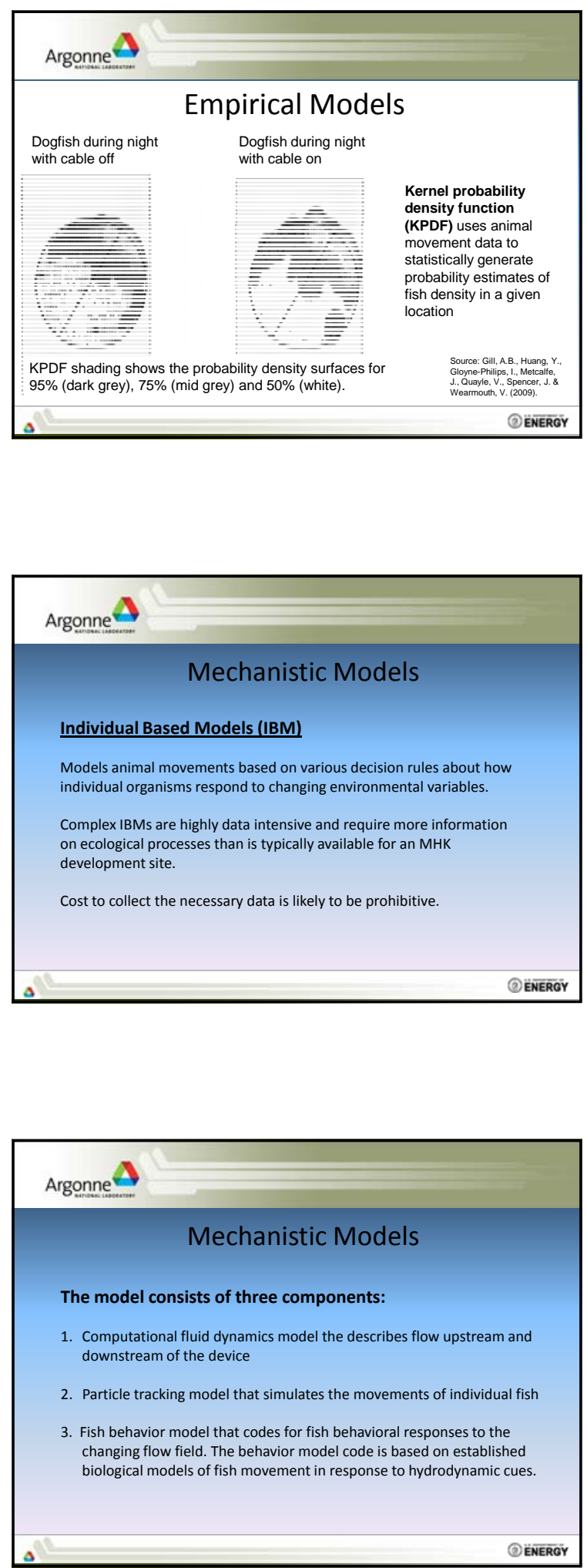

Go to "Insert (View) | Header and Footer" to add your organization, sponsor, meeting name here; then, click "Apply to All" 

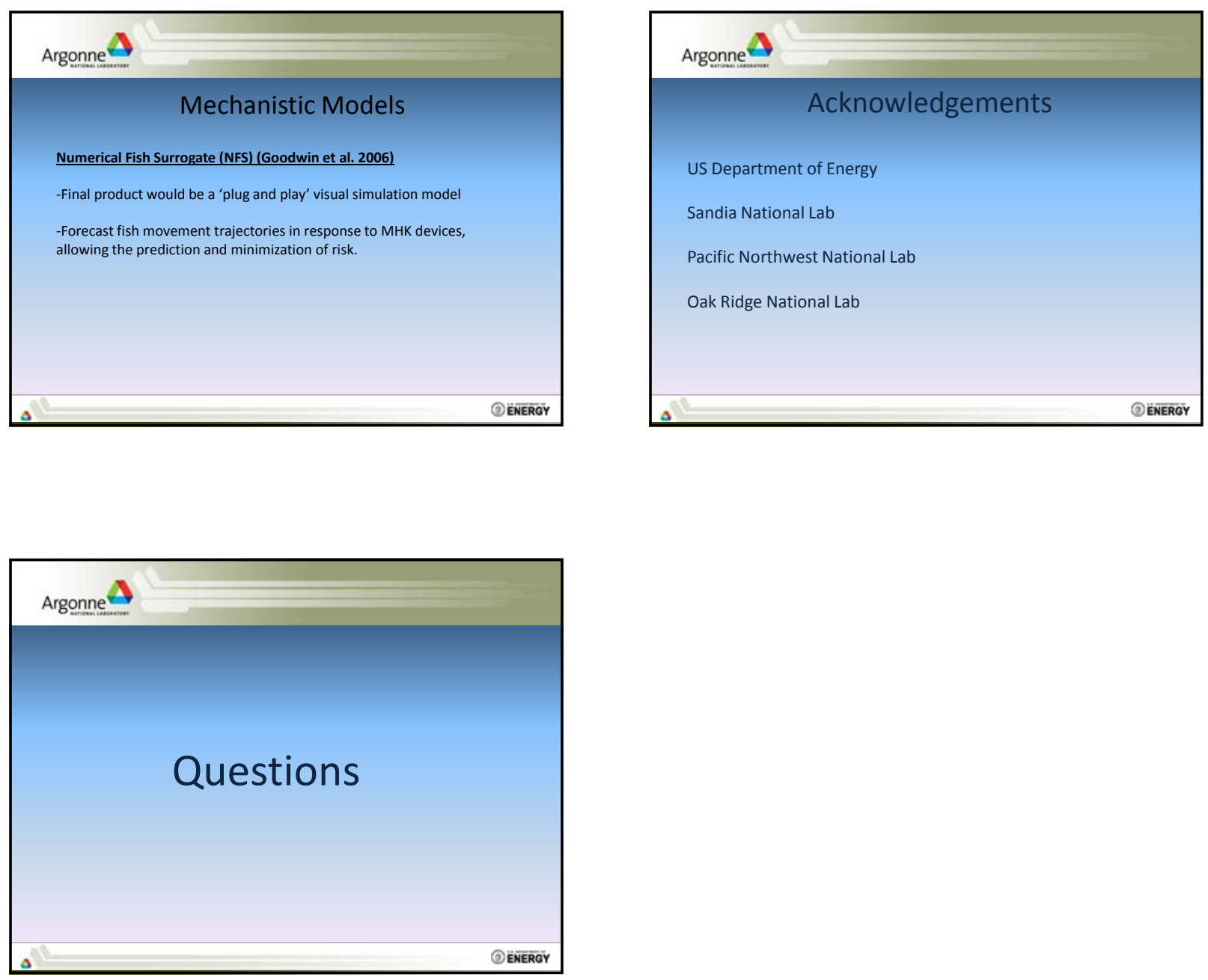

Go to "Insert (View) | Header and Footer" to add your organization, sponsor, meeting name here; then, click "Apply to All" 

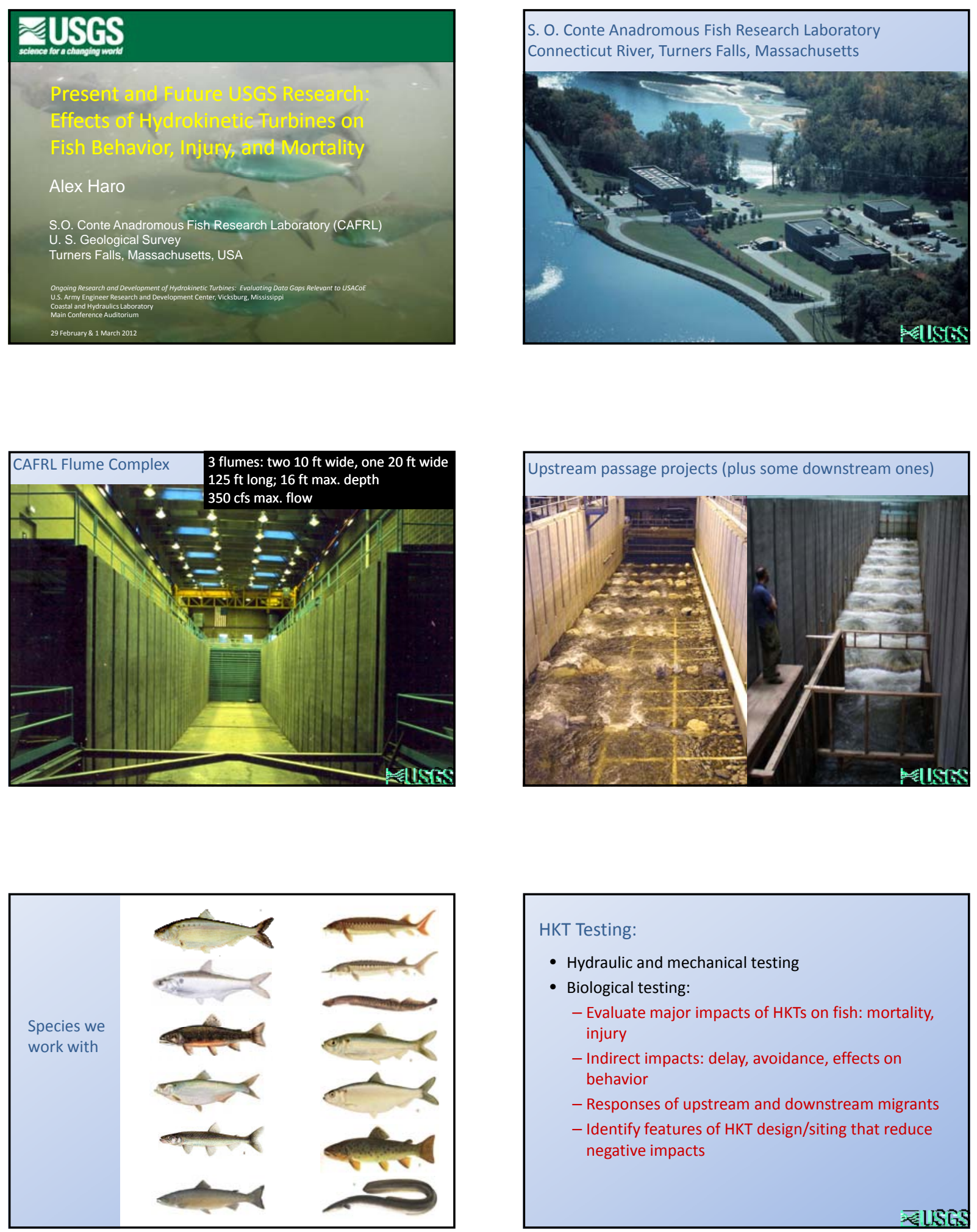

- Hydraulic and mechanical testing

- Biological testing:

- Evaluate major impacts of HKTs on fish: mortality, injury

- Indirect impacts: delay, avoidance, effects on behavior

- Responses of upstream and downstream migrants

- Identify features of HKT design/siting that reduce negative impacts 

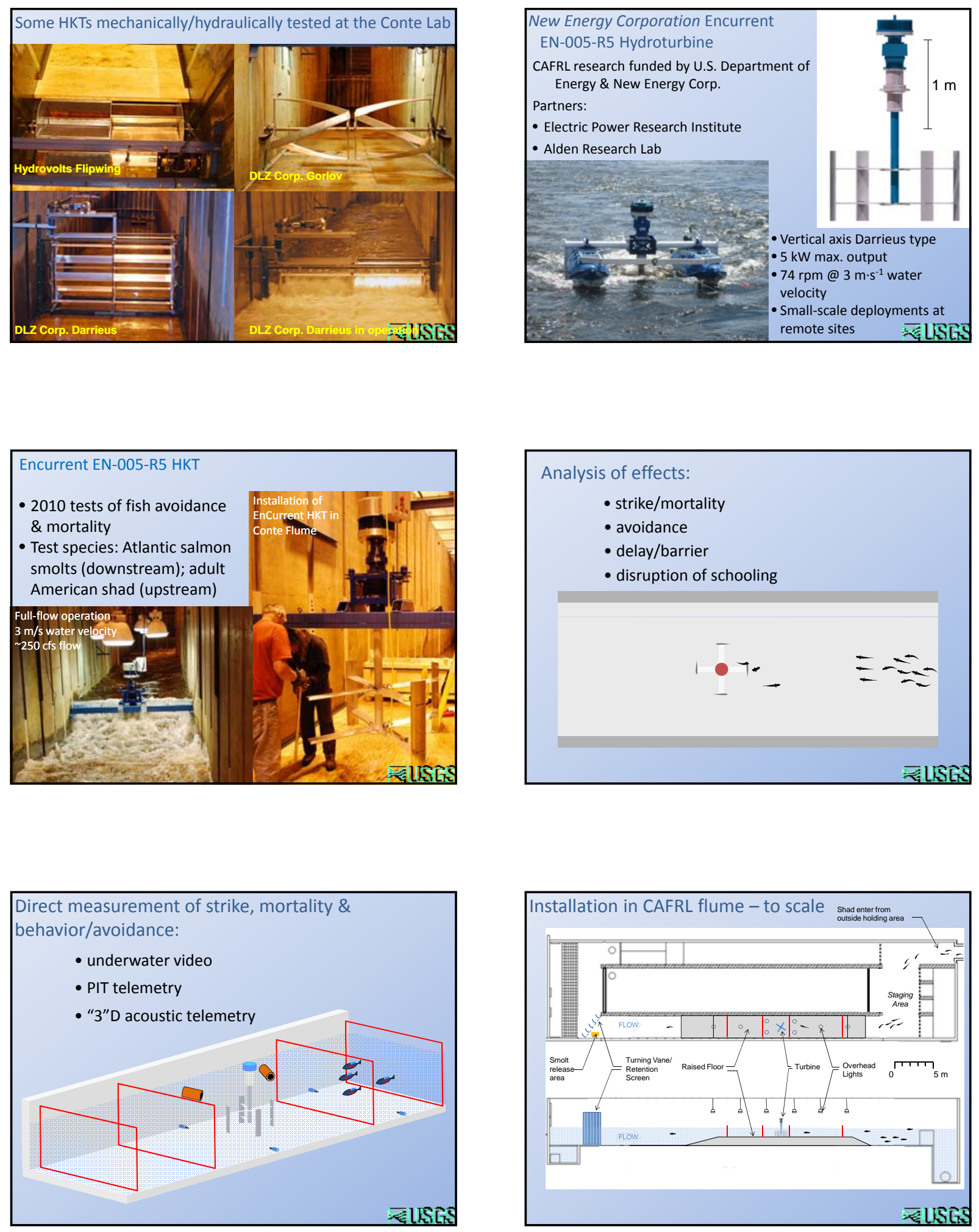

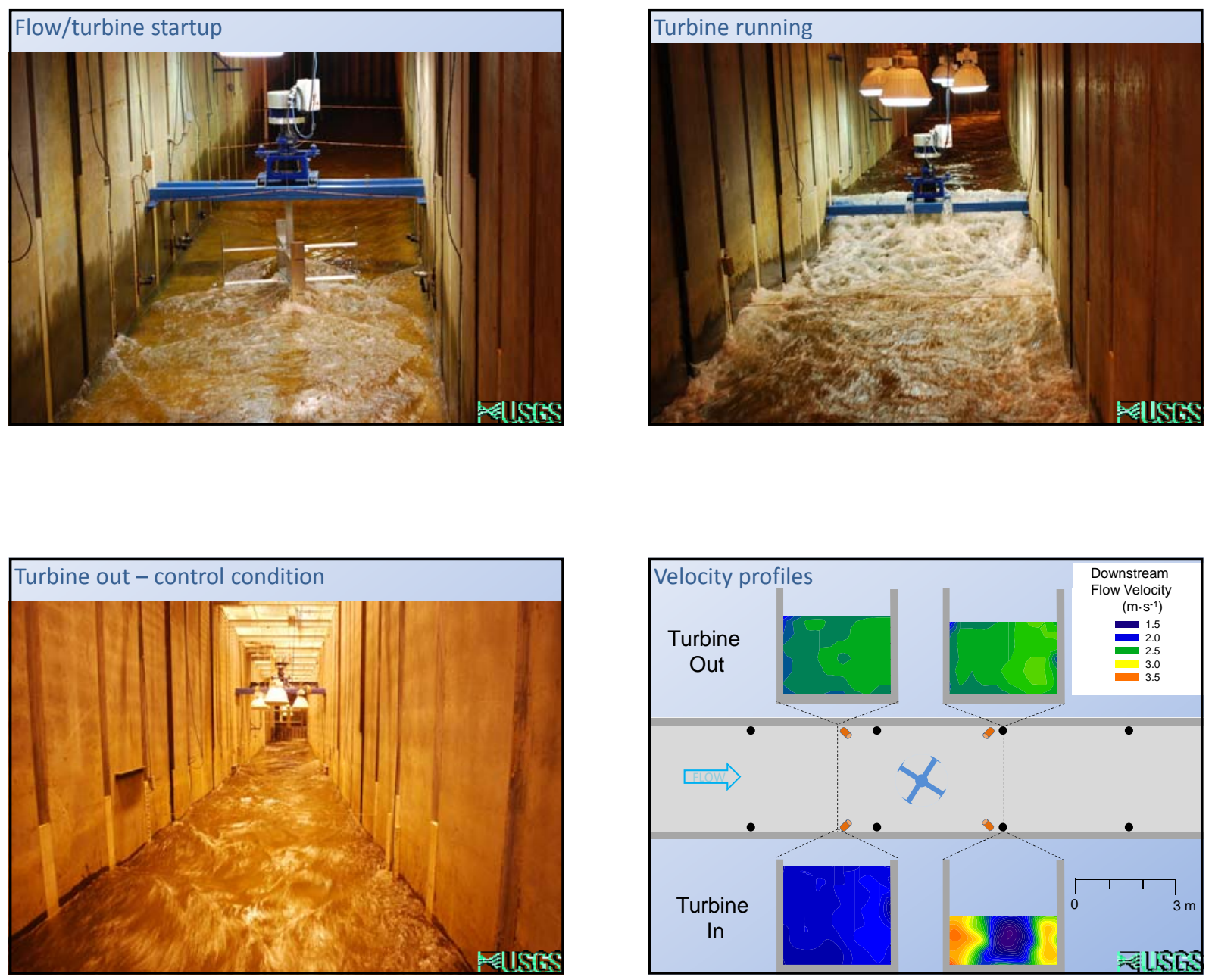

Results-Salmon smolts (downstream)

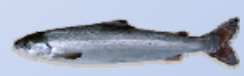

- Mean fork length: $210 \mathrm{~mm}$

- Sample size:

- Turbine In: 117

- Turbine Out: 56

- Survival:

- Immediate: $100 \%$ for both treatment and control groups

- Delayed: NS between groups

- External Injuries: none detected

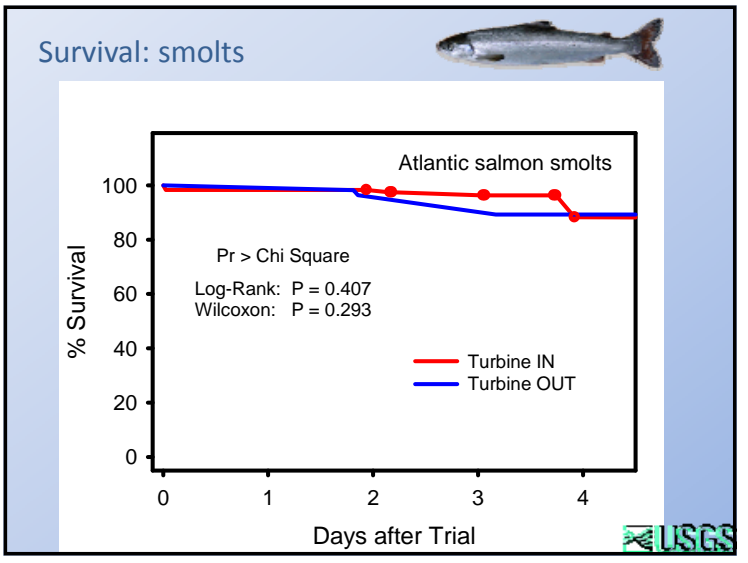



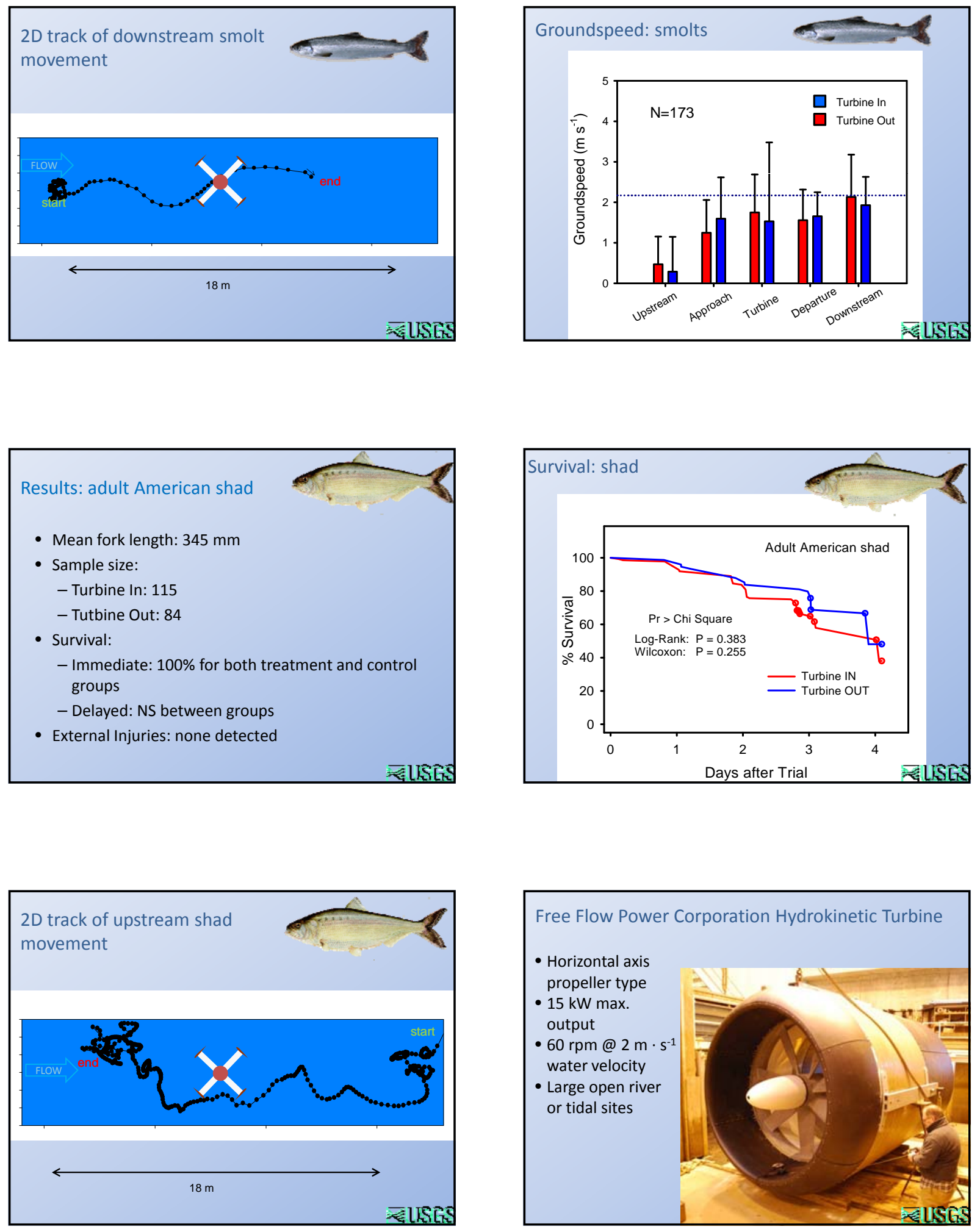

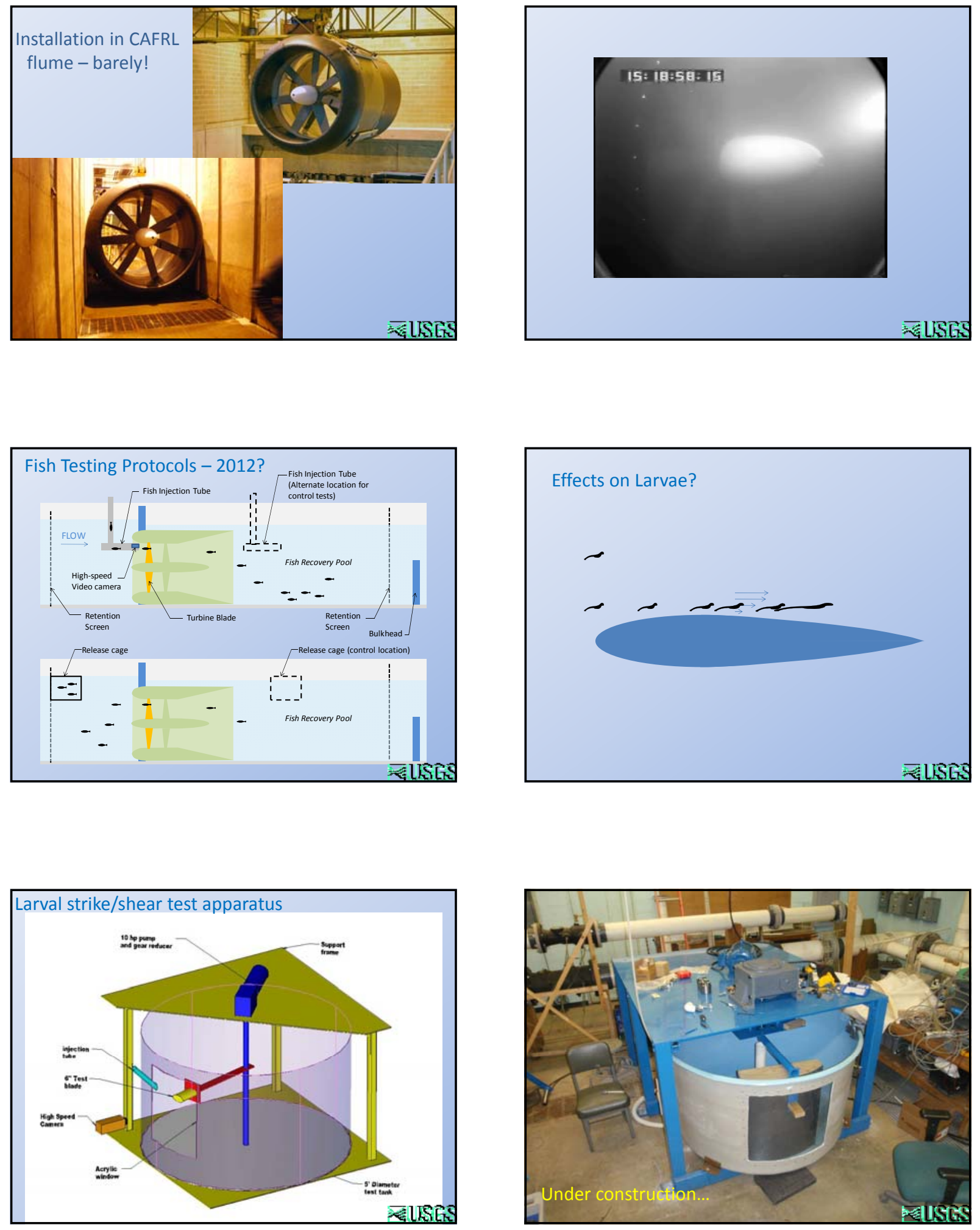

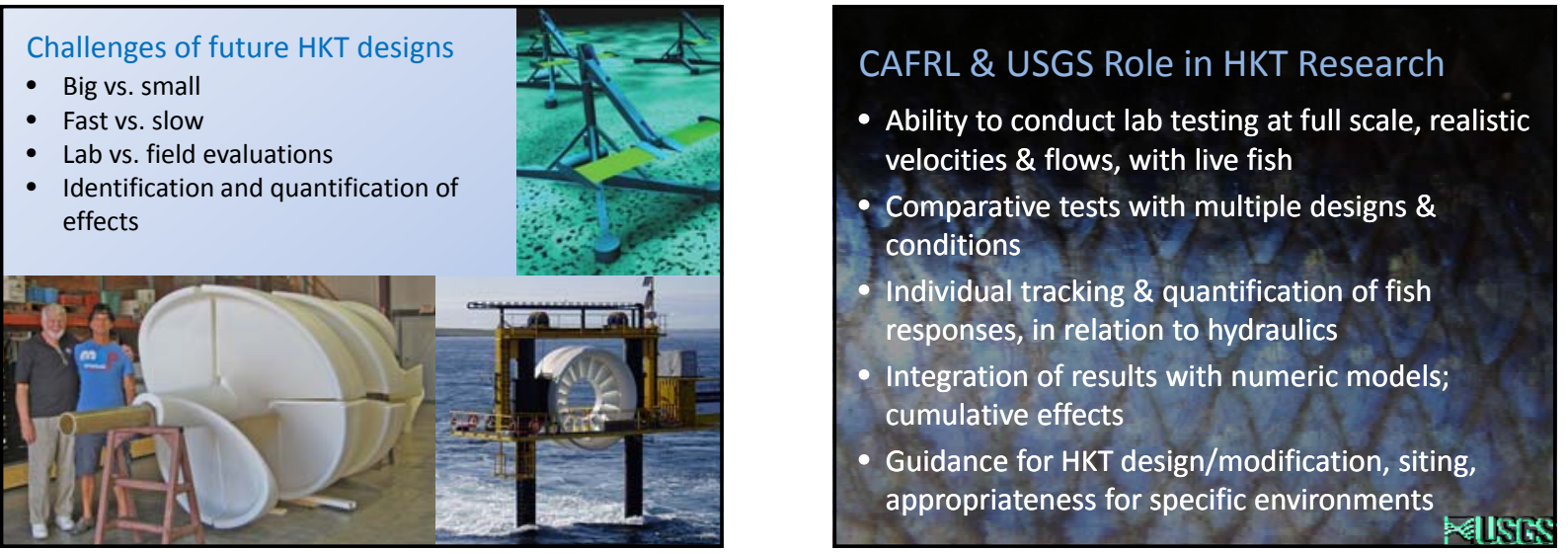
Macrohabitat Associations of Pallid Sturgeon in the Lower Mississippi River:

Application to Hydrokinetic Development.

Paul Hartfield, USFWS, Jackson, MS

Dr. Harold L. Schramm, USGS, MCRU, Mississippi State University, MS

Nathan M. Kuntz, Mississippi State University, MS
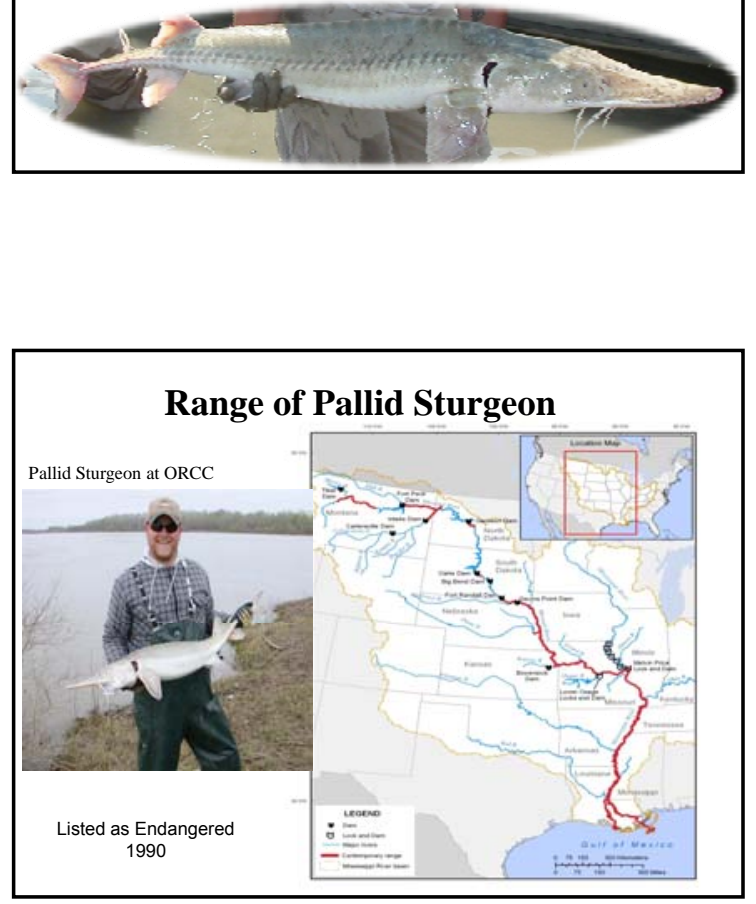

\section{Pallid Sturgeon Habitat Use and Selection in the Lower Mississippi River}

Nathan M. Kuntz ${ }^{1}$, J ason R. Herrala ${ }^{1}$, Harold L. Schramm, J r. ${ }^{2}$, and Paul Hartfield ${ }^{3}$

${ }^{1}$ Department of Wildlife, Fisheries, and Aquaculture, Mississippi State
University Mississippi State, MS 39762 ${ }^{2}$ U.S. Geological Survey, Mississippi Cooperative Fish and Wild life 3U.S. Fish and Wildlife Service, Mississippi Ecological Services Field Office,

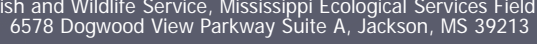

\section{Introduction}

- USFWS has multiple information needs and potential concerns over effects of hydrokinetics to fish and wildlife resources:

- composition and abundance of fish assemblages in the project area

Distribution, movement, habitat use, and behavior of fish species of concern

- Turbine entrainment of fish, invertebrates, and zooplankton

- Electromagnetic effects

- Acoustical effects

- Geomorphic effects
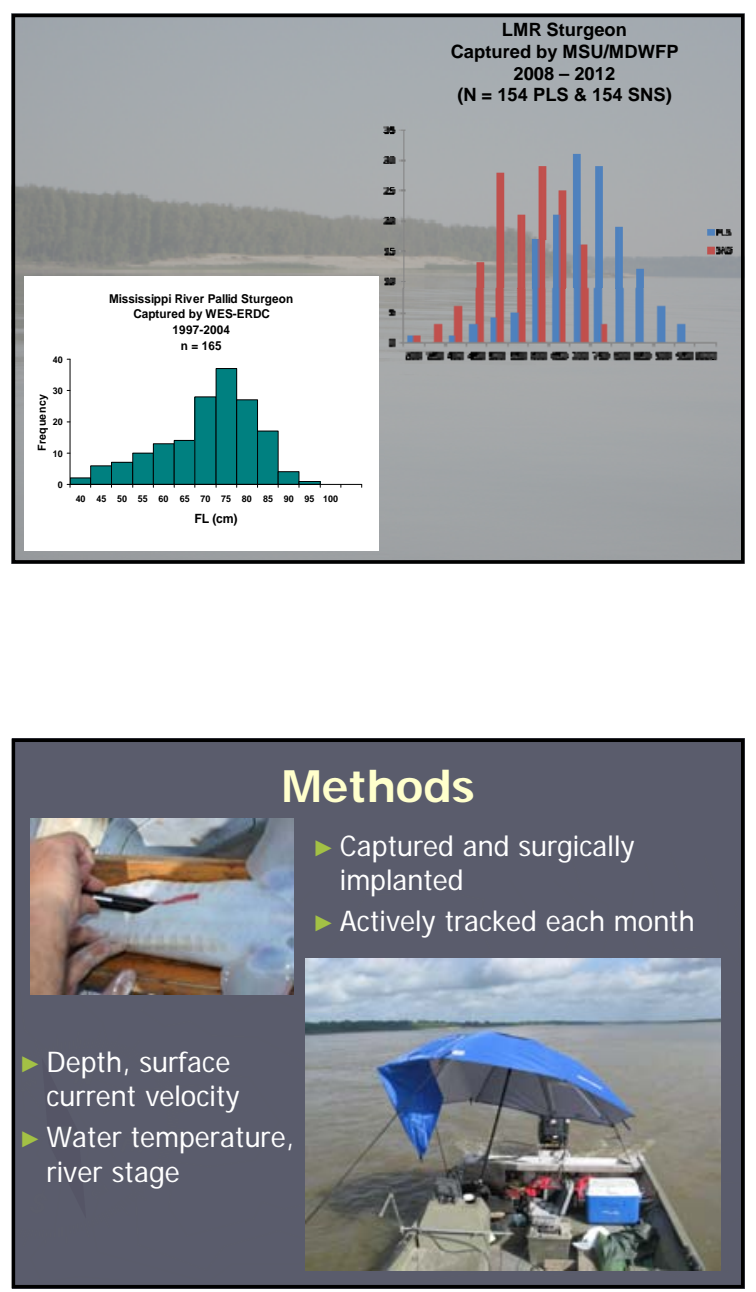

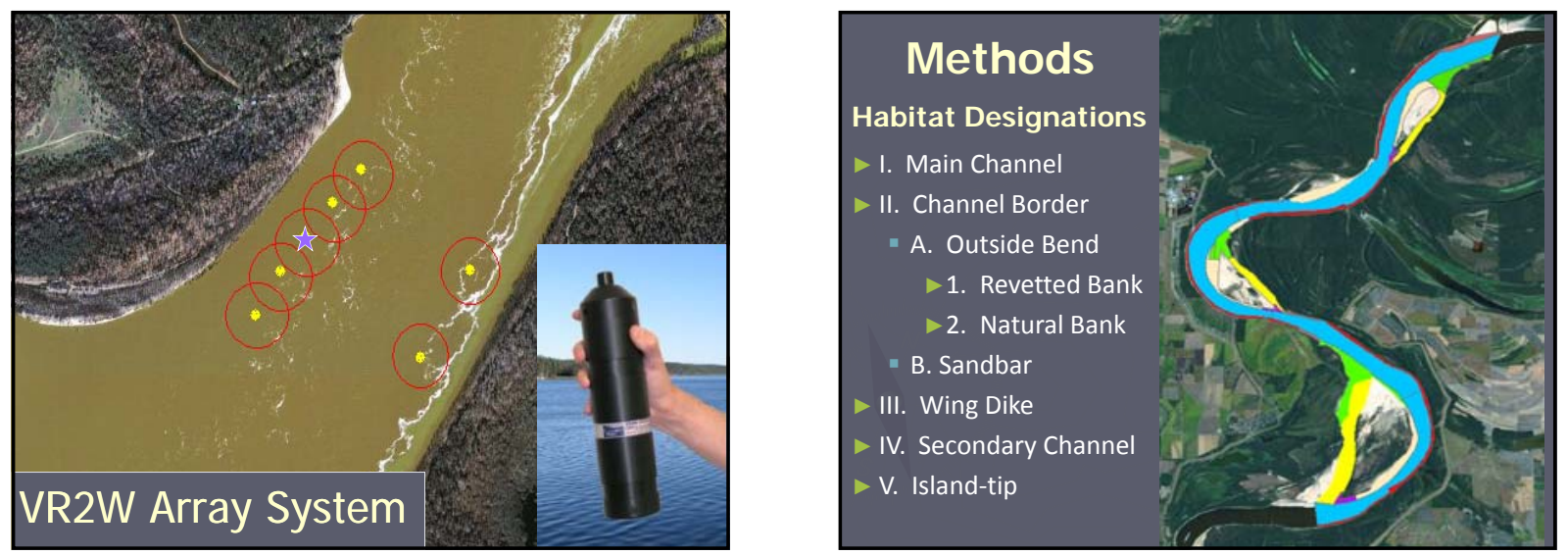

\section{Results}

$>74$ pallid sturgeon tagged

$>35$ individual fish for 165 detection

$\checkmark 27$ fish located between 2 and 14 times
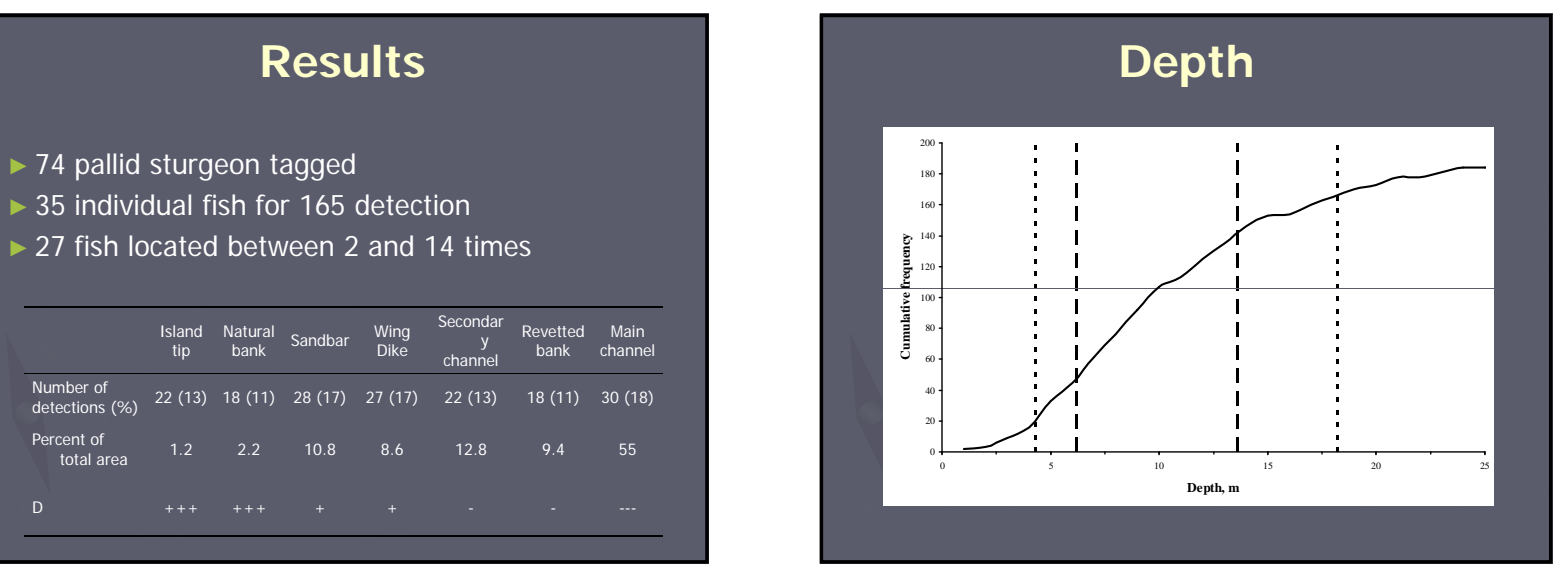

\section{Surface Current Velocity}

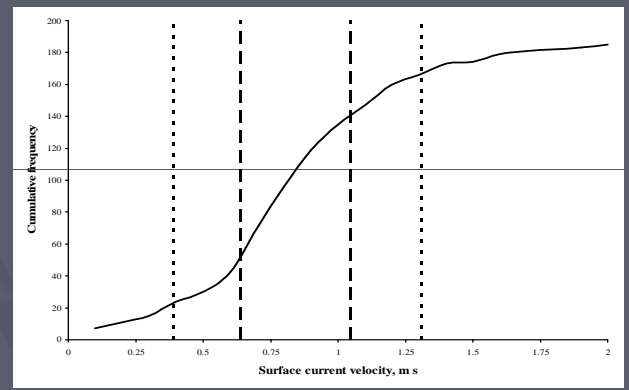

\section{NMS Ordination}

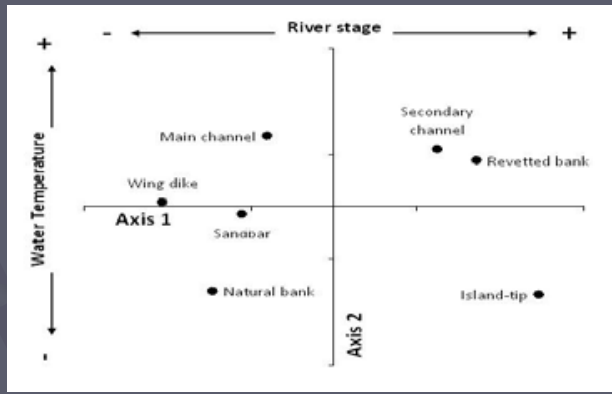



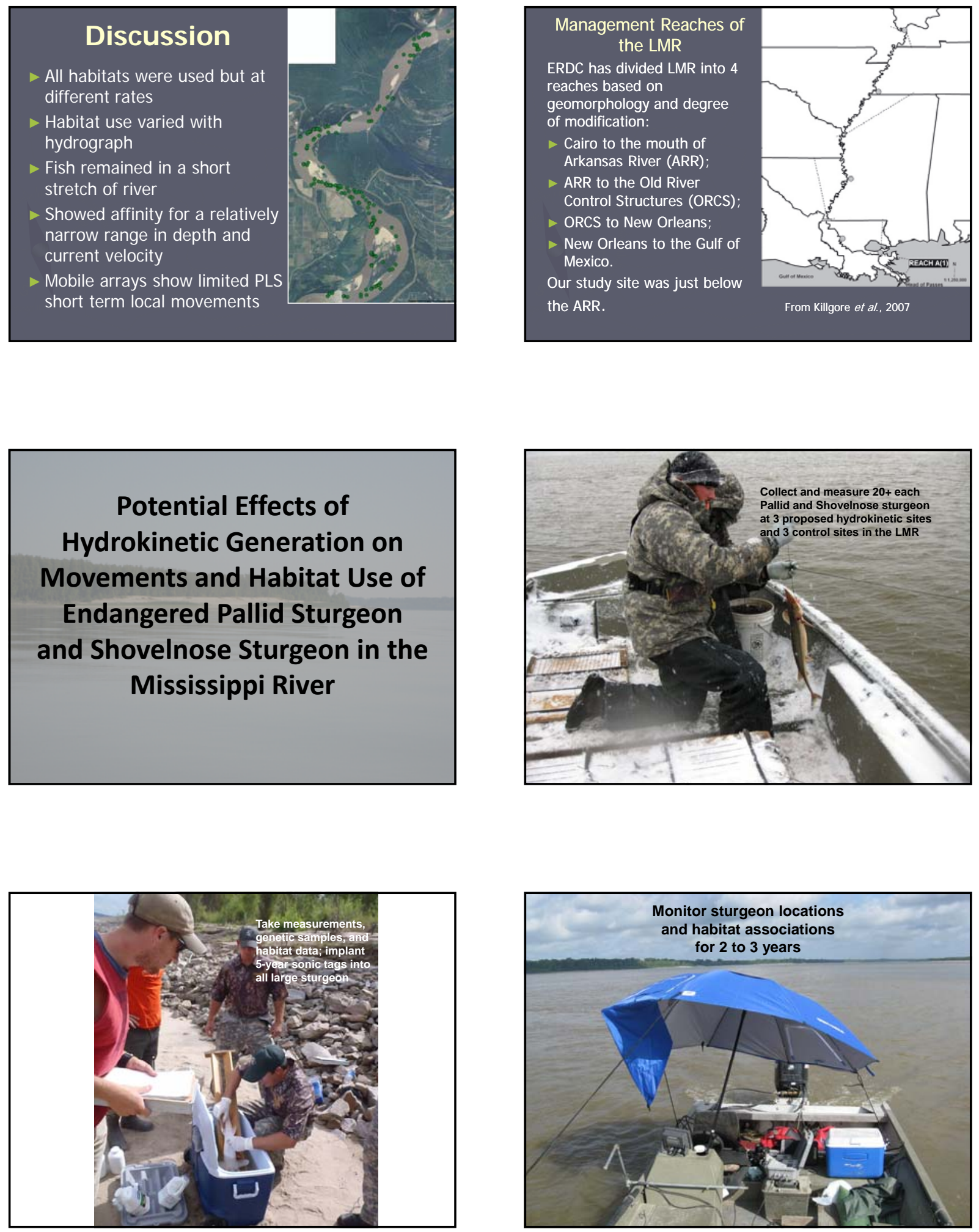


\section{Hydrokinetic Study Sites Identified by FFP}

- Tunica (Mhoon Bend), MS/AR

- Catfish Point, MS/AR

- Vicksburg, MS/LA

- Milliken Bend, Willow Cutoff, MS/LA

- Baton Rouge, LA

- Profit Island, LA
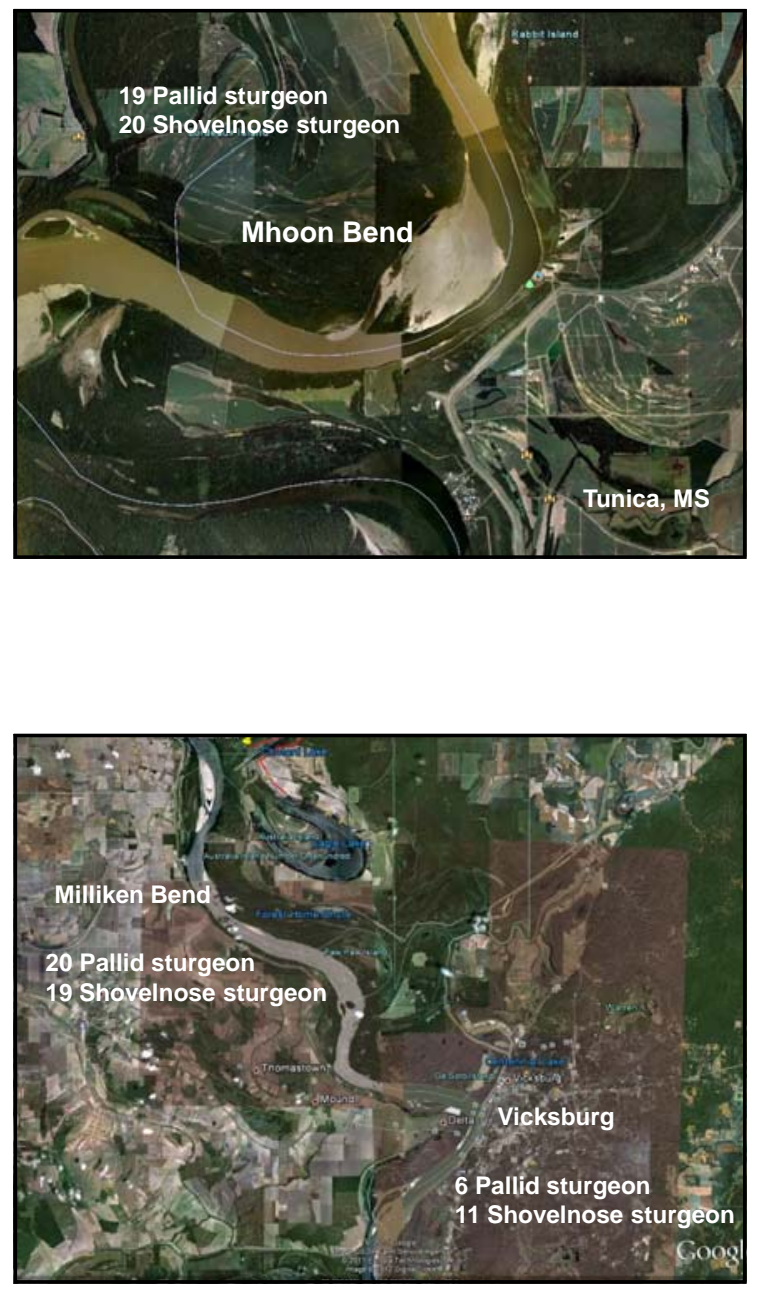

STURGEON IMPLANTED FOR HYDROKINETIC STUDY

\begin{tabular}{|c|c|c|c|c|}
\hline Locality & PLS & SNS & INT & TOTAL \\
\hline $\begin{array}{c}\text { Tunica, MS } \\
\text { (RM 665 - 685) }\end{array}$ & 19 & 20 & 1 & 40 \\
\hline $\begin{array}{l}\text { Catfish Point, MS } \\
\text { (RM } 559-580 \text { ) }\end{array}$ & 60 & 2 & & 62 \\
\hline $\begin{array}{l}\text { Greenville, MS } \\
\text { (RM } 537-540 \text { ) }\end{array}$ & 8 & 0 & & 8 \\
\hline $\begin{array}{l}\text { Milliken Bend } \\
\text { (RM 454-461) }\end{array}$ & 20 & 19 & & 39 \\
\hline $\begin{array}{l}\text { Vicksburg, MS } \\
\text { (RM } 430-440 \text { ) }\end{array}$ & 6 & 11 & 2 & 19 \\
\hline $\begin{array}{l}\text { Profit Island, LA } \\
\text { RM 240 - 246) }\end{array}$ & 4 & 3 & & 7 \\
\hline $\begin{array}{c}\text { Baton Rouge, MS } \\
\text { (RM 233-238) }\end{array}$ & 4 & 3 & 1 & 8 \\
\hline Total & 121 & 58 & 4 & 183 \\
\hline
\end{tabular}



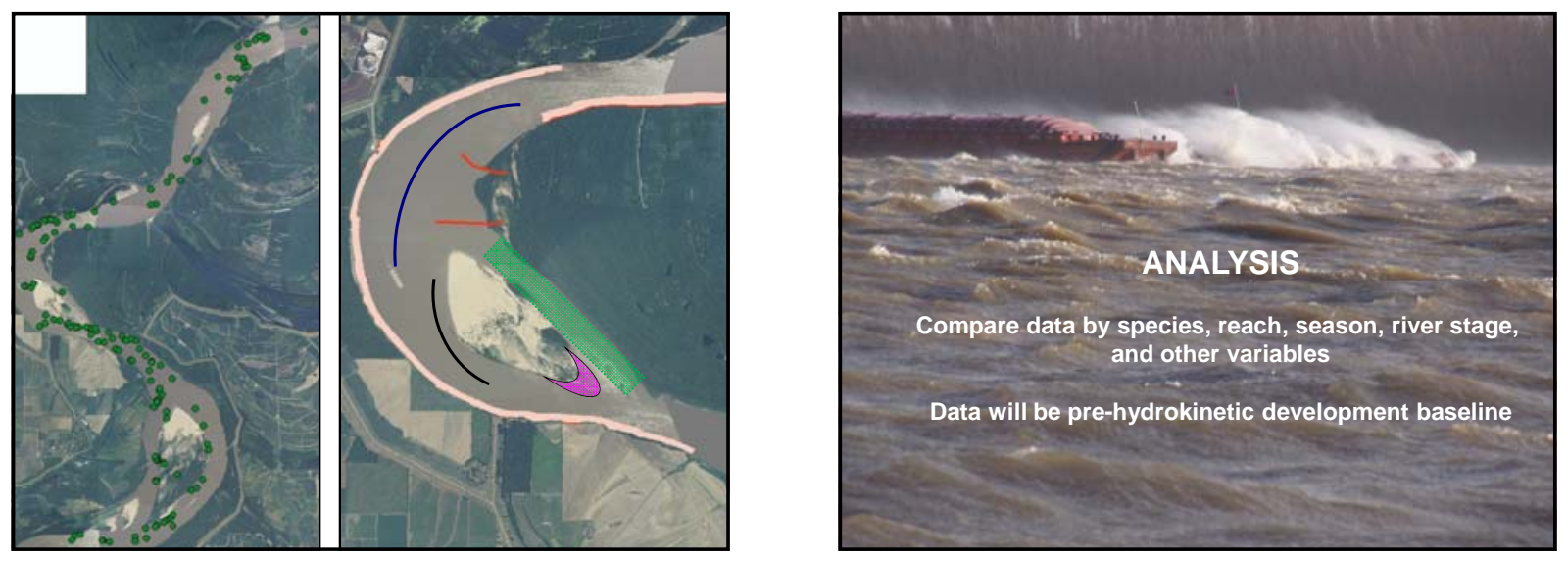

Questions? 

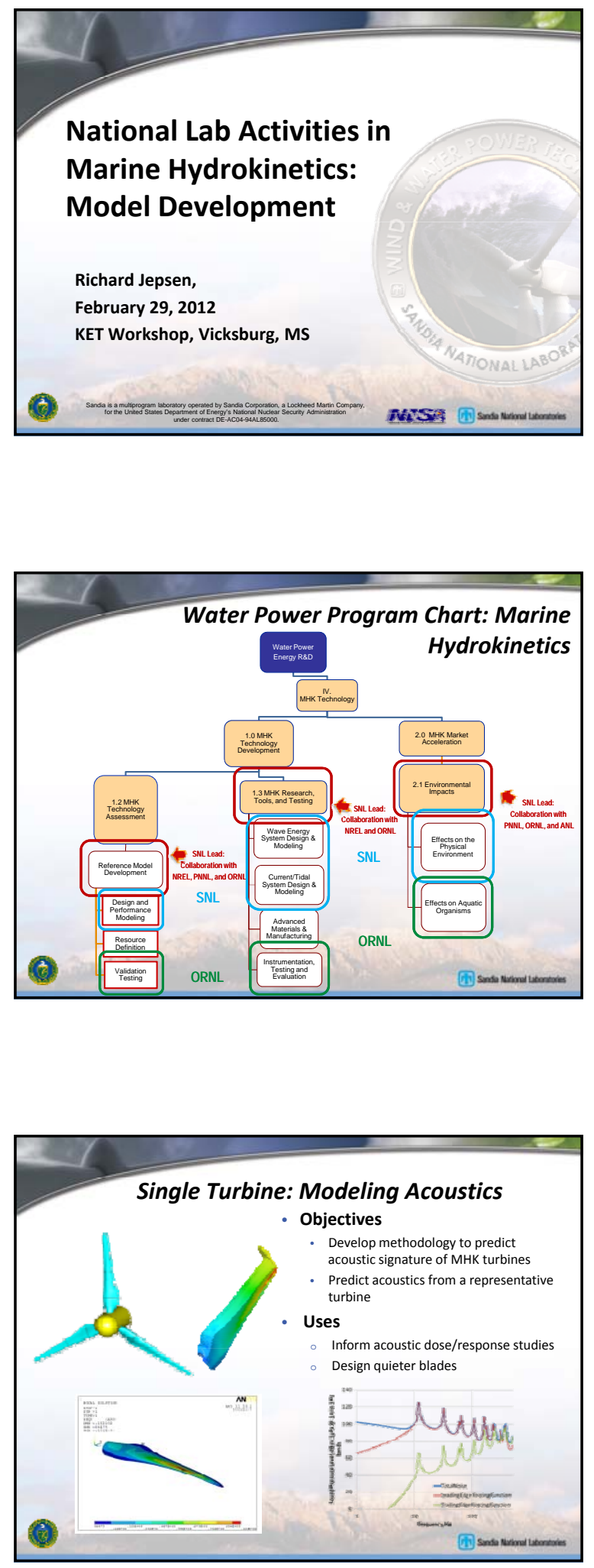

\begin{tabular}{|l|} 
Water Power Program Mission \\
- Research, test, and develop innovative technologies capable of \\
generating renewable, environmentally responsible, and cost \\
effective electricity form water resources. \\
- Marine Hydrokinetic Technologies \\
- Resource \\
- Wave energy has a potential resource of $400 \mathrm{GW}$ \\
- Tidal currents have a potential resource of $60 \mathrm{GW}$ \\
- Free flowing rivers have a potential resource of $60 \mathrm{GW}$ \\
- R\&D Focus \\
- Determine convertible resource potential \\
- Demonstrate performance viability and identify technology leaders \\
- Identify key cost drivers and opportunities for cost reduction \\
\end{tabular}
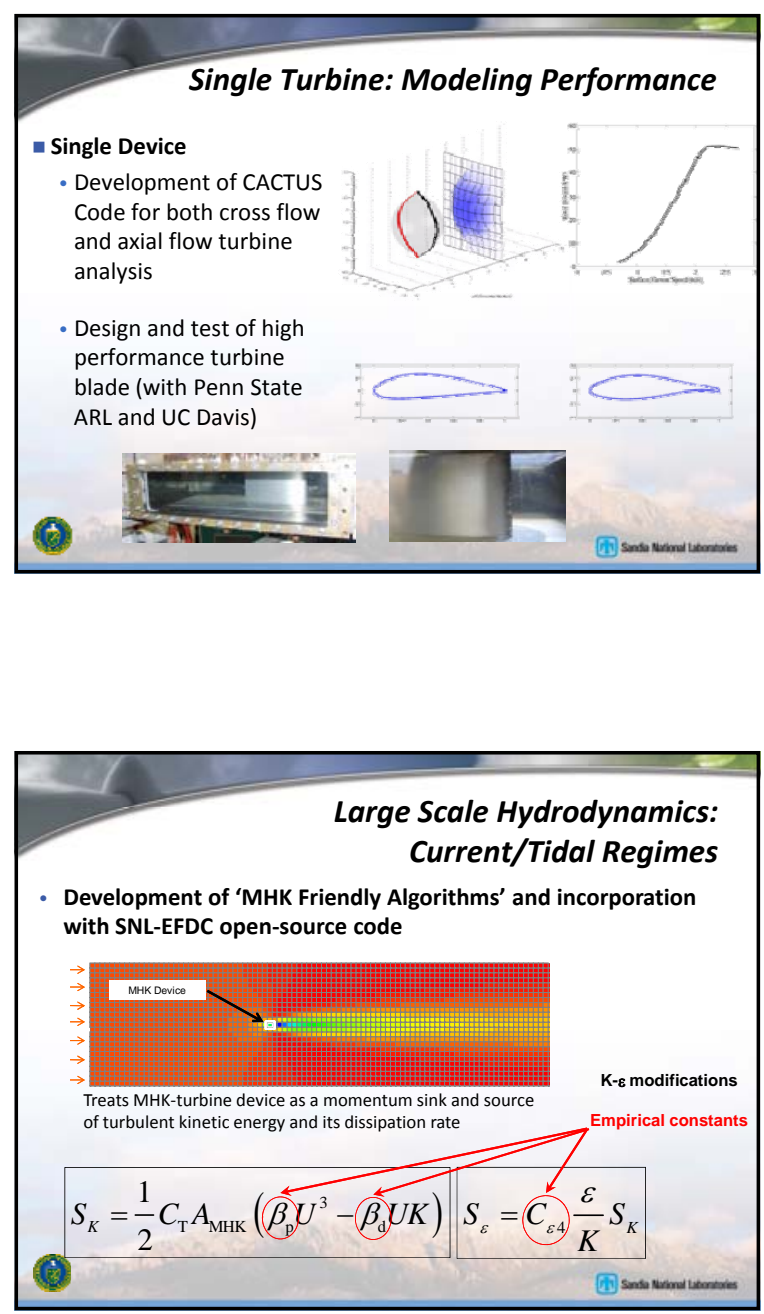


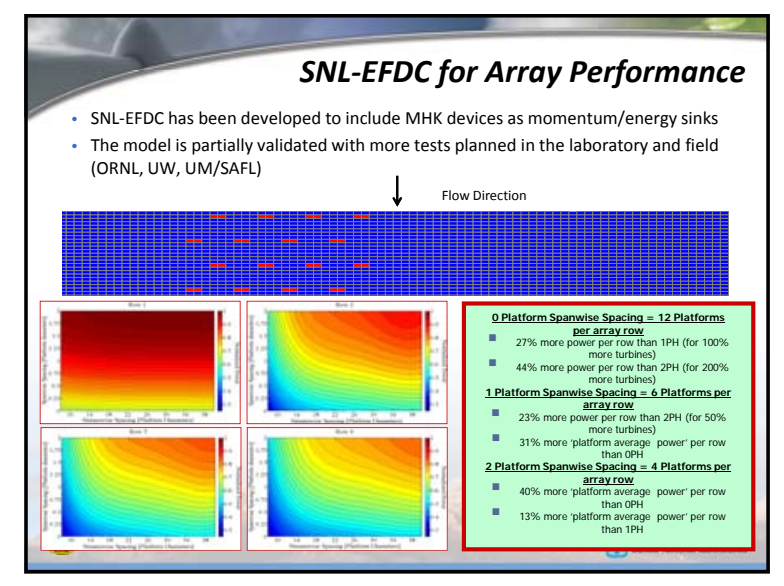

Turbine Array Comparisons

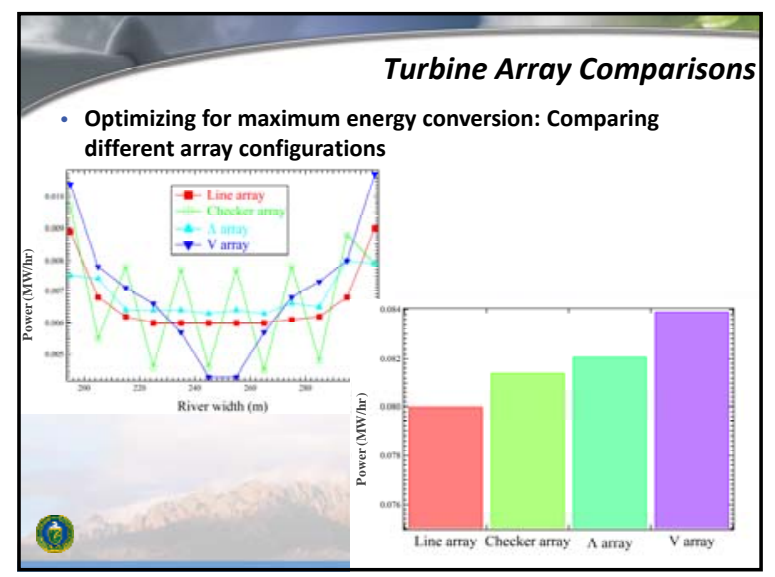

Mooring and Device Modeling

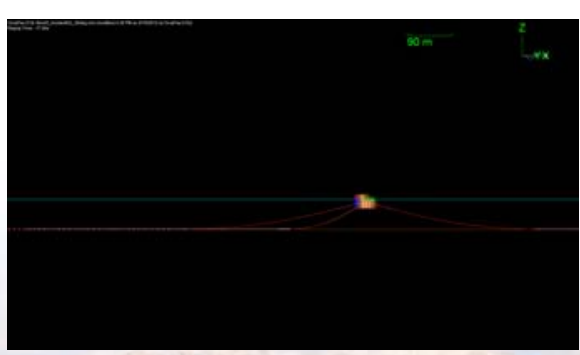

(2)

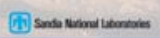
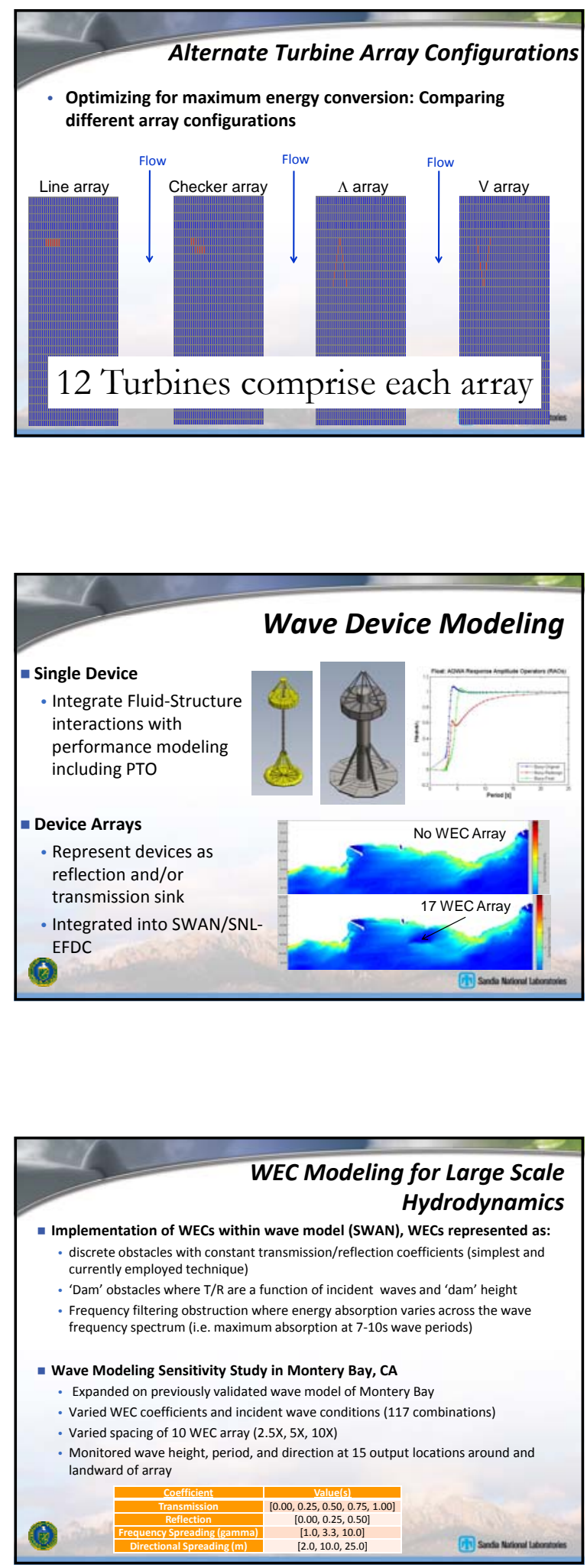

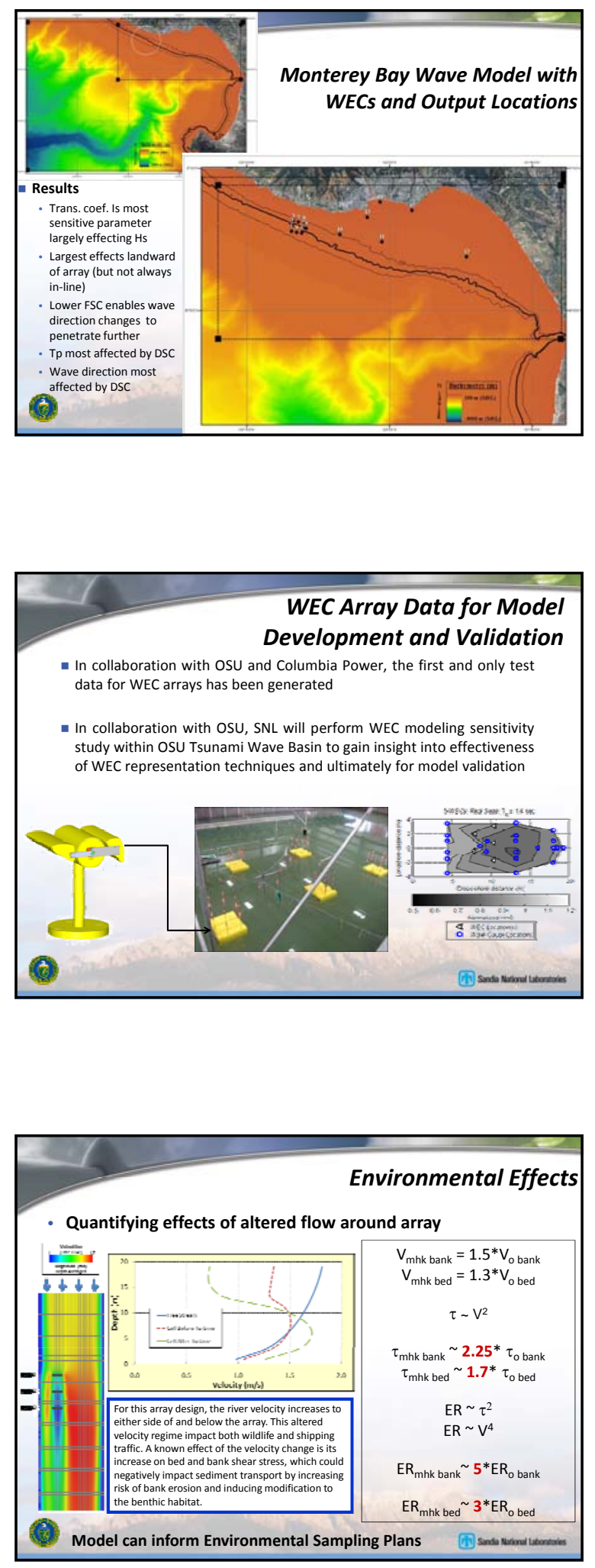
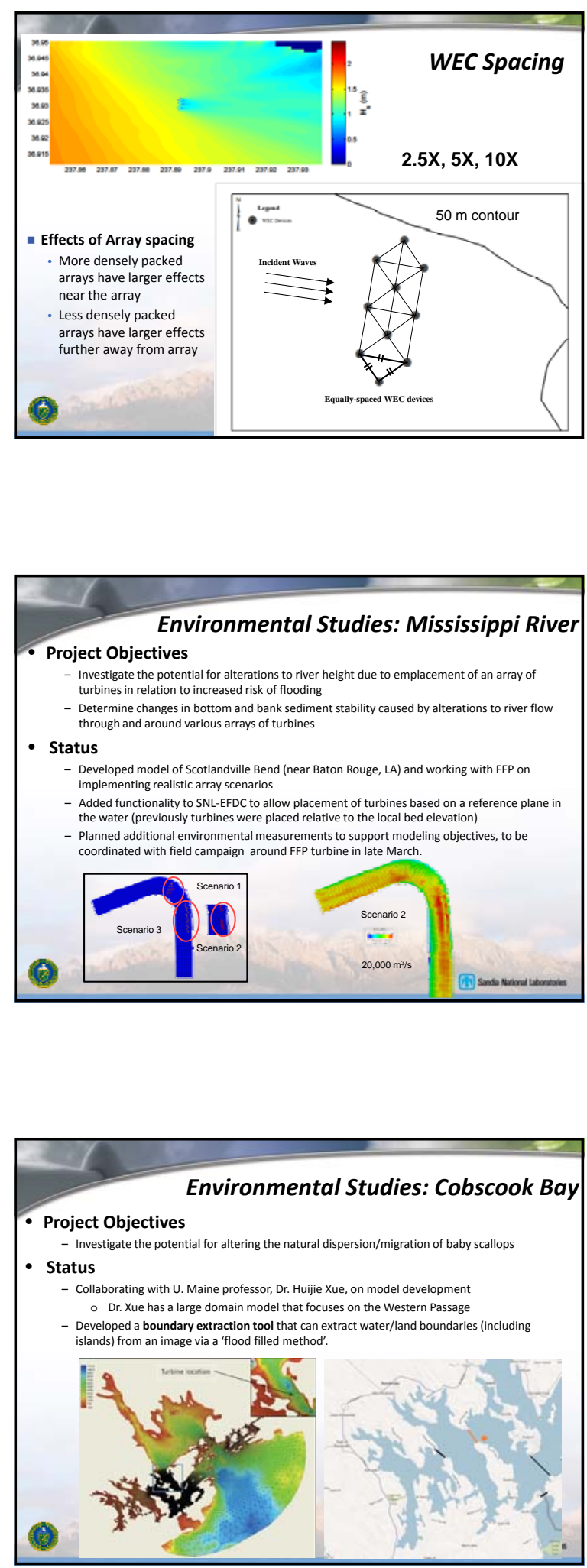

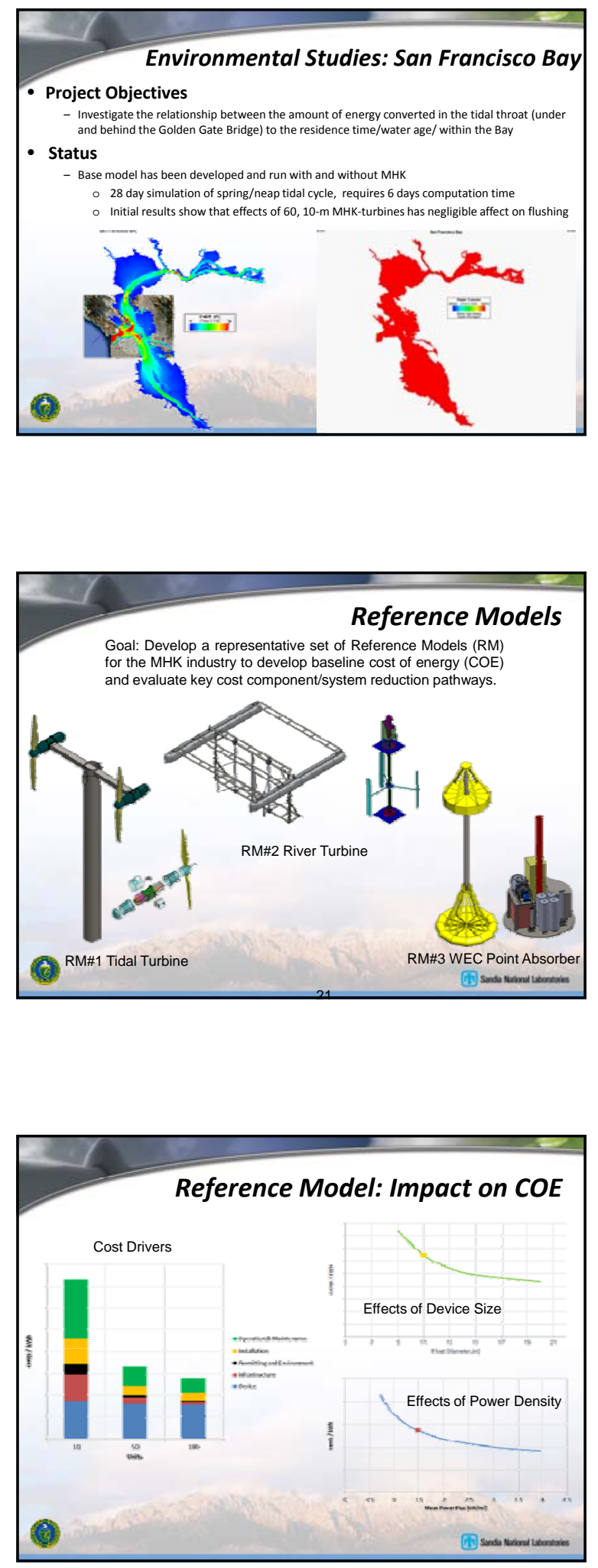
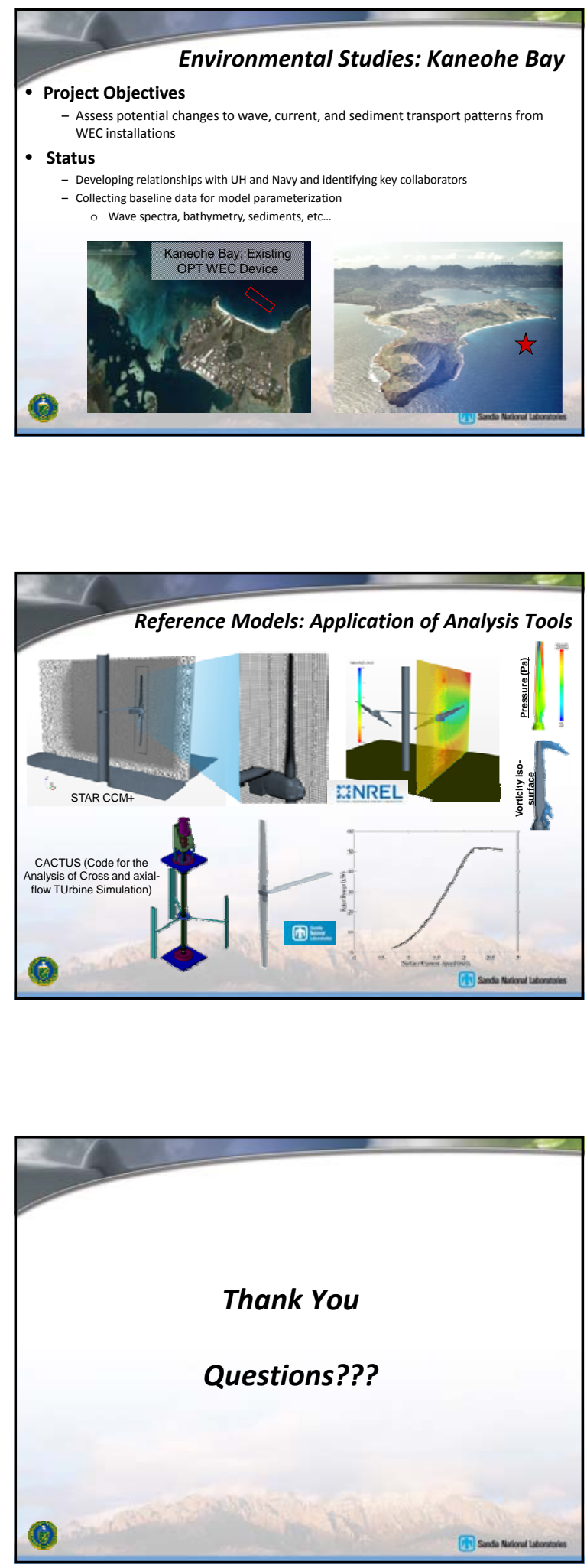


\section{USACE Regulatory}

- Section 10 Rivers and Harbors Act of 1899

- Structures/work affecting the course, location, or condition of Navigable Waters

- Section 404 Clean Water Act

- Discharges of Dredged or Fill Material into Waters of the United States

- District Commanders make permit decisions $\triangleright \sim 1,300$ regulators reviewing $\sim 80,000$ applications/yr $\triangleright$ Regulatory vs. Civil Works boundaries

\section{USACE Regulatory}

- FERC lead agency, USACE cooperating agency

- MOU - March 11, 2011

- Review/Comment on EIS documents

- Participate in the development of monitoring/data collection protocol plans

- Permit Type: Individual vs. General

- NWP \#52 Water-Based Renewable Energy Pilot

Projects

- Public Interest Review

-404(b)(1) Guidelines

- Coordinate with USACE Navigation and Hydropower

\section{Challenges and Opportunities}

- Competing interests

- Corps must determine proposed project is not contrary to the public interest

- Public interest review factors include:

- Navigation, Safety, Recreation, Fish and Wildlife,

Energy Needs, Wetlands, Historic Properties,

Shore erosion and accretion, Water Supply and

Conservation, and 11 others.

- Understanding potential effects and how to mitigate them

- Forums such as this to exchange information and ideas

- Proactive federal approach 

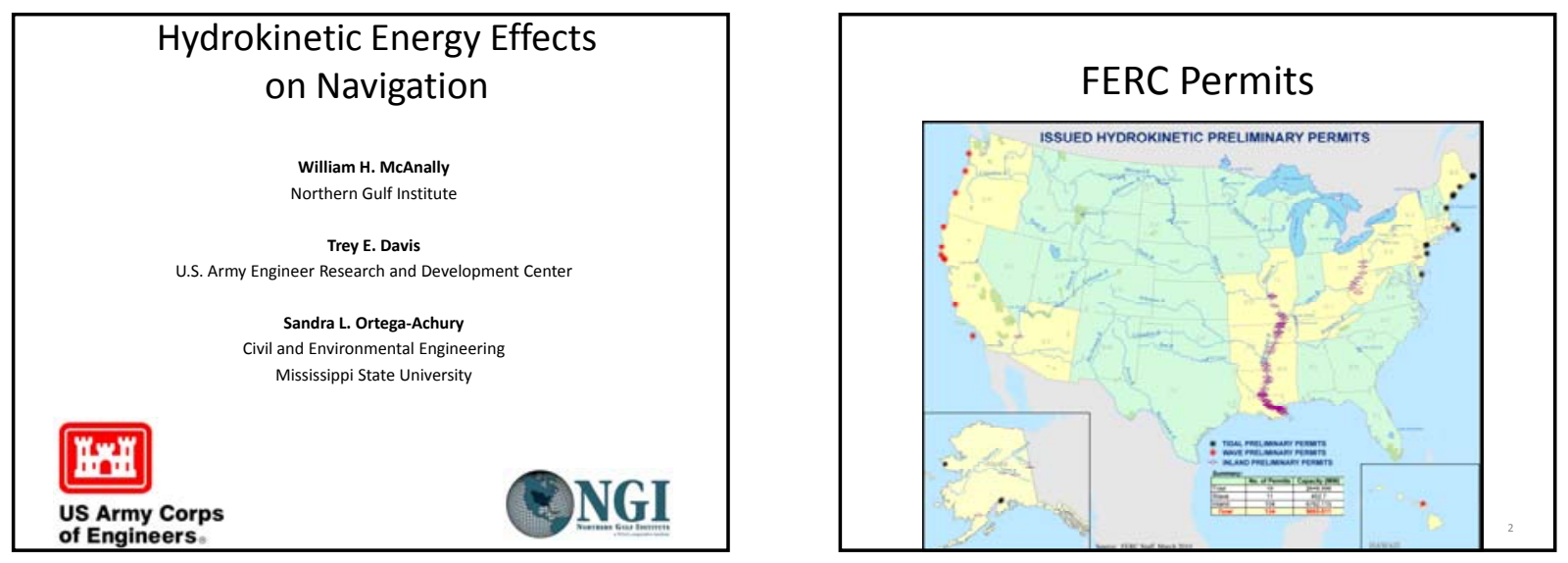

\section{In-Stream Hydrokinetics}

Potential effects* from hydrokinetic facility installation, supporting infrastructure, operation, or signage on:

- Visual navigation

- Electronic navigation and communications

- Search and rescue, counter pollution, or salvage operation in or around an installation

- Tides, streams and currents

- Navigation safety (likelihood of allision and collision)

* Marine and Hydrokinetic Renewable Energy Technologies: Potential Navigational Impacts and Mitigation Measures, Office of Energy Efficiency and Renewable Energy, U. S. Department of Energy, Washington, DC. 2009.

\section{Probability of Vessel Excursion}

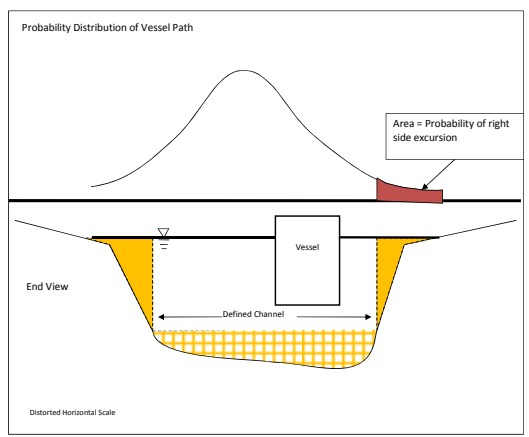

\section{Safety Example}

- A sample* of 936 vessel accidents occurring in the Lower Mississippi River between 1979 and 1987:

-207 vessel-vessel collisions

-422 vessel-fixed structure allision

-297 groundings

-10 other

- 0.32 out-of-channel accidents per mile per yr * Le Blanc, L. A. and C. T. Rucks 1996. A multiple discriminant analysis of vessel accidents,
Accident Analysis and Prevention, 28, No. 4. 501-510. 
Physical Effects Example: Hypothetical Waterway

\begin{tabular}{|l|c|}
\hline \multicolumn{1}{|c|}{ Variable } & Value \\
\hline Discharge & $10,000 \mathrm{~m}^{3} / \mathrm{sec}$ \\
\hline Roughness Coefficient, $n$ & 0.025 \\
\hline Length of Channel & $2,000 \mathrm{~m}$ \\
\hline Bottom Slope & 0.0001 \\
\hline KE Coefficient & 1 \\
\hline Tailwater Depth & $3 \mathrm{~m}$ \\
\hline Extraction Loss Fraction & 0 to $30 \%$ \\
\hline
\end{tabular}

\section{Hydraulic Calculations, No Extraction}

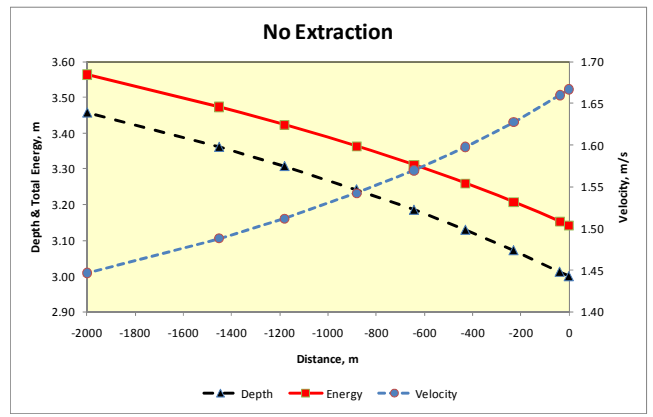

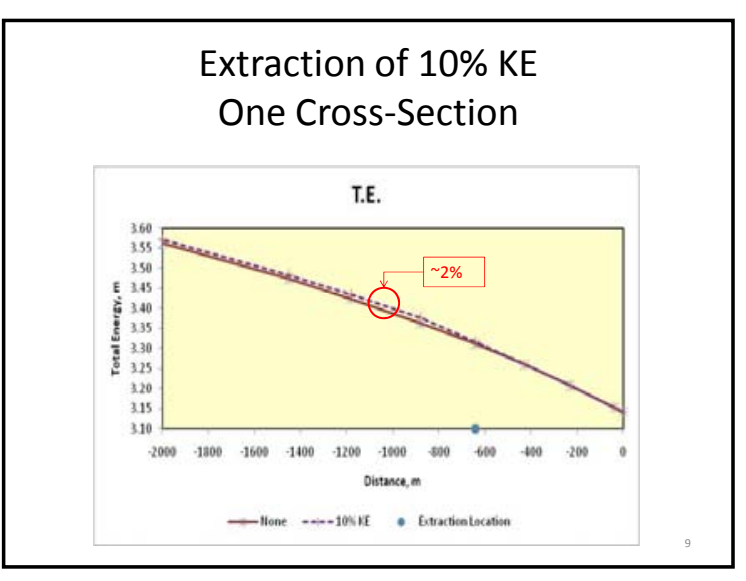
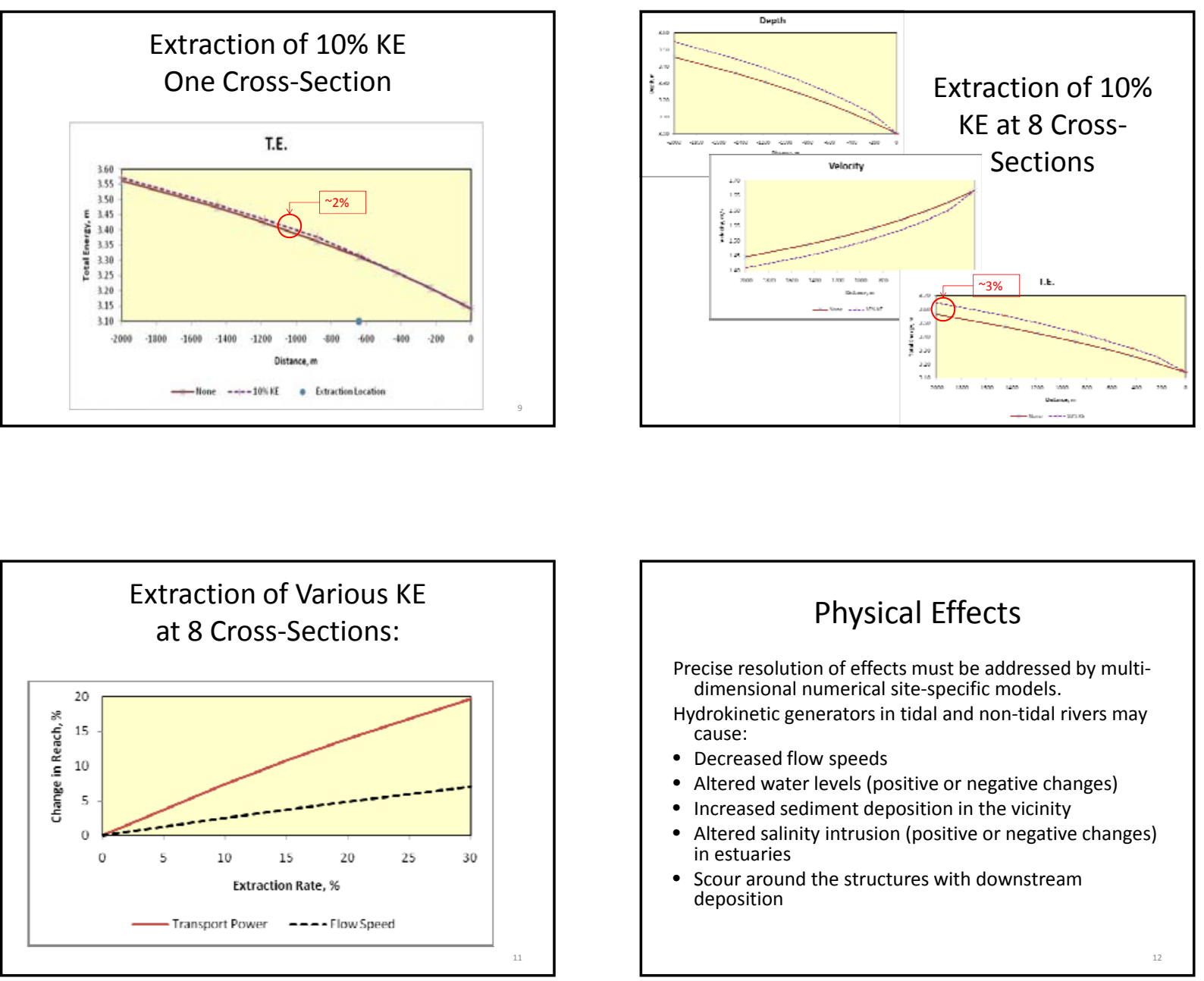

\section{Physical Effects}

Precise resolution of effects must be addressed by multidimensional numerical site-specific models.

Hydrokinetic generators in tidal and non-tidal rivers may cause:

- Decreased flow speeds

- Altered water levels (positive or negative changes)

- Increased sediment deposition in the vicinity

- Altered salinity intrusion (positive or negative changes) in estuaries

- Scour around the structures with downstream deposition 


\section{Conclusions}

- Hydrokinetic power offers a significant contribution to U.S. electricity needs.

- Potential effects of hydrokinetic installations on navigation include:

- Vessel accidents

- Decreased flow speeds \& altered water levels

- Localized bed scour \& far field sediment deposition

- Altered salinity intrusion in estuaries

- Site conditions will dictate whether a specific site is suitable for hydrokinetic electricity generation or not.

- Multi-dimensional numerical modeling of sites is required.

- Cumulative impacts of multiple installations must be considered.

\section{Contact Information}

Trey E. Davis

Trey.e.davis@usace.army.mil

William H. McAnally

mcanally@ngi.msstate.edu

MII MLSISSIPPI SWIE

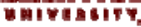



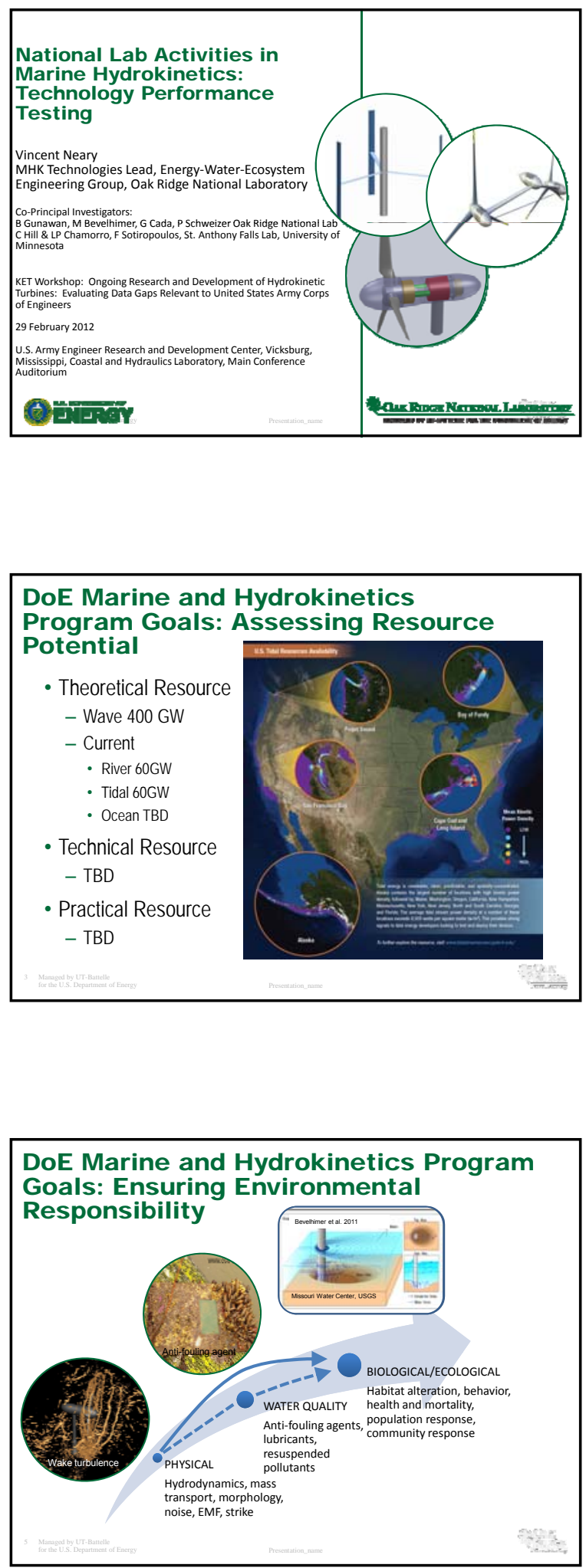

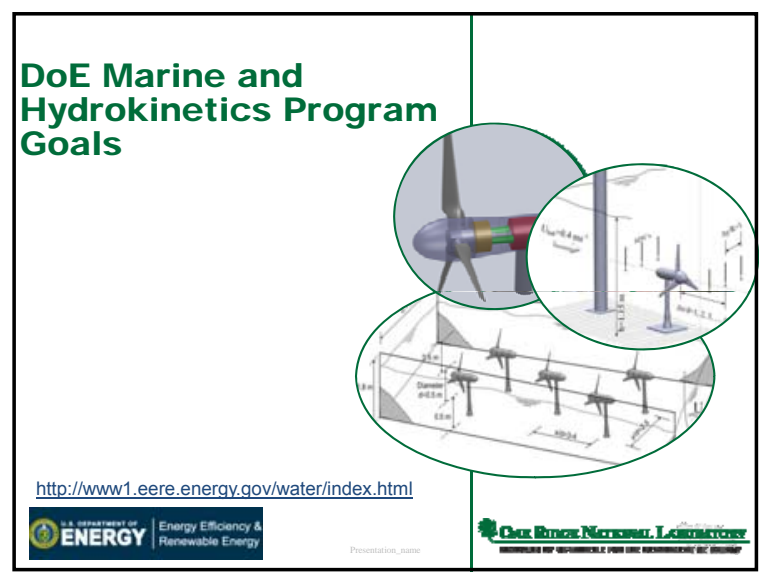

DoE Marine and Hydrokinetics Program Goals: Advancing Technology Readiness

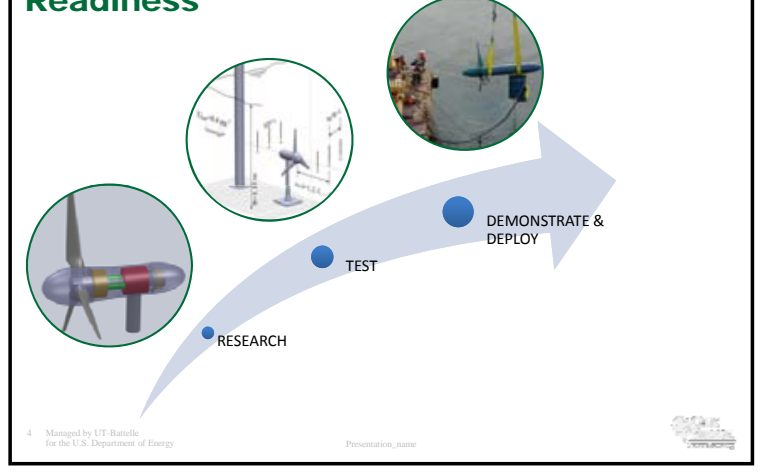

DoE Marine and Hydrokinetics Program Goals: Reducing the Cost of Energy (COE)

$$
C O E=\frac{\text { Cost }}{A E P}
$$

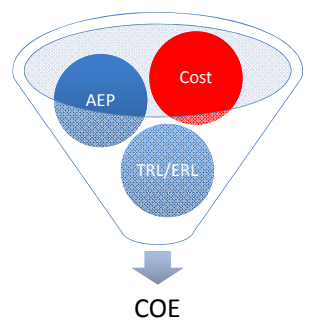

Cost $=\mathrm{f}($ manufacturing, $\mathrm{O} \& \mathrm{M}$, environmental mitigation, monitoring, permitting...)

Annual Energy Production $(A E P)=f($ current frequency, duration, magnitude) 

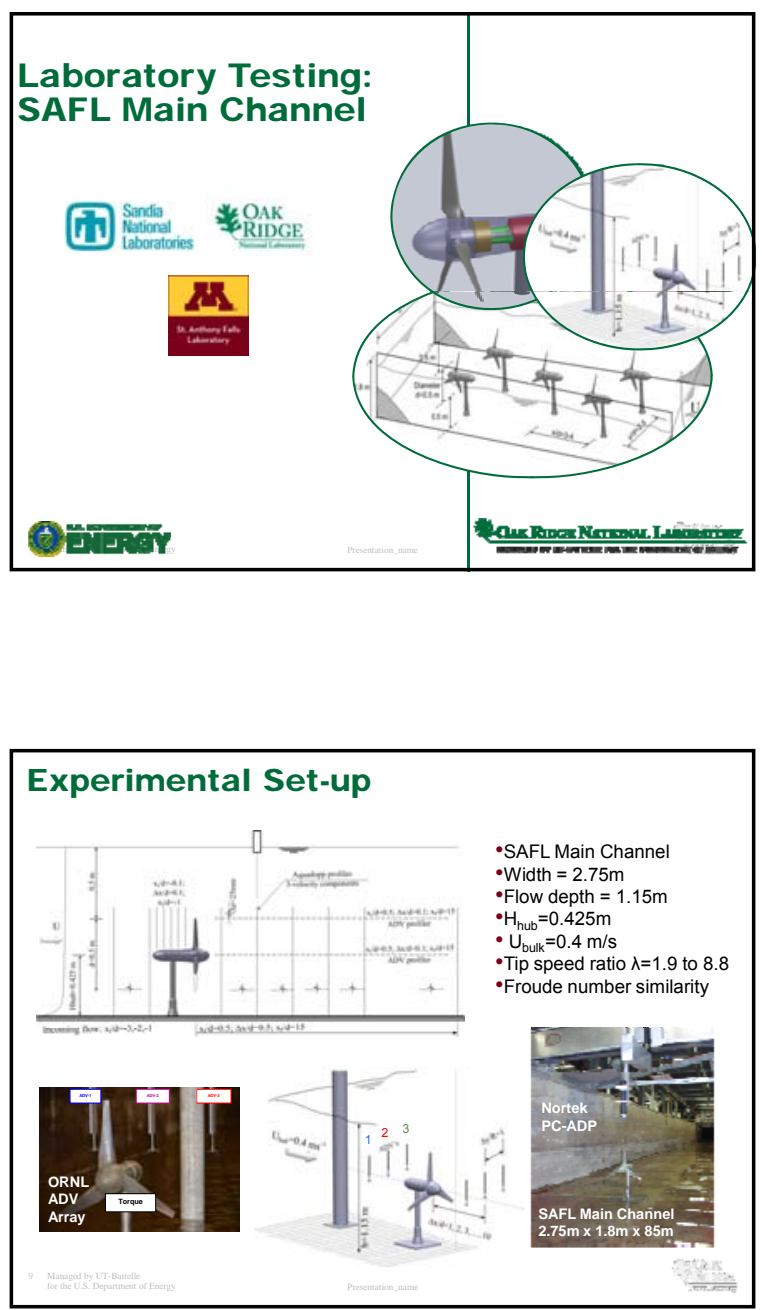

Inflow and wake measurements: vertical mean longitudinal velocity
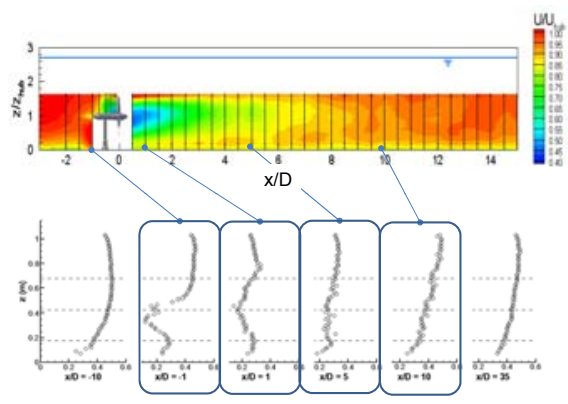

\section{Study objectives}

- Validation data sets

- Technology CFD design models: Performance curves

- Near- and far-field CFD hydrodynamic models: Inflow and wake characteristics

- TRL and ERL assessment

- COE assessment

- Best practices for lab and field testing

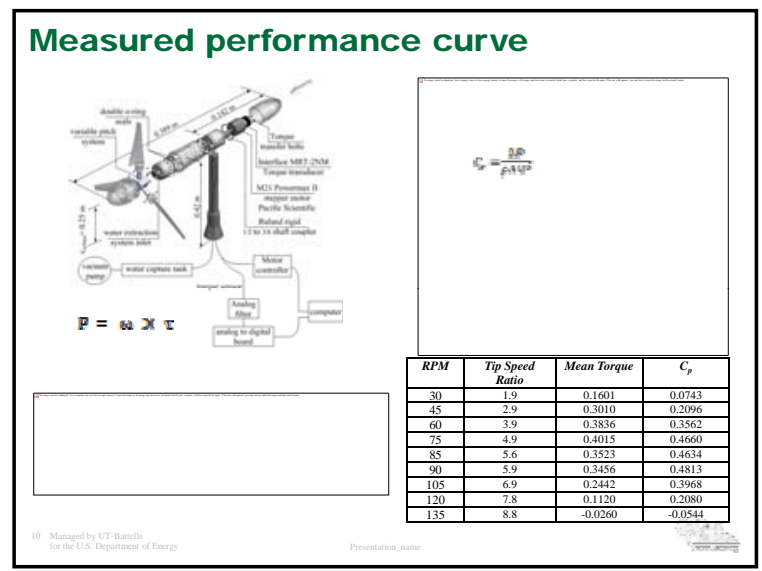

Inflow and wake measurements: turbulence intensity

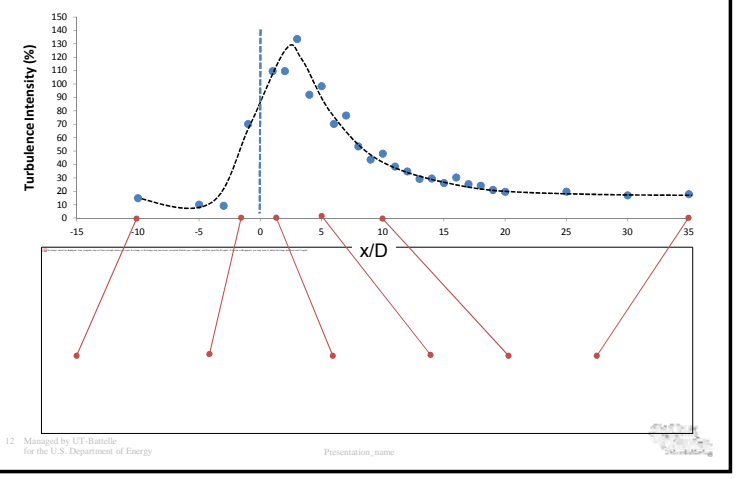


Inflow and wake measurements: SNLEFDC Verification and Validation

- Verification and validation of SNL-EFDC, open-source code for optimizing machine array spacing
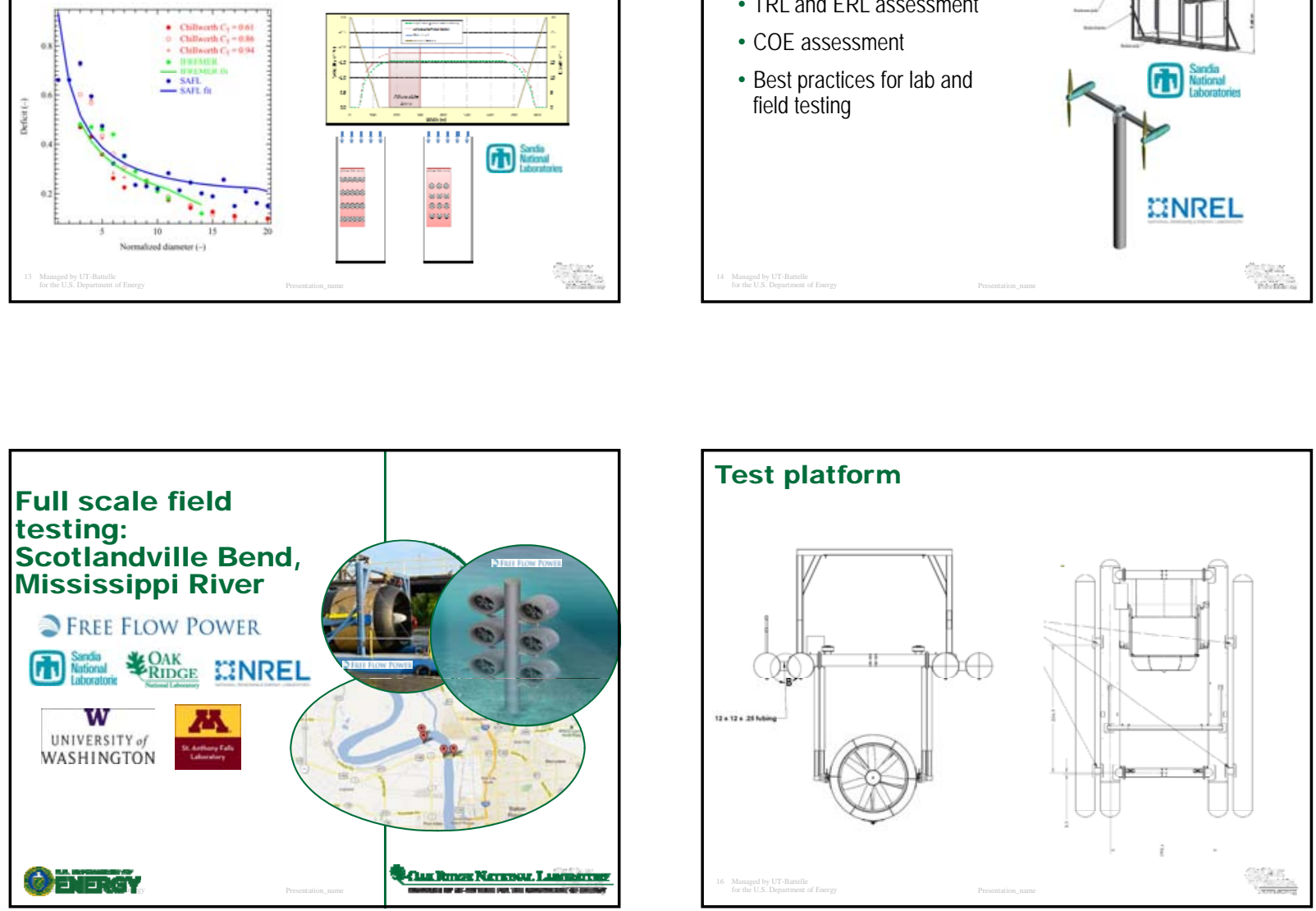

\section{Future work: Reference turbine} testing

- Validation data sets

- TRL and ERL assessment

- COE assessment

- Best practices for lab and field testing
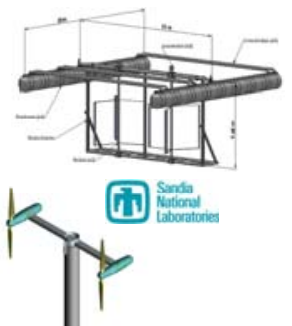

\%NREL

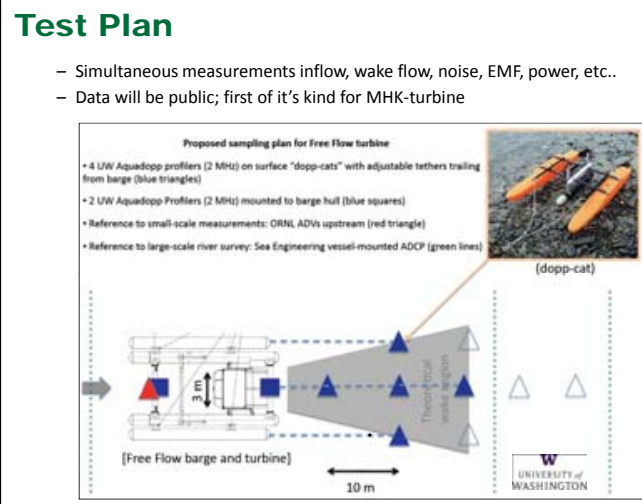

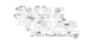

Data Gaps (Most pressing data needs, DoE)

\begin{tabular}{|c|c|c|c|}
\hline MHK resource & $\begin{array}{l}\text { Technology } \\
\text { readiness }\end{array}$ & $\begin{array}{l}\text { Environmental } \\
\text { readiness }\end{array}$ & $\begin{array}{l}\text { Cost of energy } \\
\text { drivers }\end{array}$ \\
\hline $\begin{array}{l}\text { Machine } \\
\text { specs, } \\
\text { performance } \\
\text { curves, } \\
\text { spacing } \\
\text { Siting } \\
\text { constraints }\end{array}$ & $\begin{array}{l}\text { - Survivability } \\
\text { in harsh } \\
\text { environment } \\
\text { - Wake effects } \\
\text { on machine } \\
\text { spacing }\end{array}$ & $\begin{array}{l}\text { - Fish-machine } \\
\text { interaction } \\
\text { - Physical } \\
\text { impacts of } \\
\text { wakes } \\
\text { - EMF } \\
\text { - Noise }\end{array}$ & $\begin{array}{l}\text { - Spacing } \\
\text { - Maintenance } \\
\text { costs } \\
\text { Permitting } \\
\text { and } \\
\text { monitoring }\end{array}$ \\
\hline
\end{tabular}




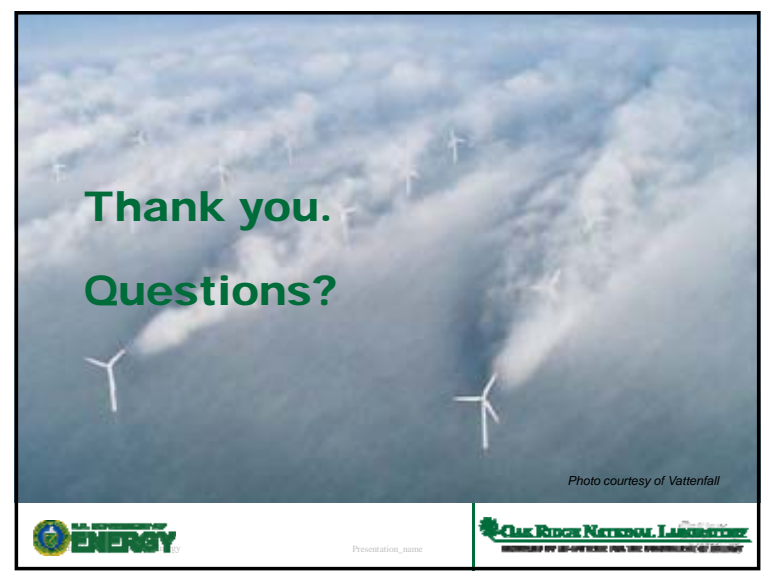

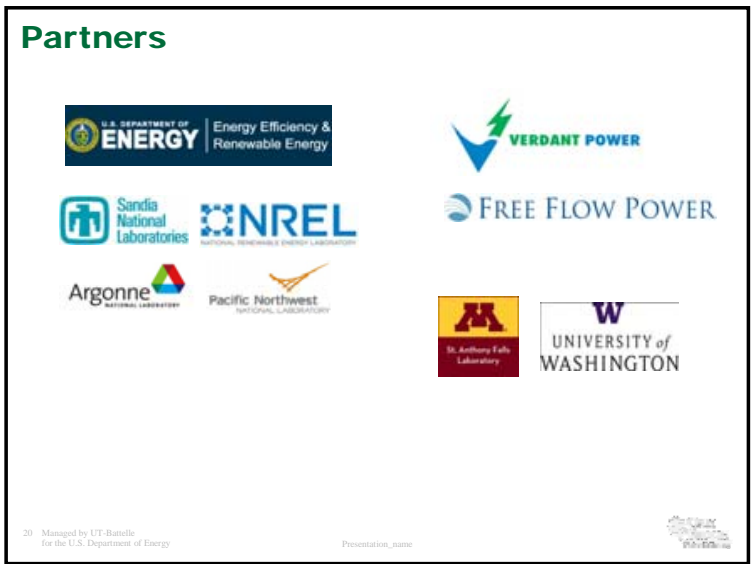

Inflow and wake measurements: velocity deficit

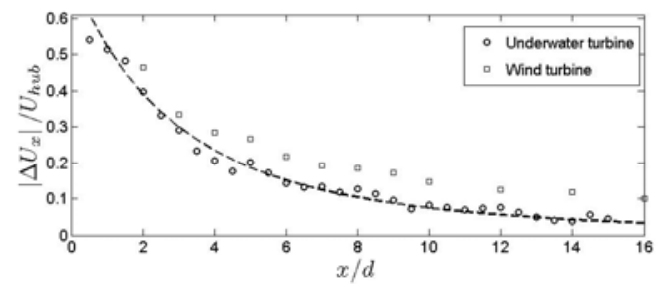



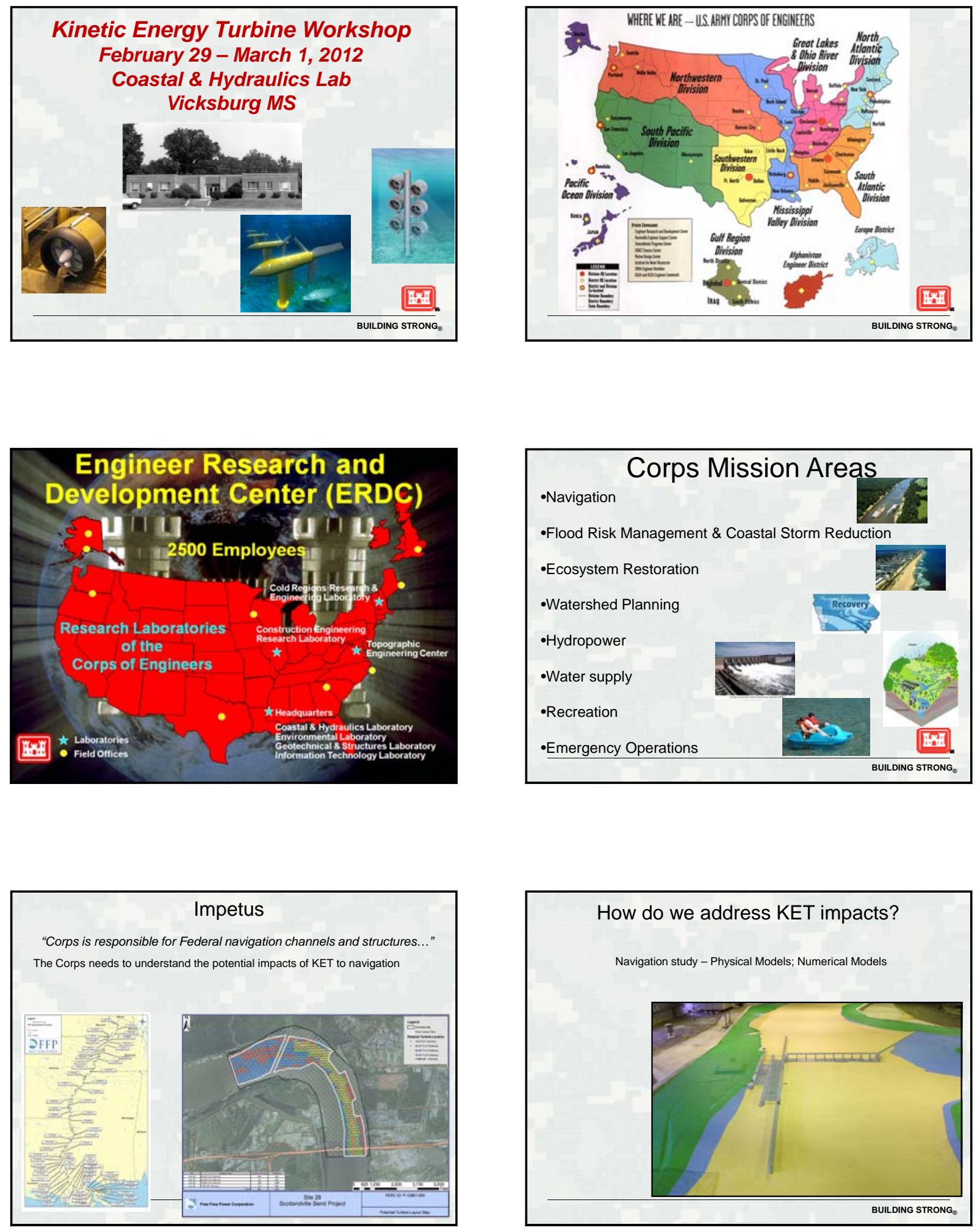


\section{Kinetic Energy Turbine Workshop}

-Present ongoing research/planning activities by USACE and Federal agencies

-Identify potential regulatory and permitting needs that require USACE action

-Develop a list of research and development needs to address unresolved navigation, flood risk management and environmental issues
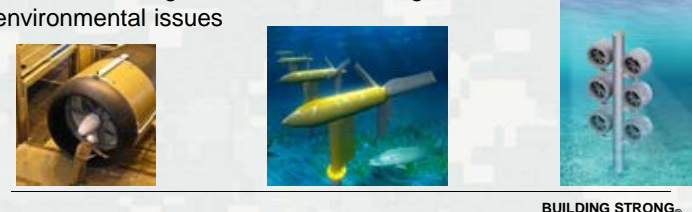
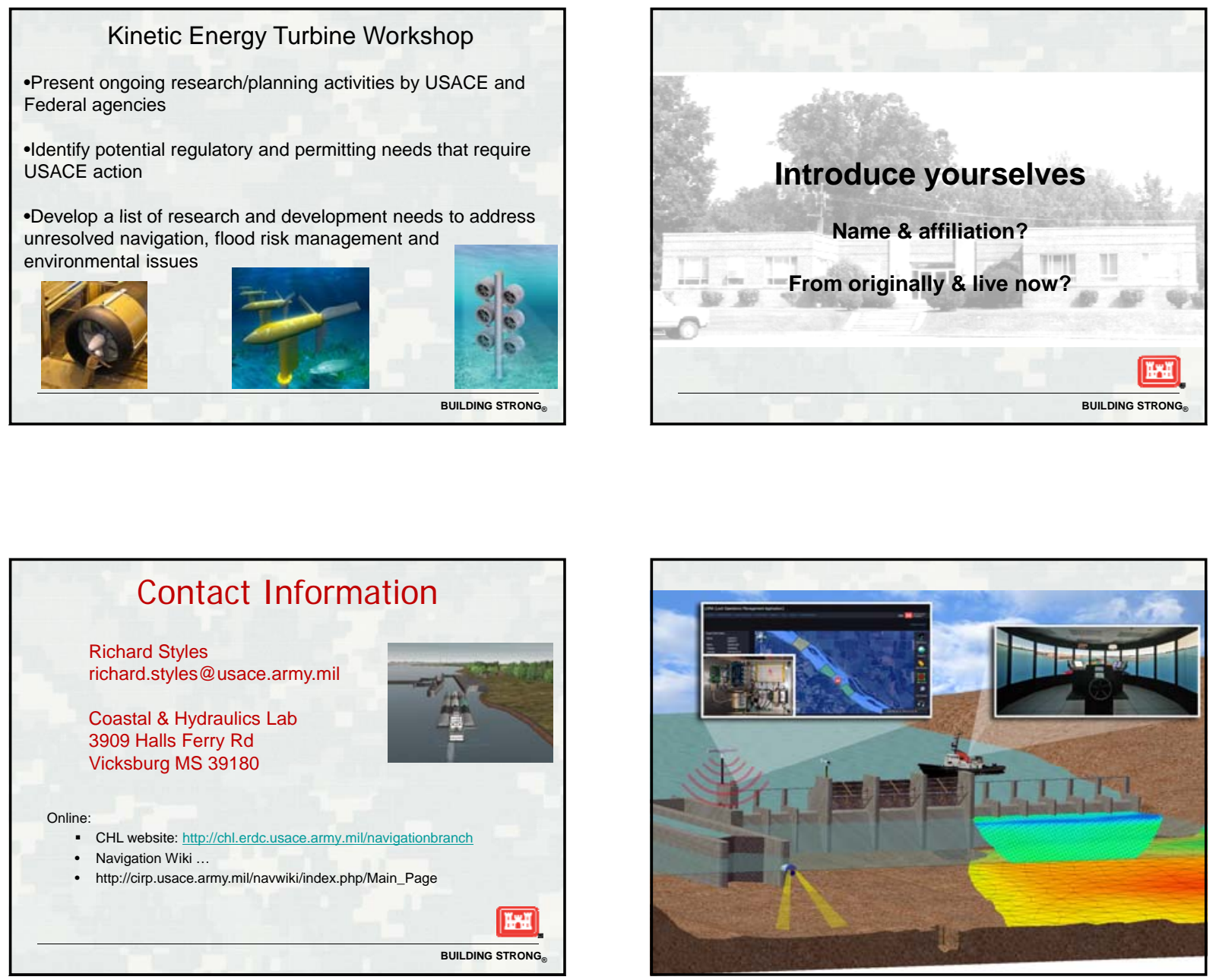
Ongoing Research and Development of Hydrokinetic Turbines

Hosted by USACE

February 29,2012

Vicksburg, MS

A National Park Service (NPS) Perspective

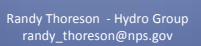

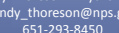

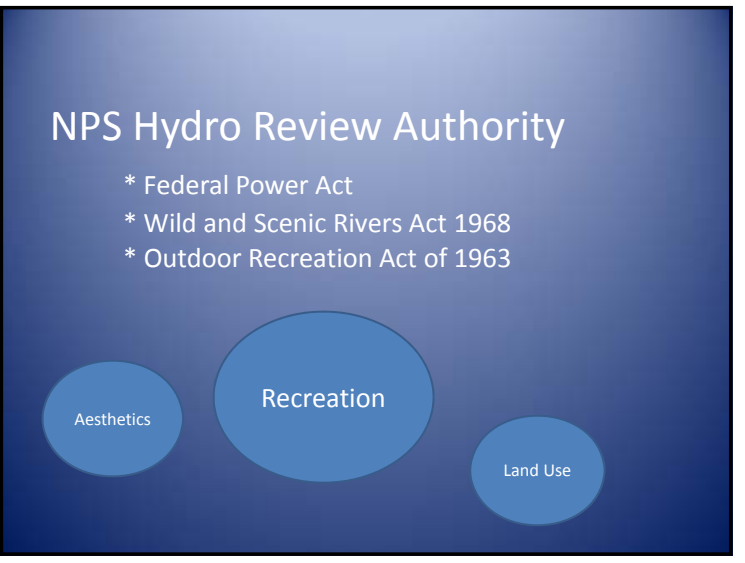

\section{NPS and Hydrokinetics}

Department of Energy (DOE) - report to Congress (2009) relating to MHK projects

- Covered varying types of impacts and issues

- Did not cover Social and Recreation impacts

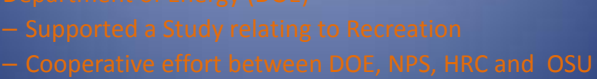

Confluer

- Document produced by Hydro Work Group.

Completed in December 2010 . Available in 2011.

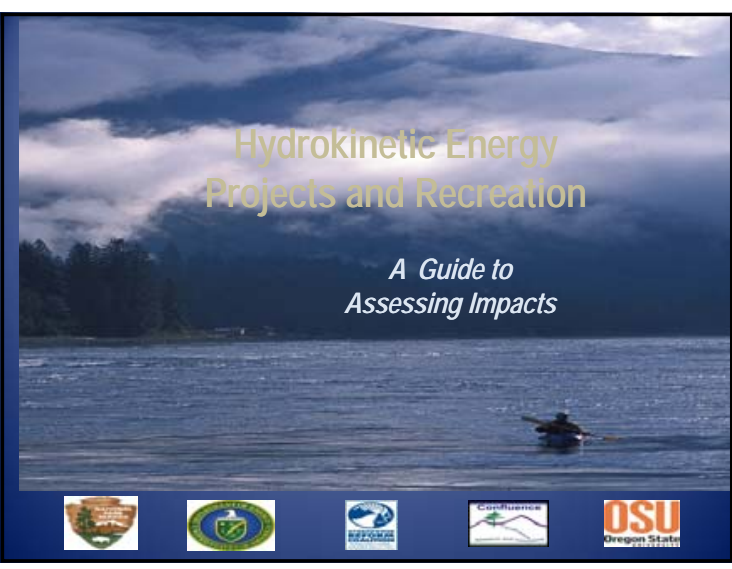

\section{Key elements of the document}

- Types of Hydrokinetics Projects

- Types of recreation in Hydrokinetic settings

- Concepts for assessing impacts

- Potential impacts on recreation opportunities

- Types of studies for recreation impacts of Hydrokinetics projects

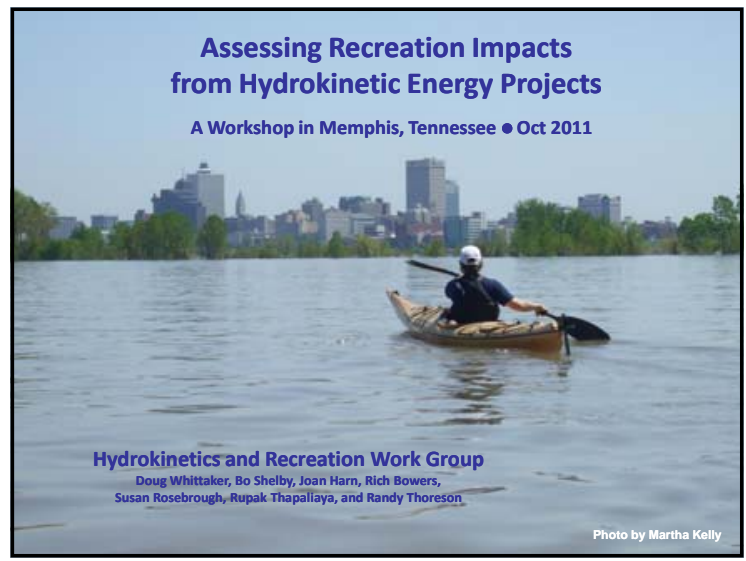




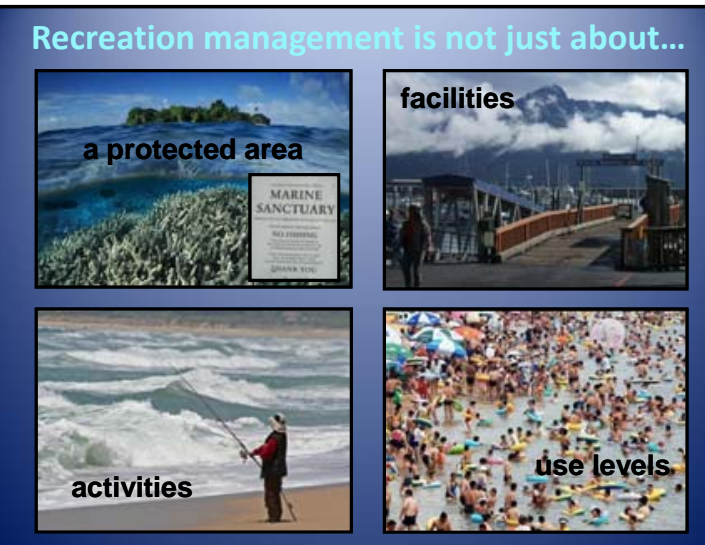

The recreation opportunity spectrum

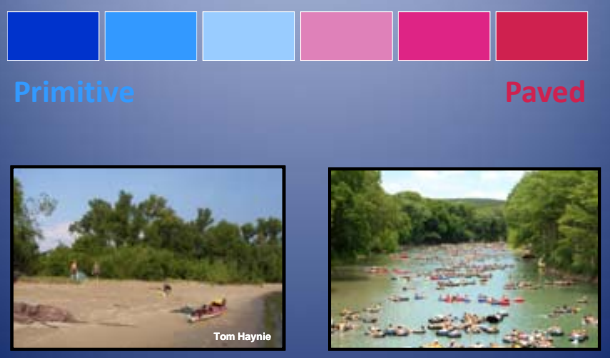

Scale and cumulative efifects

Other development / uses

Other potential restrictions
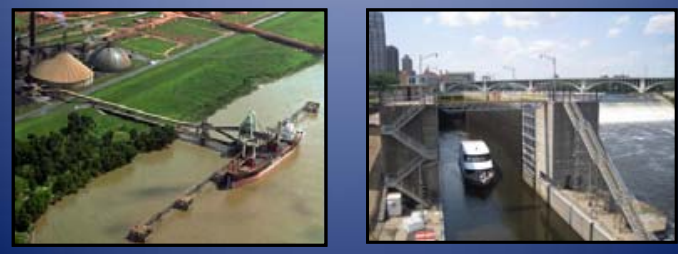

\section{Experiences}

But conditions create opportunities for them..
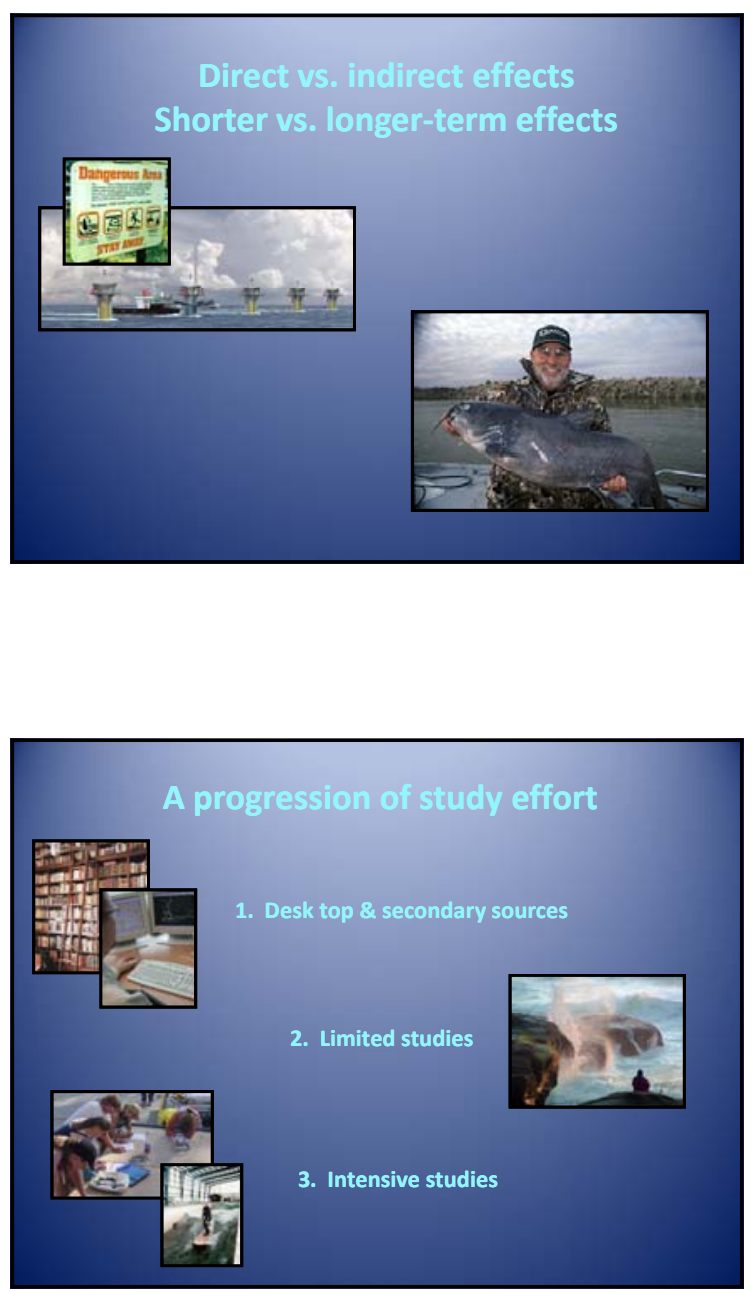


\section{Protection \& mitigation strategies}

- More vs. less sensitive areas

- Reducing impacts (project modifications)

- Mitigation (trade-offs)
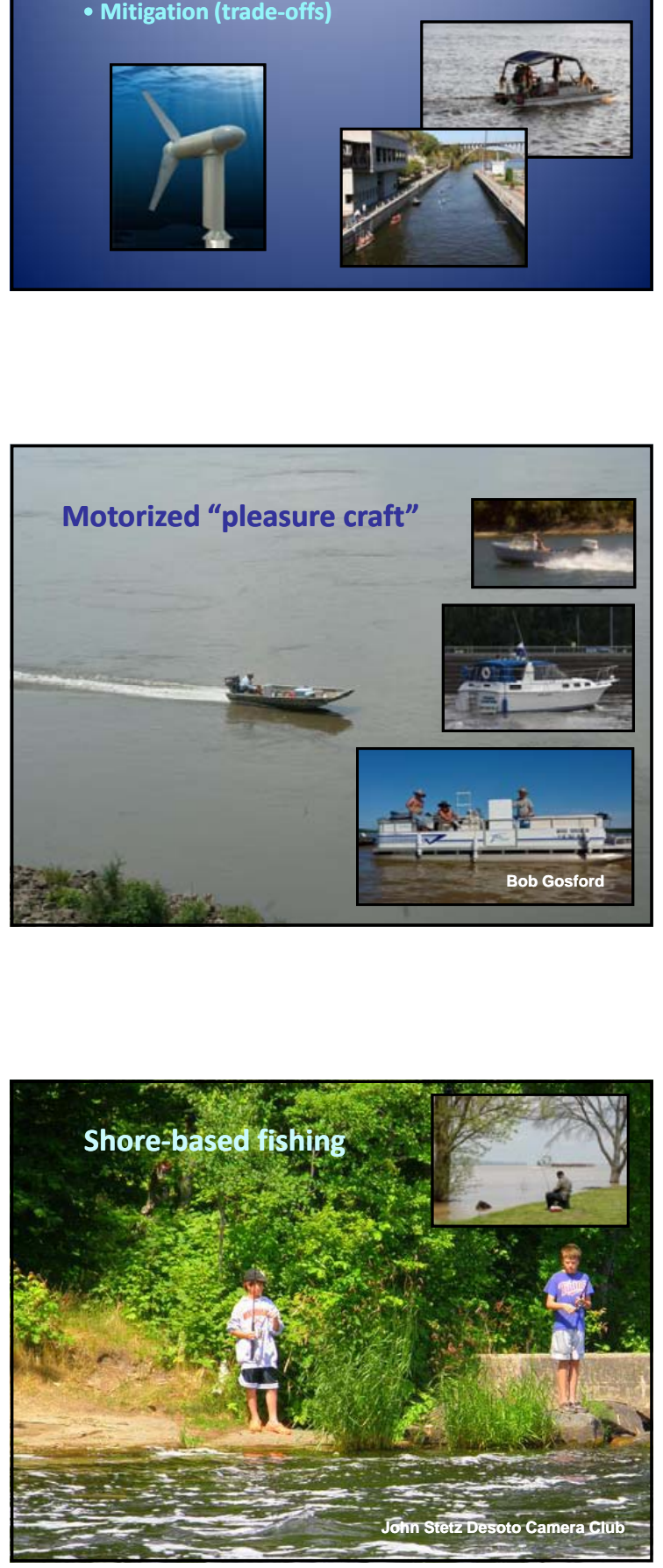

Types of Large River Recreation: Non-motorized canoeing and kayaking
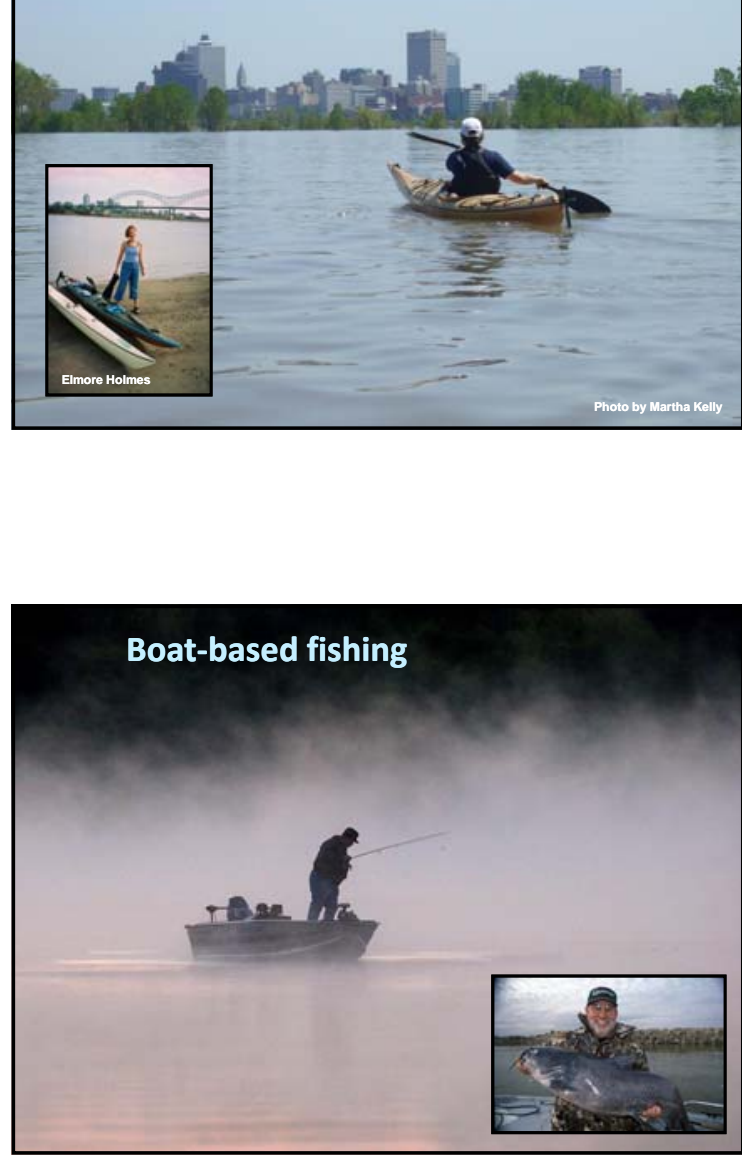

Beach use (boat and road-accessible)

2

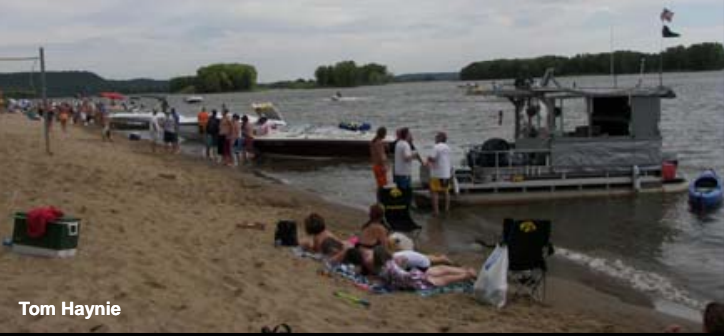



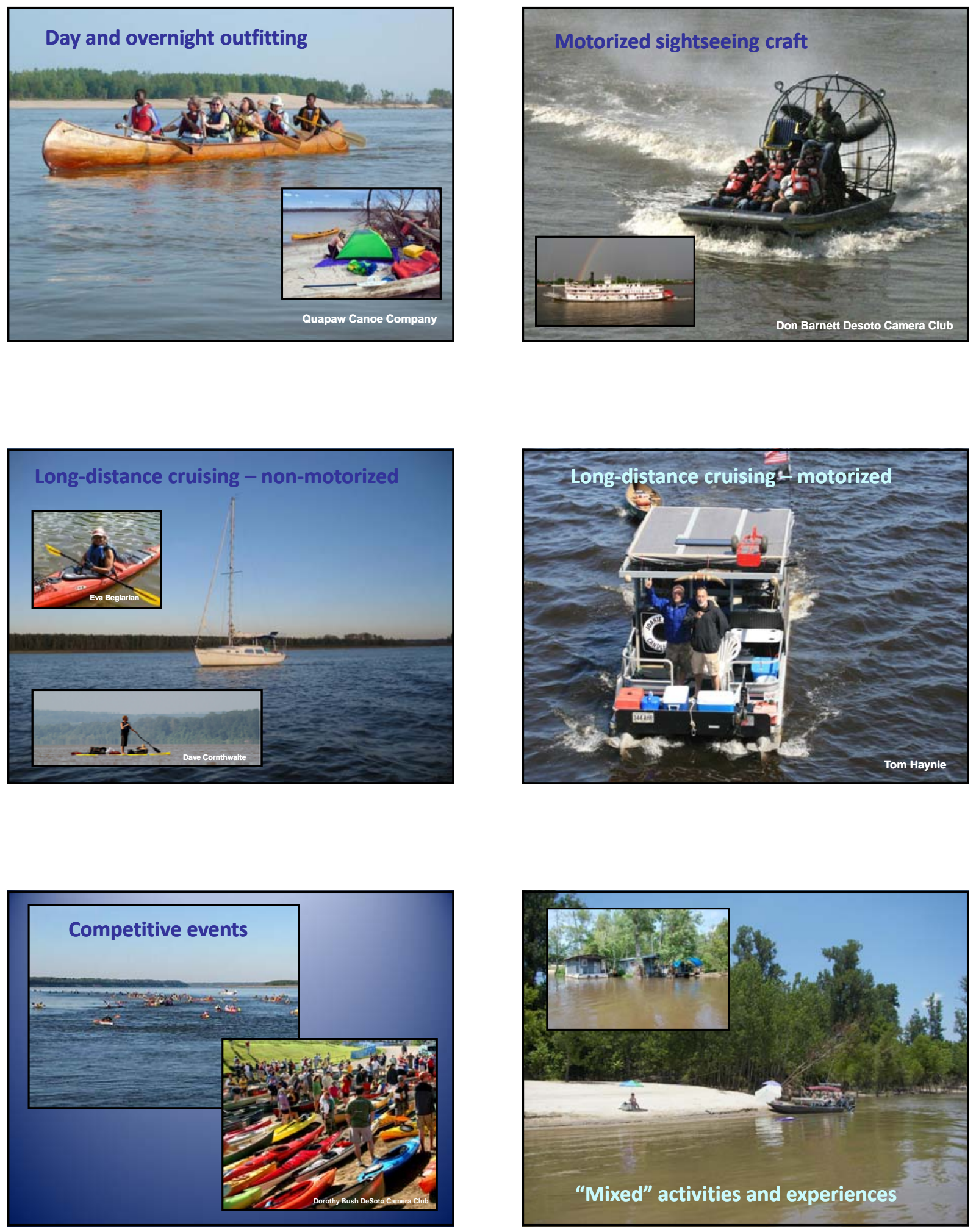

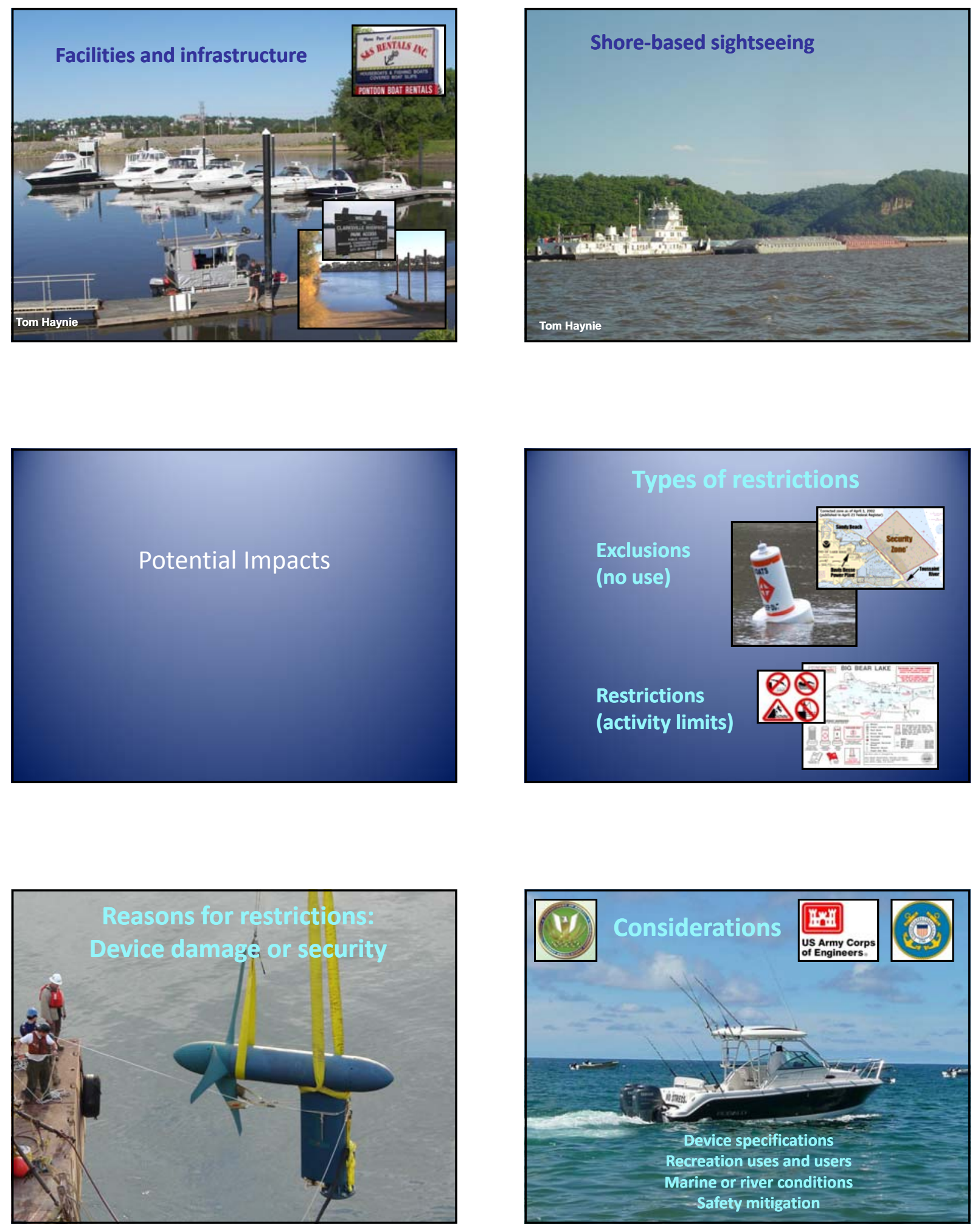

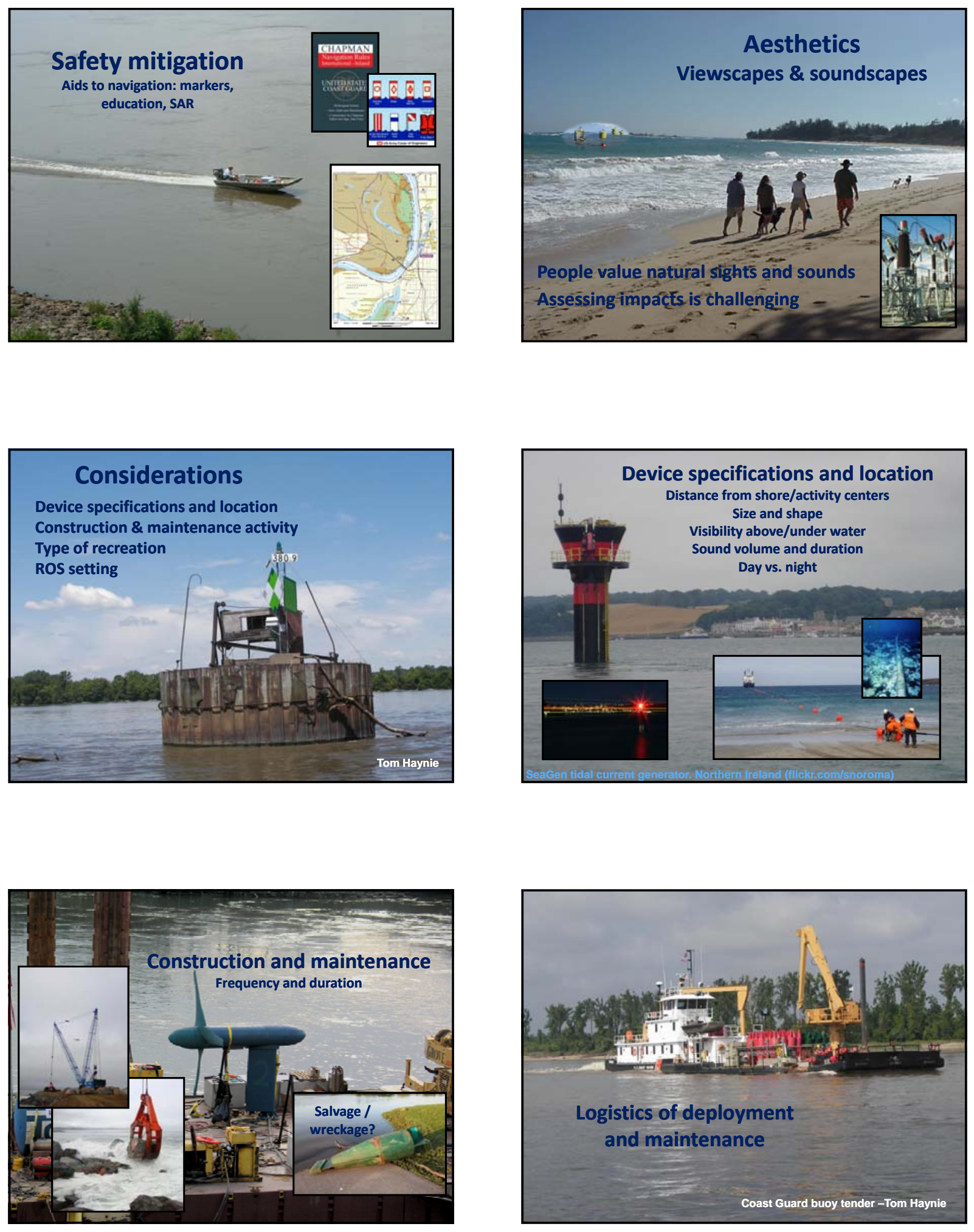


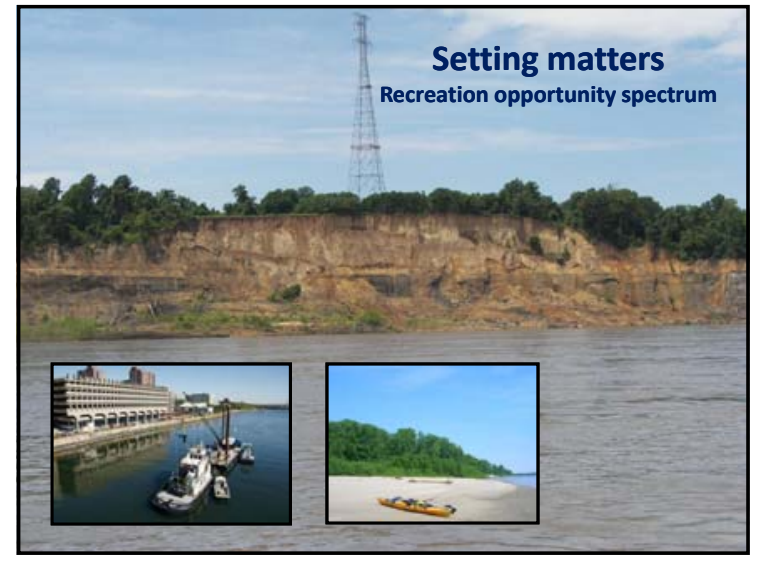

Social scientists study

How ecological changes affect recreation

Human evaluations of those effects

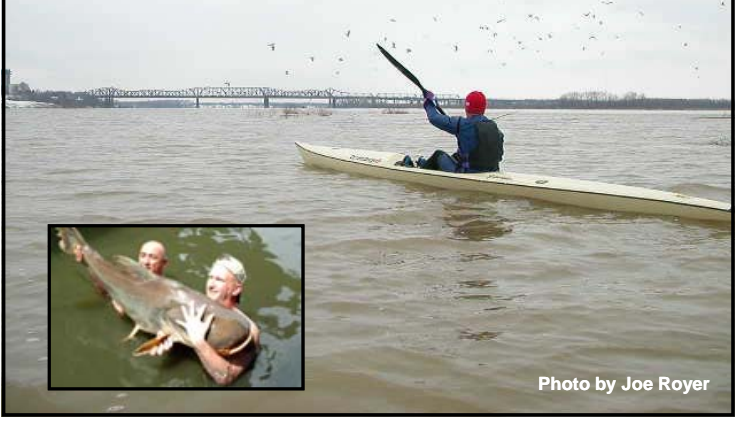

\section{Stakeholders !!}

- Miss. Wild miles

- Local, Regional, National interest groups

- Clubs. Organizations

- Local citizens

- Shoreline property owners

- Non profits

- Local gov't

- The business community
Biologists study

Impacts on ecological resources
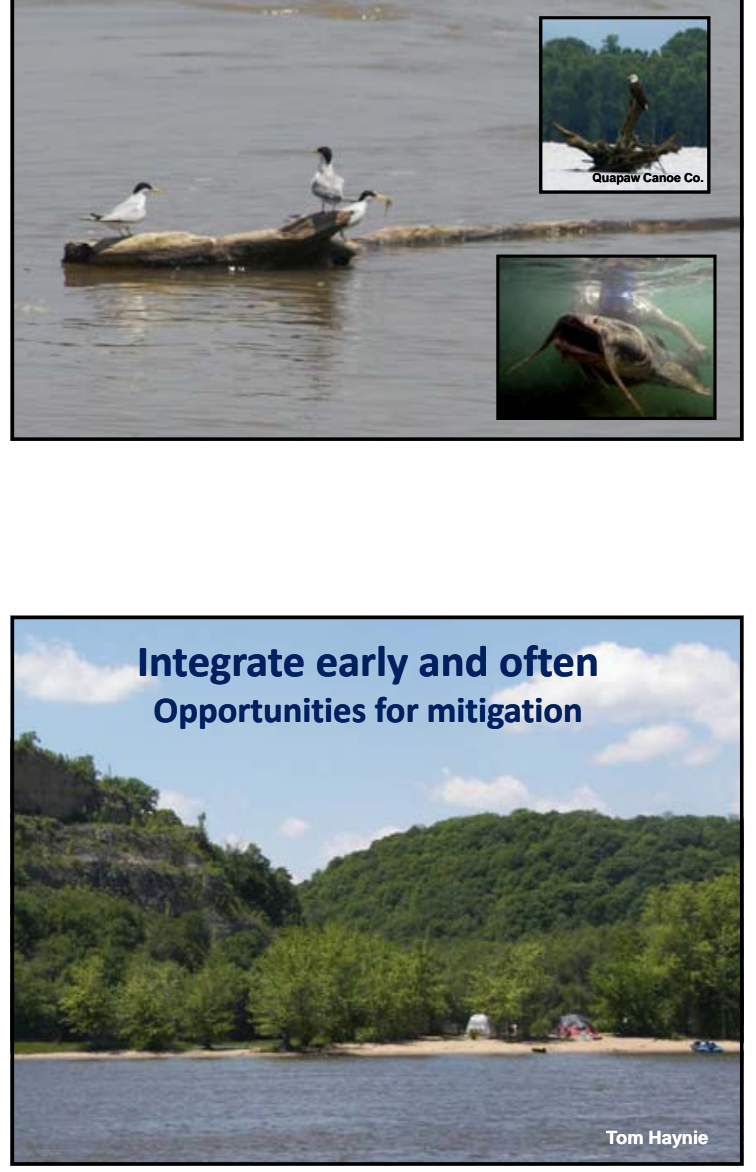

Main Conclusicn:

Jing aesthetics and land use), as it relates to Hydrokinetics impacts, can be recognized and evaluated in a systematic way!

\section{Thank You !}




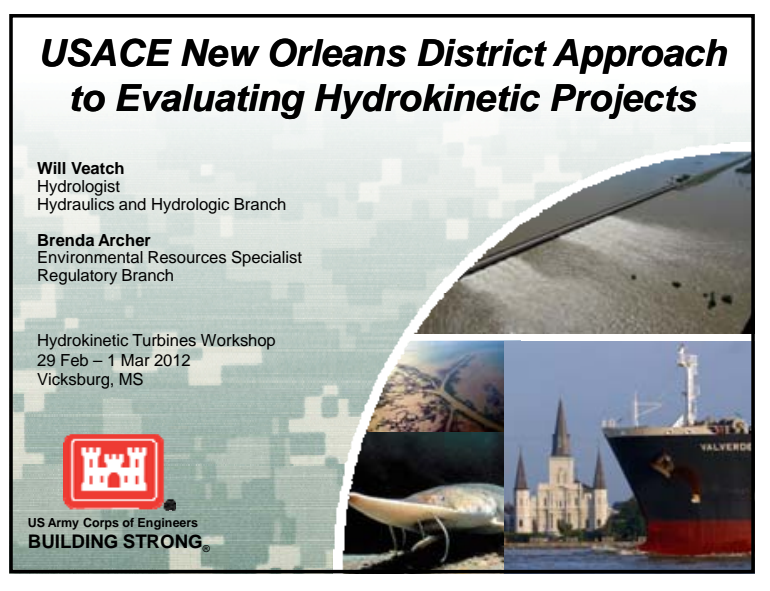

MVN Approach to Hydrokinetics

-Overview of New Orleans District

-MVN Regulatory Process

-MVN Regulatory Process for Hydrokinetic

Turbine Projects

-Areas of Concern

-Conclusions and Discussion

BUILDING STRONG,
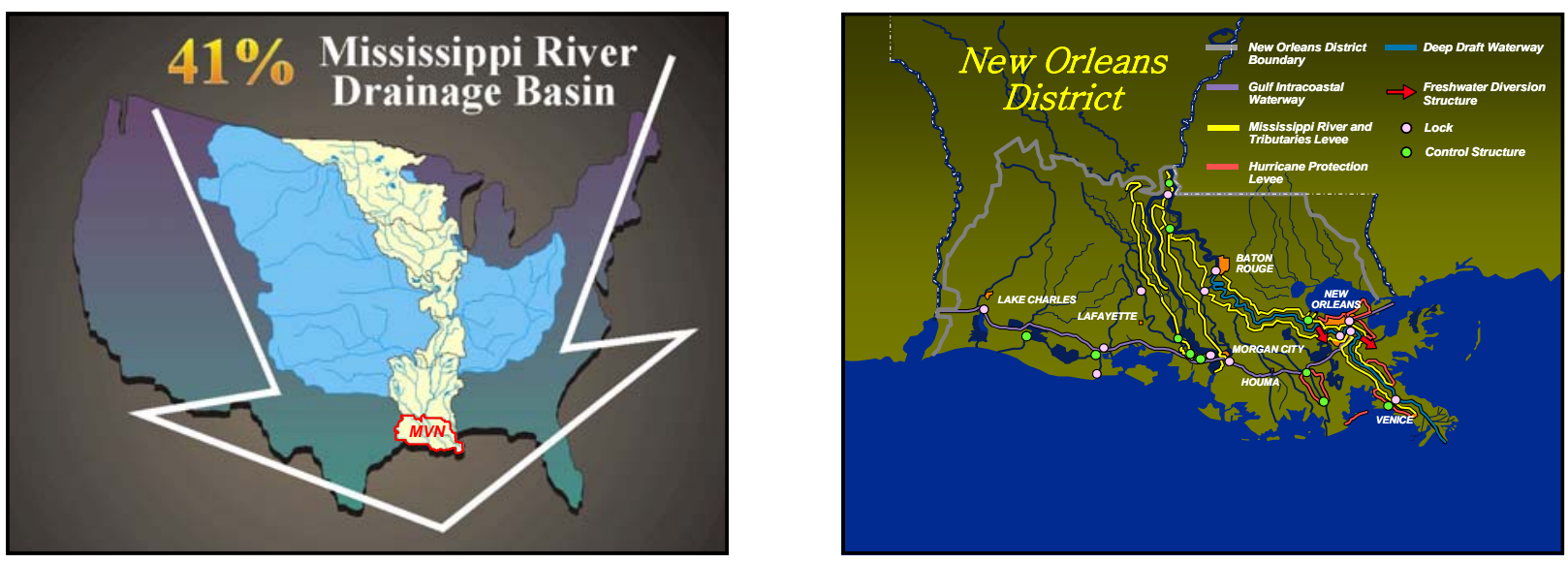

\section{MVN Regulatory Process}

-DA Permits

$>$ Section 10 Rivers and Harbors Act (navigable waters)

$>$ Section 404 Clean Water Act (waters of the U.S. including wetlands)

-Typical Permit Process

$>$ Pre-application consultation (optional, informal MVN review team)

$>$ Permit application submission

$>$ Review of permit app (incl. Public Interest Review)

$>$ Permit decision
MVN Regulatory Permit Process For Hydrokinetic Turbine Projects

-Pre-application consultation

> FERC is the lead federal agency, requires pre-application consultations

MVD requested Regulatory have a formal review team,

Hydrokinetic Project Team, multiple disciplines (Hydraulics, Dredging, Channel Stabilization, Counsel, Project Management, Real Estate, Public Affairs)

-Permit application submission

U.S. Coast Guard and FERC government process workshop

FERC license app and USACE DA app coordinated submittal

-Review of Permit App (incl. Public Interest Review)

Review is the same; provide comments and recommendations during the pre-app and the development of an EIS;

-Permit Decision

FERC license incl. USACE Section 10 RHA special condition USACE, if applicable, issues a separate Section 404 permit 


\section{Areas of Concern}

Public Interest Review Evaluation

- Water Quality

- Wetlands

- Fish and Wildlife

- Navigation

- Floodplain Management

$>$ Sedimentation

$>$ Flowline

$>$ Channel Stability

\section{Areas of Concern}

- Water Quality

>Evaluate compliance with applicable effluent limitations and water quality standards

$>$ Major concern is the leakage of lubricants, etc.

- Wetlands

$>$ Evaluate impacts to wetlands in the project area

$>$ Major concern are impacts to riparian wetlands associated

- Fish and Wildlife

$>$ Evaluate impacts to fish and wildlife (incl. T\&E) within the entire project area

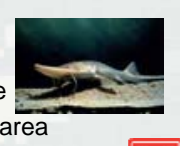

\section{Areas of Concern: Navigation}

- Low-water navigational hazards

-Altered river currents

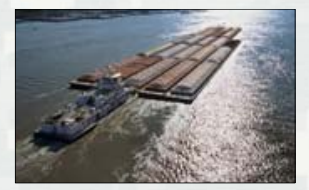

-Traffic during installation / maintenance

-Altered sedimentation patterns $\rightarrow$ hazards and currents

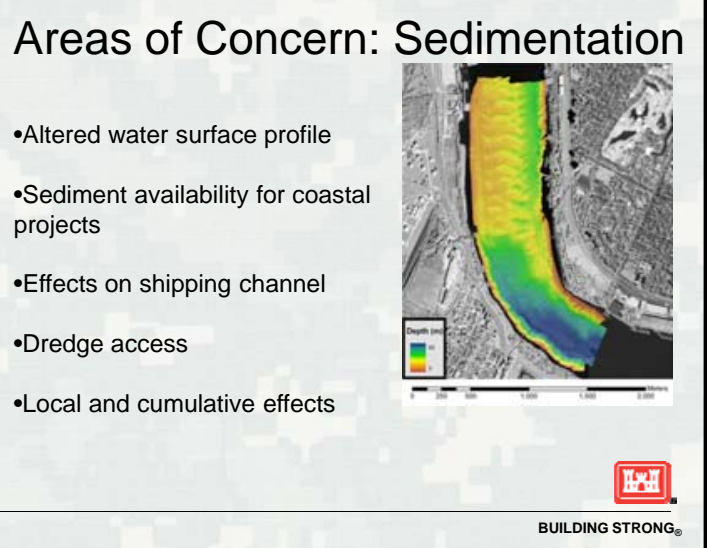

Areas of Concern: Channel Stability

-Revetment integrity

-Access to failure areas

-Altered currents

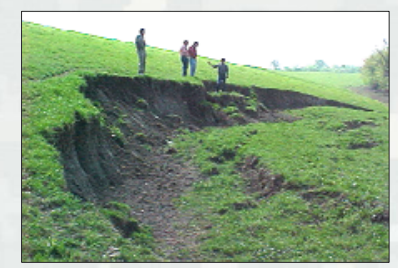

-Levee loading during construction

-Power lines crossing levees 


\begin{tabular}{l} 
Conclusions and Discussion \\
•MVN supports alternative energy and further \\
development of hydrokinetic electricity, provided concerns \\
are addressed. \\
•We work closely with FERC to streamline our work \\
processes. \\
•Many concerns remain to be addressed. \\
•MVN's Hydrokinetic Project Team and Independent \\
Technical Review Team address concerns and technical \\
validity. \\
\hline
\end{tabular}



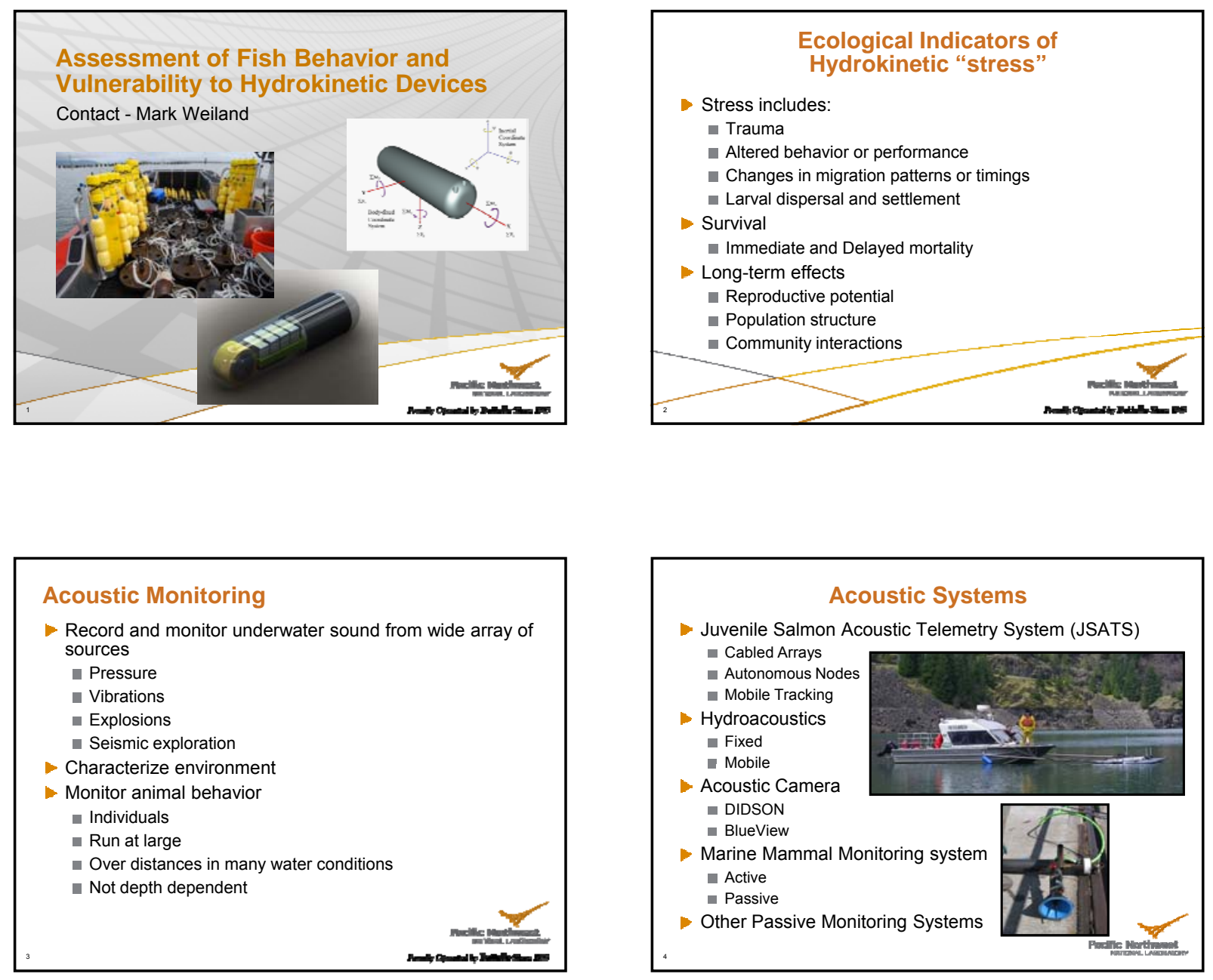

\begin{tabular}{|c|c|c|c|c|}
\hline \multicolumn{5}{|c|}{ JSATS-Tagging Alternatives } \\
\hline $\begin{array}{l}\text { Transmitter/ } \\
\text { tag treatment }\end{array}$ & Picture & $\begin{array}{l}\text { Weight in } \\
\text { Water }(\mathrm{g})\end{array}$ & $\begin{array}{l}\text { Weight in } \\
\text { Air }(\mathrm{g})\end{array}$ & Volume $(\mathrm{mL})$ \\
\hline PIT & $\Rightarrow$ & 0.059 & 0.096 & 0.036 \\
\hline Single battery & & 0.191 & 0.305 & 0.114 \\
\hline $\begin{array}{l}\text { Single battery } \\
\text { w/ PIT }\end{array}$ & & 0.250 & 0.400 & 0.150 \\
\hline $\begin{array}{l}\text { Double battery } \\
\text { w/ PIT }\end{array}$ & & 0.356 & 0.536 & 0.180 \\
\hline & & & & Pachis Northese \\
\hline
\end{tabular}

\section{JSATS -}

Injectable Acoustic Micro-transmitter

- In development

- Spring 2013 in-water trial

Weight in air $0.2 \mathrm{~g}$

- Weight in water $\sim 0.135 \mathrm{~g}$

- Volume $100 \mathrm{~mm}^{3}$

= $\sim 14 \mathrm{~mm}$ long $\times 3.2 \mathrm{~mm}$ diameter

Source level $156 \mathrm{~dB}$ re: $1 \mu \mathrm{Pa}$ at $1 \mathrm{~m}$

- Code set millions of possible codes 

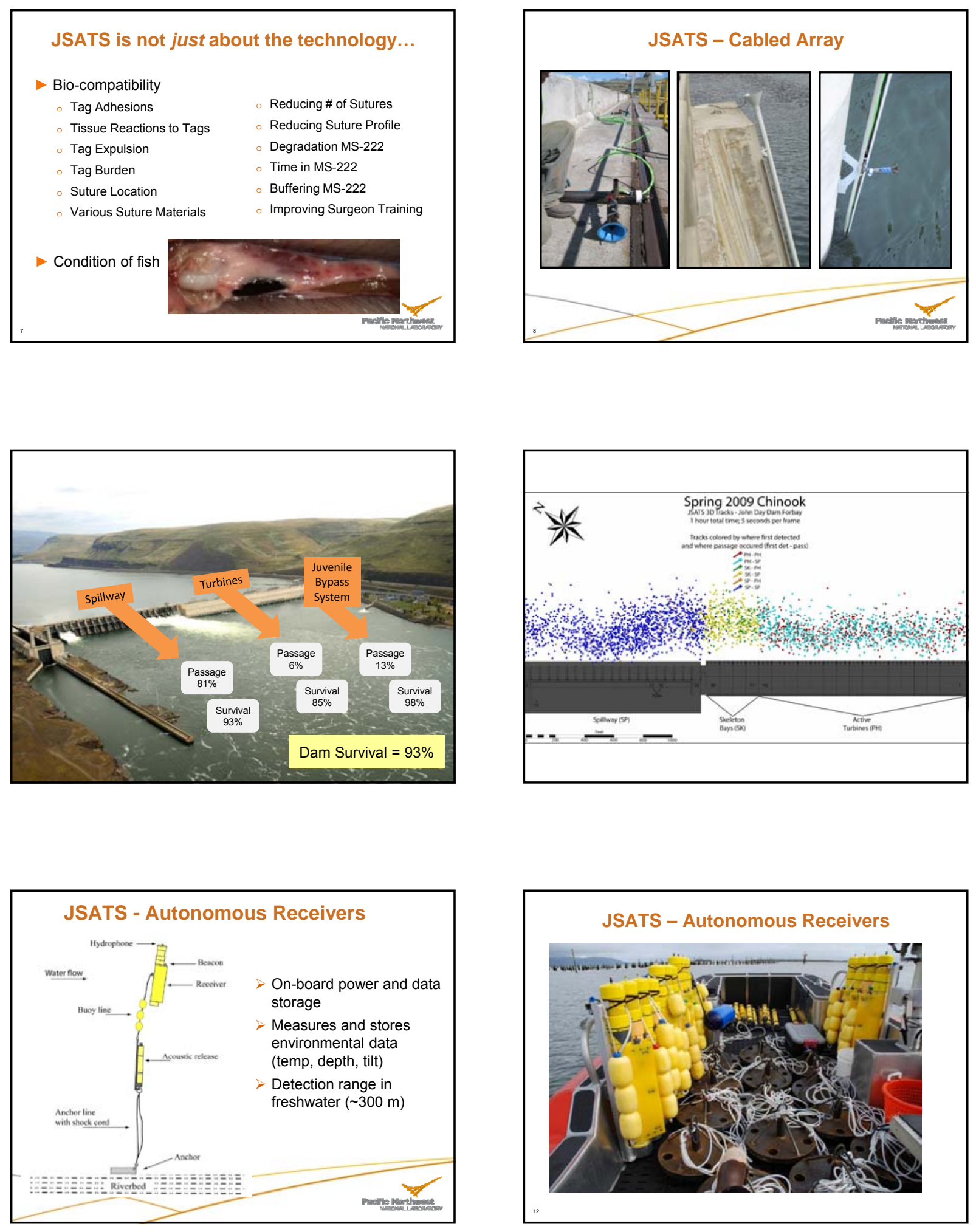

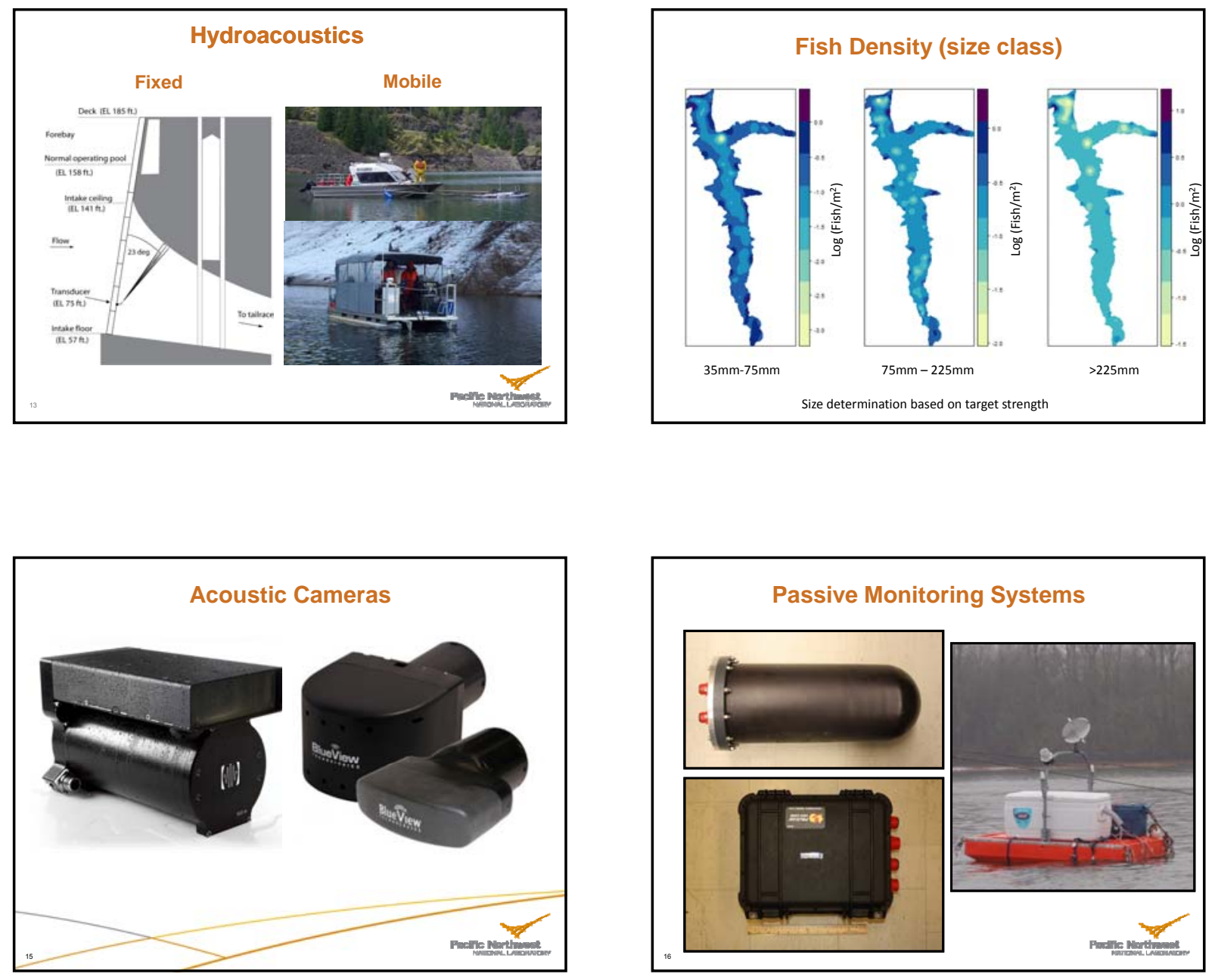

Acoustic Monitoring System for Marine Mammals - Active and Passive
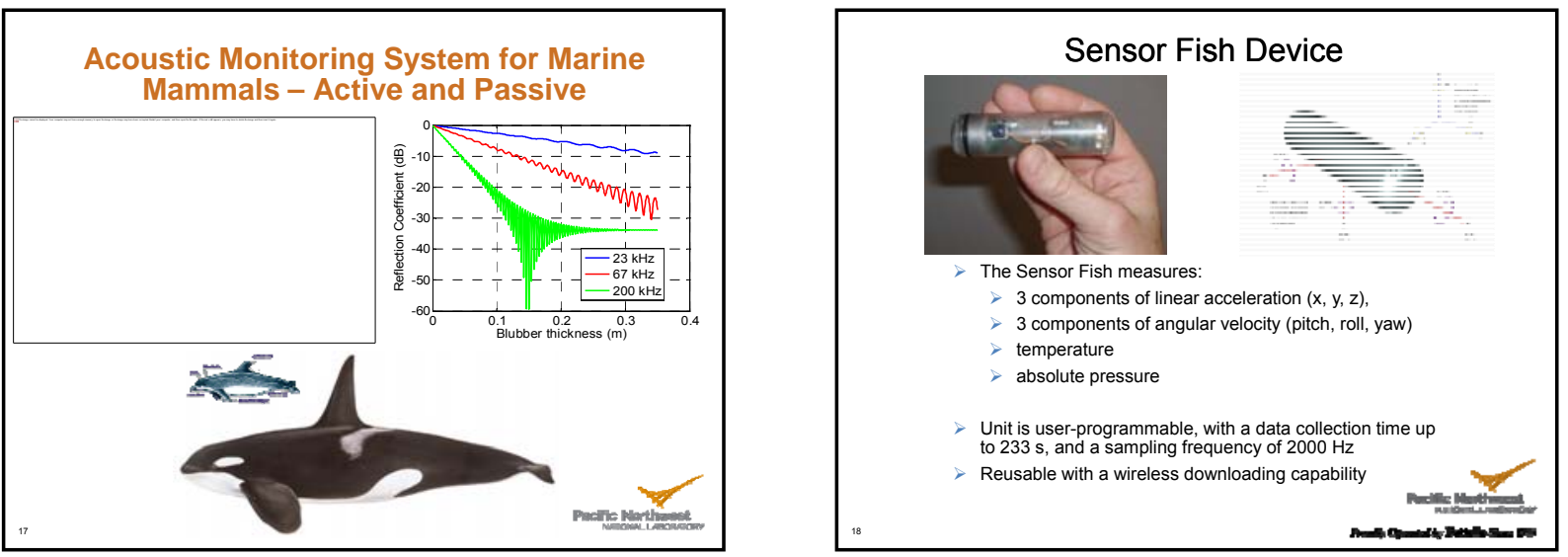

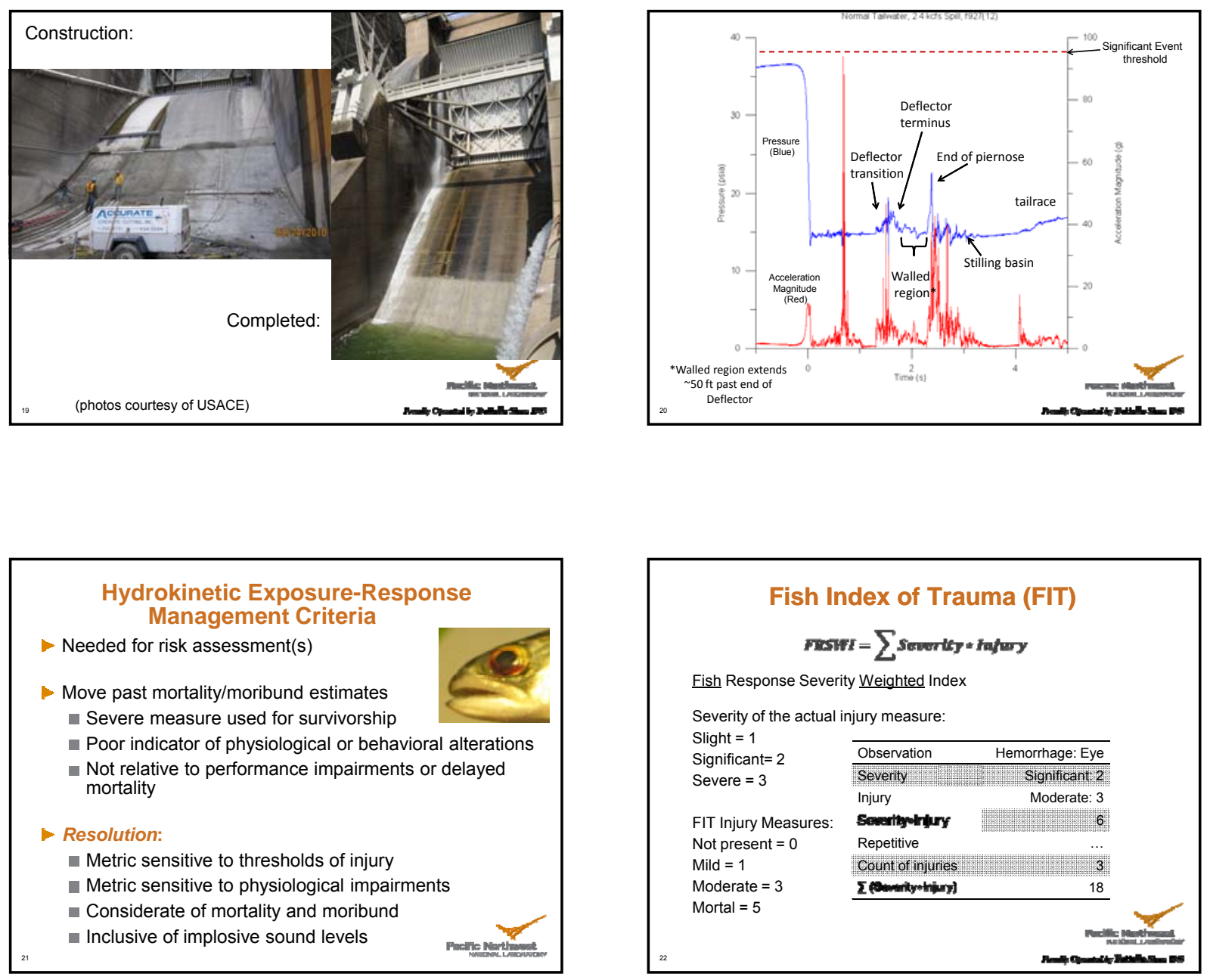

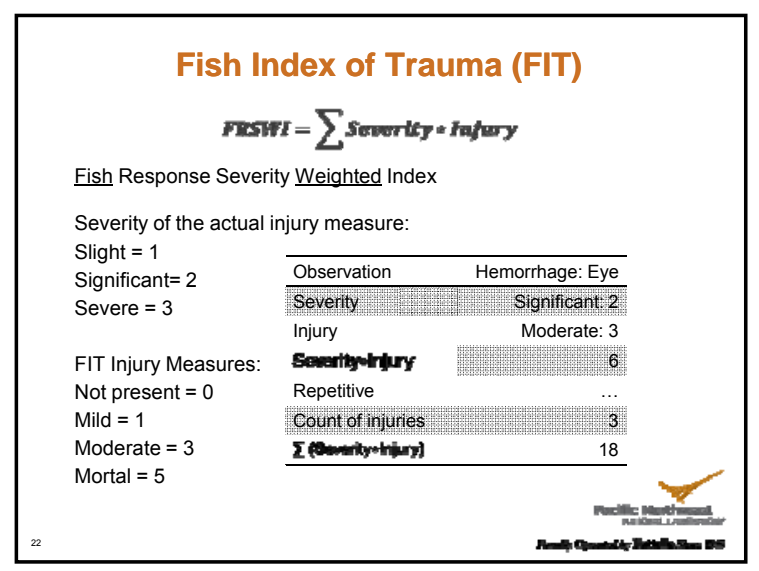

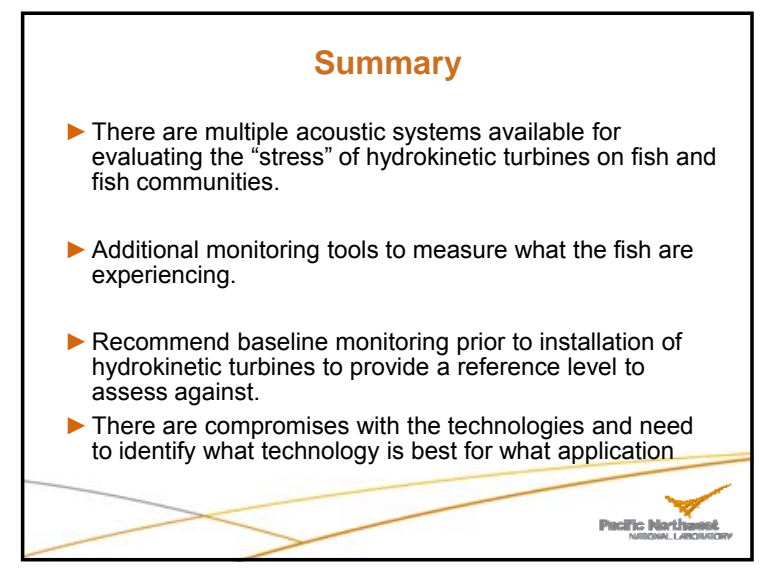

